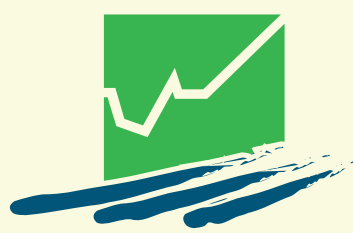

INSTITUTE OF AGRICULTURAL AND FOOD ECONOMICS NATIONAL RESEARCH INSTITUTE

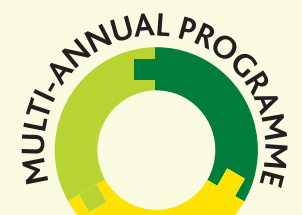

$$
{ }^{2} 015-20^{19}
$$

\title{
Innovation performance of the Polish agri-food sector: key determinants and prospects for improvements
}

\section{1 \\ MONOGRAPHS OF MULTI-ANNUAL PROGRAMME} WARSAW 2017 
Innovation performance of the Polish agri-food sector:

key determinants and prospects for improvements 



\section{INSTITUTE OF AGRICULTURAL AND FOOD ECONOMICS NATIONAL RESEARCH INSTITUTE}

\section{Innovation performance of the Polish agri-food sector: key determinants and prospects for improvements}

Edited by dr hab. Szczepan Figiel, prof. IERiGŻ-PIB

Authors: dr hab. Szczepan Figiel, prof. IERiGŻ-PIB dr hab. Marcin Gospodarowicz, prof. IERiGŻ-PIB dr hab. Renata Grochowska, prof. IERiGŻ-PIB dr Dominika Kuberska mgr inż. Justyna Kufel-Gajda dr Marian Oliński dr Adam Wasilewski

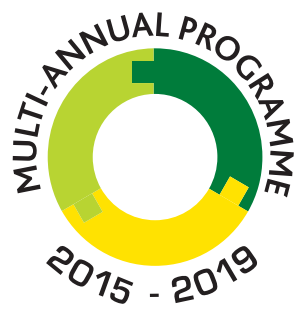

THE POLISH AND THE EU AGRICULTURES 2020+ CHALLENGES, CHANCES, THREATS, PROPOSALS 
Dr Dominika Kuberska and dr Marian Oliński are the researchers of the University of Warmia and Mazury in Olsztyn.

The other authors are the researchers from the Institute of Agricultural and Food Economics - National Research Institute.

This monograph was prepared under the theme Factors determining the innovative activity in the agri-food sector, in the tasks:

Evaluation of the innovations in the Polish agri-food sector

Organizational conditions of the innovations in the Polish agri-food sector

Regional strategies to encourage innovations in agriculture, food industry

and rural area

The aim of the monograph is to discuss selected aspects of innovation performance of the Polish agri-food sector and highlight its key determinants and prospects for improvements.

Reviewers:

Dr hab. Matgorzata Juchniewicz, prof. UWM, University of Warmia and Mazury in Olsztyn

Dr hab. Joanna Paliszkiewicz, prof. SGGW, Warsaw University of Life Sciences

Proofreader

Joanna Gozdera

Translated by

Summa Linguae S.A.

Cover project

Leszek Ślipski

ISBN 978-83-7658-695-3

Instytut Ekonomiki Rolnictwa i Gospodarki Żywnościowej

- Państwowy Instytut Badawczy

ul. Świętokrzyska 20, 00-002 Warszawa

tel.: (22) 5054444

fax: (22) 5054636

e-mail:dw@ierigz.waw.pl

http://www.ierigz.waw.pl 


\section{Contents}

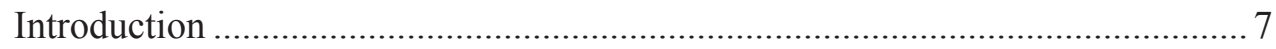

1. Innovativeness and competitiveness of national economies.......................... 10

1.1. Dimensions and criteria for evaluation of innovativeness

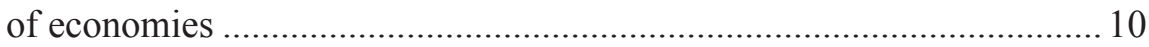

1.2. Importance of innovativeness in building competitive advantages........ 21

2. Factors influencing development of innovations in the agri-food sector ....... 29

2.1. Endogeneity and exogeneity of incentives for innovation

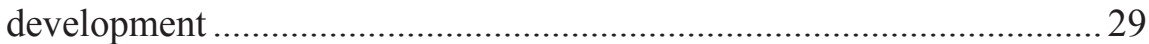

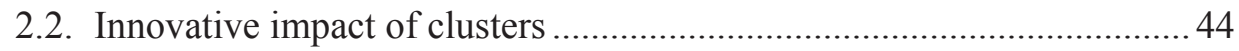

2.3. Innovative trends in the food products markets .........................................54

3. Institutional determinants of innovation transfer in the Polish agri-food sector 66

3.1. Rationale for public intervention in the light of innovativeness

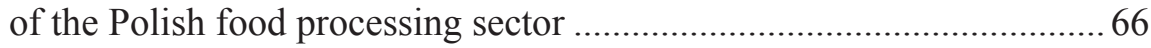

3.2. Innovation policies and regulation adjustments in Poland ..................... 72

3.3. Organizational structure of the innovation transfer system .................... 86

3.4. Strengths and weaknesses of the innovation transfer institutions .......... 98

4. Prospects for the growth of innovativeness in the agri-food sector and rural areas in the light of the analysis of the Regional Innovation Strategies ....... 105

4.1. Historical outline and implementation of the Regional Innovation Strategies in Poland

4.2. Smart specializations as a leading element of the third generation RIS.

4.3. Potential increase in innovativeness of the agri-food sector and rural areas based on the existing RIS.

4.4. Impact of the RIS on the agri-food sector and rural areas in the future

Summary.

Bibliography 126 



\section{Introduction}

Views on the role of innovations in economic development, and so related theories, evolve over time. Certain core elements of the theoretical dispute about innovations, such as for example classic Schumpeter's [1942] concept of creative destruction, Drucker's [1985] view on innovations and entrepreneurship, or Christensen's [1997] notion of disruptive innovation, remain relevant, but there are new factors coming into the picture in recent times. An interesting perspective regarding those factors and related implications has been provided by Downes and Nunes [2014] who forged a phrase "Bing Bang Disruption" to shed light on the nature of competitive forces shaping temporary markets.

First of all, as digitalization continues to influence every area of our lives, the authors claim that Bing Bang Disruptors are starting to appear in ever industry. Second, products are no longer developed only in secret on the basis of proprietary technologies and research methods, because entrepreneurs and companies work in the open letting early users test and extent initial versions of the proposed solutions. Third, new markets are longer created just from the top down. Contemporary innovators often work from the bottom up introducing lower quality substitutes entering the markets first by picking off the least profitable customers and then competing with market leaders. Also, new innovators often stop thinking about traditional products and competitors and come sort of sideways addressing unmet hitherto consumer needs. Indeed, the new disruptors may attack existing markets not just from the top, bottom, and sides but from all three at once. They tie their products to the exponential growth and falling costs of new technologies, therefore what they offer can be both better and cheaper, and more customized as well [Downes and Nunes 2014].

The importance of innovations in building competitive economies is acknowledged not only by researchers by also by policy makers in many countries. This is seen especially in the EU where stimulating and supporting innovativeness seems to be a key part of the policy agenda articulated in the Horizon 2020 Programme $^{1}$. It is rather a matter of common understanding that innovativeness of economies results not only from market efforts of competing private entities but it can also be publicly supported in order to strengthen competitive advantages of the nations. To achieve such goals identifying economic importance and innovative potential of particular sectors in any economy is a preliminary condition to be met before allocating and directing public support.

\footnotetext{
${ }^{1}$ https://ec.europa.eu/programmes/horizon2020/what-horizon-2020 (Accessed: 01.12.2017).
} 
The goal of the monograph is to discuss selected aspects of innovation performance of the Polish agri-food sector and highlight its key determinants and prospects for improvements. Motivation for addressing such topic is twofold. First of all, as it has been already mentioned, the issues of innovations and innovativeness of national economies and their various sectors have recently become leading points of both economic research and policy agendas. The other reason is a relatively high importance of the agri-food sector for the Polish economy. Being very successful in exporting in the last two decades it contributes very significantly to economic prosperity of the country. Poland is a top producer and exporter of many agricultural and food items. Value of the agrifood exports has been dynamically rising and currently amounts to approximately 25 billion euros. Yet, there are some uncertainties about sustaining both the growth and competitive position of the Polish agri-food sector in the international markets.

Quite widely accepted consensus is that sources of simple competitive advantages such as, for instance, favorable natural conditions or cheaper labor cannot guarantee ongoing market success if a sector is lagging in terms of innovative performance. According to European Commission [European Commission 2017] Poland as a country belongs to the group of so-called moderate innovators. Since none of the sectors in the economy operates in a vacuum it is plausible to assume that agri-food in Poland is not much different in terms of innovativeness than the whole Polish economy. In fact, there are some data [GUS 2017] indicating that food processing enterprises are less innovative than all enterprises on average. Considering this, we make an attempt to identify key factors determining innovativeness of the Polish agri-food sector in the context of the EU and national innovation policies. Part of our focus is also a preliminary assessment of potential impacts of these policies.

Because any sector is an integral part of the national economy we begin with discussing dimensions and criteria for evaluation of innovativeness of economies and importance of innovativeness in building competitive advantages. Multidimensionality of the term innovativeness and potential controversies about measuring innovative activities are examined in order to avoid simplistic assessments of the considered problem. Then, based on the Industrial Organization Theory we look at the key factors shaping competitiveness of economic sectors, classifying them into endogenous and exogenous ones. Such distinction can be useful in designing policy actions and effective tools to stimulate innovativeness of the Polish agri-food sector. As a relatively new finding the role of business clusters in nurturing innovativeness is underlined. Bearing in mind interconnectedness of the more and more globalized food markets we also 
analyze innovative trends in the international food products markets and potential implications of their intensity of occurrence for the Polish food companies.

Considering that Poland as one of the EU member state is supposed to follow certain policy directions to build institutional support for development innovative economy, especially to establish an effective system of innovation transfer, innovation policies and regulation adjustments in Poland are described, with particular emphasis on the food-processing sector. The aim of this part of the study is to analyze changes in the last period in policies to improve innovativeness and induced by them modifications in legislation and organizational structures of the innovation transfer system. Strengths and weaknesses of the innovation transfer institutions are indicated to show where public support should be allocated to improve the situation.

Finally, we address the issue of Regional Innovation Strategies (RIS), which are supposed to be regional policy vehicles to improve innovativeness at regional and local levels. Special emphasis is put on so-called "Smart Specializations" as a leading element of the third generation RIS. Examining the content of the selected strategic documents we try to find components which might be important for stimulating innovative development of the Polish agri-food sector and rural areas in the future.

The monograph was prepared using various literature and data sources as well as results of the authors' own research. We are aware that many questions are still to be answered but we hope that this publication will contribute to a better understanding of the current state of the innovativeness of the Polish agrifood sector and real chances of its improvement in near future delineated by the EU 2014-2020 financial perspective. The discussed topics are in large related to the reality of Polish food sector but certain aspects of the discussion are universal, so, some more general lessons can be drawn as well. 


\section{Innovativeness and competitiveness of national economies}

\subsection{Dimensions and criteria for evaluation of innovativeness of economies}

The theory of innovation and innovativeness is multi-faceted. The result of the development of considerations on these issues is its location at three levels of analysis: macro-, meso-, and micro-level. Within each of these, partial theories have been developed which correspond to their nature, although they remain interrelated. The relationships between innovativeness considered at each of these levels, are indicative of the significant level of complexity in the relationships between entities shaping innovativeness, regardless of their role in the economic system.

The variety of standpoints on the issues of innovation and innovativeness is manifested, inter alia, in the multitude of definitions of these concepts, which may be found in the literature. It is also a reason for which a discussion on the ways to measure innovativeness has been developed, both with regard to the methods of this measurement, techniques used and tools applied. All the time, attempts are being made to create a uniform methodology, which could be used to evaluate innovativeness of specific economic entities. Each of them gives rise to a discussion, in which opinions both supporting and opposing the designed research process are raised.

For a very long time, the measurement of economy's innovativeness has not been the focal point of interest of researchers. Not before the second half of the 20th century, did considerations in that regard start on a larger scale. One of the reasons for this state of affairs was the insufficient development of the research methodology, by means of which it was possible to capture scientific and technical progress [Fiedor 1979]. The works on the innovativeness measurement proceeded along with the development of models of innovation processes. Their expansion by further factors and conditions resulted in the development of innovativeness measurement methodology [Kowalski 2013]. Further suggestions for measurement instruments were also substantiated by a will and need to respond to the demand for the innovativeness measurement, which was and still is formulated by the representatives of the public sphere. As already mentioned, the evolution that has been taking place in relation to looking at the issue of models of innovative processes is accompanied by the development of the research apparatus regarding the innovativeness measurement indicators. A detailed summary in this regard is quoted and developed by Kowalski [2013] (Table 1.1). 
Table 1.1. Evolution of innovativeness measurement against the background of models of innovative processes

\begin{tabular}{|c|c|c|c|}
\hline $\begin{array}{c}\text { Type of } \\
\text { innovation } \\
\text { model }\end{array}$ & Name of model & $\begin{array}{l}\text { Period of } \\
\text { emergence }\end{array}$ & Measures of innovativeness \\
\hline \multirow{2}{*}{ 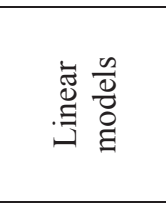 } & $\begin{array}{l}\text { Model of } \\
\text { technology push }\end{array}$ & $\begin{array}{l}\text { 1950s - mid- } \\
1960 \mathrm{~s}\end{array}$ & Expenses on the R\&D activity \\
\hline & $\begin{array}{l}\text { Model of market } \\
\text { pull }\end{array}$ & $\begin{array}{l}\text { Mid-1960s - } \\
\text { early 1970s }\end{array}$ & $\begin{array}{l}\text { As above and also the statistics of patents, } \\
\text { balance of payments in the field of } \\
\text { technology }\end{array}$ \\
\hline \multirow[b]{3}{*}{ 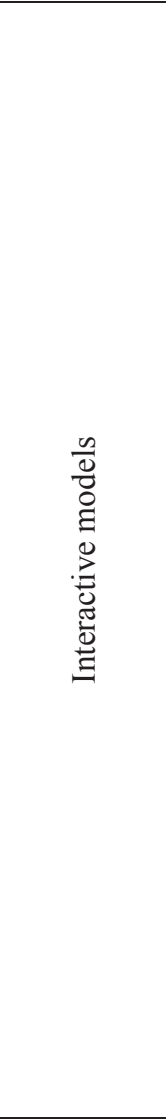 } & Coupling model & $\begin{array}{l}\text { Early } 1970 \mathrm{~s}- \\
\text { mid-1980s }\end{array}$ & $\begin{array}{l}\text { As above and also high technology } \\
\text { products, bibliometry, human resources } \\
\text { statistics, surveys of the innovative } \\
\text { activity }\end{array}$ \\
\hline & $\begin{array}{l}\text { Integrated - } \\
\text { parallel model }\end{array}$ & $\begin{array}{l}\text { Early 1990s - } \\
\text { mid-1990s }\end{array}$ & $\begin{array}{l}\text { As above and also surveys of the } \\
\text { innovative activity in the manufacturing } \\
\text { sector, overview of production } \\
\text { technologies, innovations described in the } \\
\text { technical literature, budget support for the } \\
\text { innovative activity, investments in } \\
\text { intangible assets, ICT technology } \\
\text { indicators, productivity, high risk capital }\end{array}$ \\
\hline & Network model & Late $1990 \mathrm{~s}$ & $\begin{array}{l}\text { As above and also surveys of the } \\
\text { innovative activity in all sectors, } \\
\text { technological (product, process) } \\
\text { innovations, non-technological } \\
\text { (organizational, marketing) innovations, } \\
\text { tax incentives, cooperation between } \\
\text { science and economy, commercialization } \\
\text { of scientific research; cooperation among } \\
\text { enterprises (e.g. within clusters), } \\
\text { internationalization and technoglobalizm, } \\
\text { development of new sectors (e.g. } \\
\text { biotechnology and nanotechnology), } \\
\text { statistics on the knowledge-based } \\
\text { economy, intellectual capital, creativity } \\
\text { indicators, disaggregations of government } \\
\text { spending on research and development } \\
\text { (GBAORD) }\end{array}$ \\
\hline
\end{tabular}

Source: Own elaboration based on Kowalski [2013].

As stated by Kozłowski [2009], despite the fact that innovations are a factor determining, inter alia, the economic growth or competitiveness, the method to measure them still seems imperfect when compared to the measurement of other economic variables. The reason for this is the fact that technological innovation is a very diversified economic category, in the case of which there are problems as for its delimitation. For example, sometimes it is difficult to deter- 
mine to which point we may talk about improvement and from which point we deal with innovation or imitation.

For the measurement of innovation we may use both measures, which are analyzed separately and those designed in a synthetic manner, which takes place in the case of the developed innovativeness indices. The data collected and processed at the level of enterprises may, through their adequate accumulation, reflect innovativeness of industries, sectors or economies.

A quantitative analysis regarding science, technology and innovation $(\mathrm{N}+\mathrm{T}+\mathrm{I}, \mathrm{STI})$ is based on three groups of indicators, including R\&D indicators, indicators referring to patent applications, grants and citations and bibliometric indicators which include the information about scientific publications and citations. Innovativeness may also be described using other three measure groups, which include [Smith 2006]:

- technometric indicators, which describe technical aspects of the functioning of products;

- synthetic indicators, in the case of which summaries are created to compare innovativeness using a series of measures, on a basis of which the value of the synthetic indicator is calculated; very often, they are a result of work of consulting companies or other international organizations;

- databases regarding issues defined in detail.

Innovative activity may be measured using two methods. The first of them, the objective method, consists in measuring the number and nature of actually existing innovations. The other, the subjective method, consists in examining entities (enterprises), which have introduced innovations. The advantage of the former method is the fact that within this approach it is possible to obtain more information about individual innovations. On the other hand, its application provides the information on their smaller number and the selection of a sample is arbitrary. Its alternative, in its research aspect, is reduced to the application of a survey addressed to enterprises. It raises issues such as, for example, the amount of innovation inputs or effects of implemented innovations [Kozłowski 2009].

From the micro-economic point of view, considerations on innovations concern, for example, the role of enterprises in creating innovations or the conditions that are necessary for the innovative activity to take place. In turn, the meso-economic approach may refer to two dimensions: sectoral and spatial (geographic). In the first one, the studies cover the innovative activity of specific groups of enterprises, for example, forming a given industry or sector. The spatial dimension of innovation refers to, for example, the issue of regional innovation systems (RIS). As part of the most extensive - macro-economic - approach, 
the subject of the studies is, inter alia, the issue of relationships between innovativeness and the development of national economies. Therefore, a particularly important aspect is to get to know determinants of innovativeness and its quantification. In connection with the multi-faceted nature of the issue of innovation and innovativeness, the further part of the subchapter will briefly present the methods to evaluate innovativeness in each of the considered approaches, the core of which are, respectively: national economy, region/sector/industry and enterprise.

In accordance with the guidelines contained, inter alia, in the third edition of the Oslo Manual, the most important innovation indicators which are applicable today include [Kozłowski 2009]:

- share of enterprises in a surveyed population, which in the recent years have introduced technological innovations;

- share of enterprises in a surveyed population which have introduced non-technological innovations (marketing or organization);

- contribution - e.g. total innovation inputs;

- effects - e.g. impact of product innovations on the sales volume;

- objectives and obstacles to innovation;

- others.

If the statistical data on science, technology and innovation are to be compared using the largest possible number of aspects, they should be collected based on a uniform methodology. The OECD in this regard undertook the standardisation of procedures. Its results are the Frascati manual (R\&D activity; the first edition in 1963, the latest edition in 2015) and the Oslo Manual (innovations; the first edition in 1992, the latest edition in 2005). In the subsequent editions of both publications, the methodology has been developed by adding additional issues to the approach.

Innovativeness is subject to a range of analyses at the level of national economies, whose level of innovativeness is very diversified. In effect, the rankings of innovativeness are published, in which the individual countries are compared with each other in terms of the aspects taken from the adopted methodology of studies. The subchapter will present the selected rankings of innovativeness, which belong to the canon of analyses carried out in this regard. They include:

- Innovation Union Scoreboard;

- Global Innovation Index;

- Global Competitiveness Index.

In the case of the European Union, as early as at the beginning of the 1990s survey studies were introduced that serve the measurement of innovation 
and innovativeness. They are carried out in a standardized manner and called Community Innovation Surveys (CIS). The methodology contained therein is based on the Oslo Manual provisions. The survey, which is carried out once every two years, involves enterprises, whose employment is at a level of more than 9 persons. According to the business profile, the survey applies to industrial and service enterprises. Based on the results obtained under the CIS, the Innovation Union Scoreboard is created. It is a publication that appears under the aegis of the European Commission in response to the underlined importance of the issue of innovativeness for the economic development of the Member States. Thanks to the developed indicator aggregating various factors of innovativeness of national economies, it is possible to compare them in several dimensions. In 2015, the 14th edition of the report was published (in 2001 a publication entitled European Innovation Scoreboard was introduced, which in 2011 was replaced by the Innovation Union Scoreboard).

Certain doubts were raised against the first proposal for the measurement of innovativeness contained in the EIS, e.g. concerning the methodological assumptions adopted therein. They included, inter alia, the following issues: the lack of an innovation model underpinning the adopted methodology; basing conclusions on one main indicator leading to the oversimplification of carried out analyses; due to the selection of numerous indicators relating to high technologies, the results in the ranking act for the benefit of economies specializing in high technology industries; co-linearity of indicators selected for the analysis; problems with the data, including their availability; problems with the interpretation of the results obtained - the methodology assumes that higher values of indicators translate into higher level of innovativeness - this is not true in the case of certain variables [Hollanders and van Cruysen 2008]. A modified methodology for the EIS was applied in 2008-2010. 2011 brought the current methodology employed in the Innovation Union Scoreboard.

Developing a uniform innovativeness measurement methodology for the European Union was related to, inter alia, the implementation of the Lisbon Agenda and the Europe 2020 Strategy. The measurement of innovativeness according to the European Commission methodology takes place using a synthetic indicator, i.e. the Summary Innovation Index, SII. Under this measure, three innovativeness indicators are aggregated (Figure 1.1).

The first group consists of factors called enablers. They include basic factors that affect the implementation of innovations. The second group, firm activities, refers to the issues related to innovativeness of enterprises, while the third group - outputs - represents the effects created by innovations. 


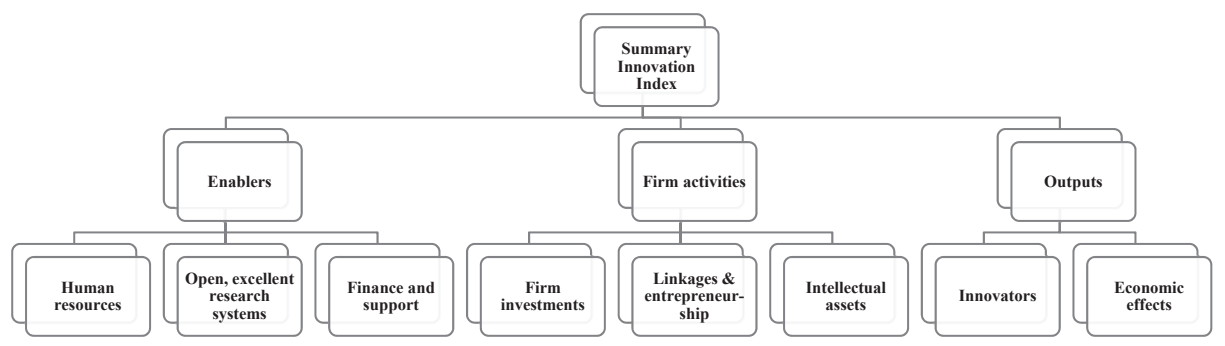

Source: European Commission [2015].

The publication from 2015 contains evaluation of the EU-28 economies. Their innovativeness is compared to selected non-EU countries. In terms of the number of the analyzed states, this report is the least developed one among those mentioned in this subchapter. The Innovation Union Scoreboard publications distinguish four groups of economies: modest innovators, moderate innovators, innovation followers, and innovation leaders [European Commission 2015].

The researchers at INSEAD launched the second of the cited rankings of innovativeness - The Global Innovation Index. The report published in 2015 evaluated 141 economies whose residents account for $95.1 \%$ of the global population and these economies are responsible for $98.6 \%$ of global GDP [Dutta et al. 2015]. The Global Innovation Index (GII) is the indicator of innovativeness of the economy in the cited ranking, whose structure is shown in Figure 1.2.

Figure 1.2. Structure of the Global Innovation Index

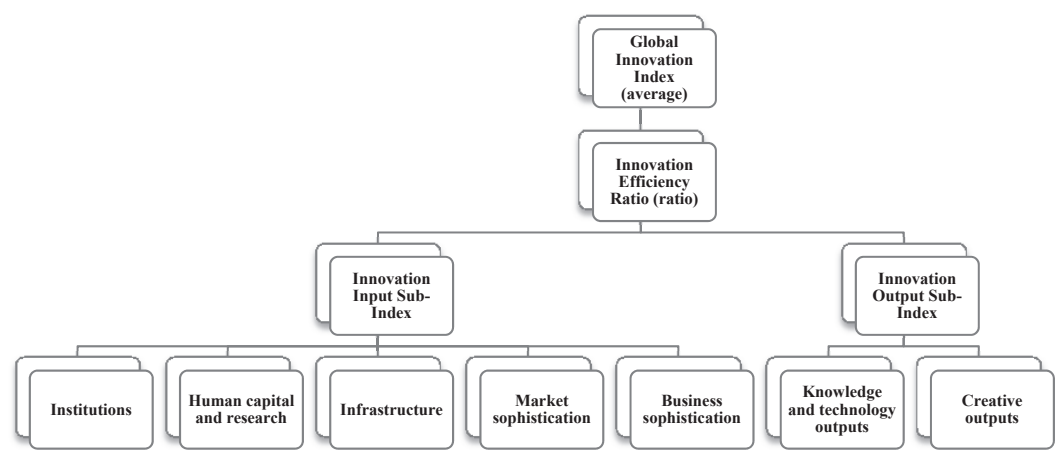

Source: Dutta et al. [2015].

The methodology of evaluating innovativeness consists of four values calculated on a basis of 79 indicators. They are as follows [Dutta et al. 2015]: 
- Global Innovation Index (arithmetic average of the value of Innovation Input and Innovation Output sub-indices);

- Innovation Input (consisting of five pillars each of which is divided into three sub-pillars);

- Innovation Output (consisting of two pillars each of which is divided into three sub-pillars);

- Innovation Efficiency Ratio (ratio of the Innovation Output sub-index to the Innovation Input sub-index).

The third of the cited rankings, which evaluate and compare innovativeness of economies at the macro-economic level, is the Global Competitiveness Report. The main purpose of its authors is to define the level of national competitiveness using the Global Competitiveness Index (GCI). However, it should be mentioned that, in accordance with the adopted methodology, innovativeness is one of the elements affecting competitiveness (Figure 1.3).

Figure 1.3. Structure of the Global Competitiveness Index

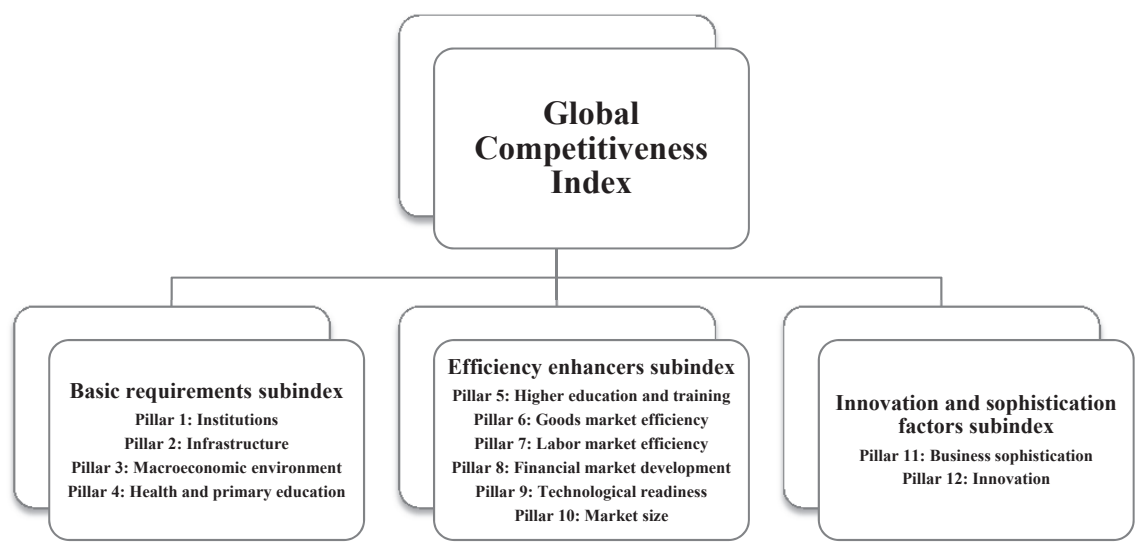

Source: World Economic Forum [2015].

Having the results derived from the cited rankings, we may compare the individual economies in terms of their levels of innovativeness. From the point of view of the Polish agri-food sector, a particularly important reference area are the EU economies being its closest competitors (Figure 1.4). Among the results in each of three rankings for the EU-28 economies, there is a strong positive correlation. It amounts to, respectively: 0.9136 (GII and SII), 0.9375 (12th pillar and SII) and 0.9113 (12th pillar and GII), which evidences the comparability of the results of the measurement of innovativeness in the individual rankings. 
Figure 1.4. Summary Innovation Index, Global Innovation Index and the 12th pillar of competitiveness of the EU-28 countries in 2015

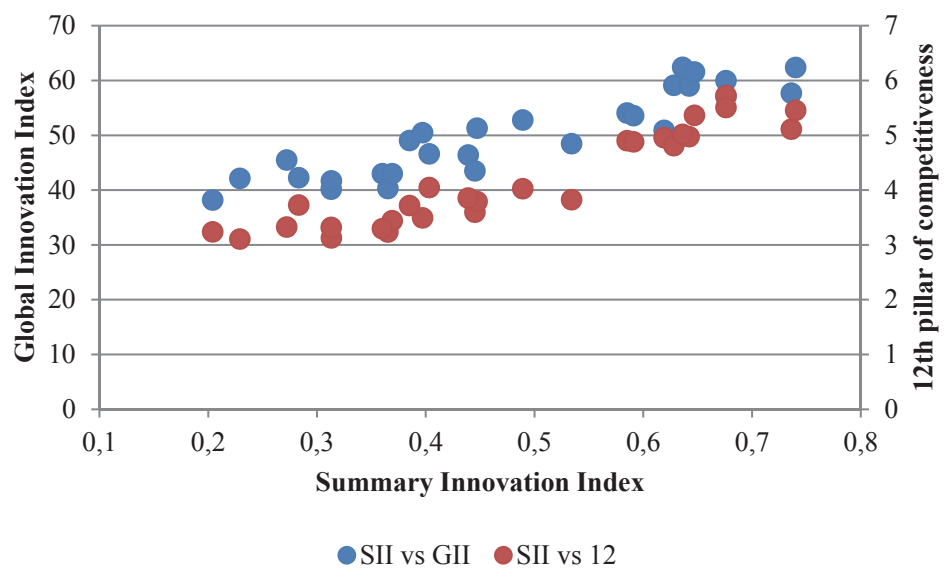

Source: Own elaboration based on Dutta et al. [2015], European Commission [2015], World Economic Forum [2015].

The analysis of innovativeness considered at the macro-economic level must not be carried out without taking innovative policy into consideration. It is defined as "conscious and intentional activity of public authorities aimed at supporting innovativeness of the economy, whose main objective is to promote innovations that increase competitiveness of the economy and enhance the quality and standard of living of people, transformation of the traditional economy towards the knowledge-based economy and to promote cooperation between all market entities" [Przychodzeń 2015].

National systems of innovation (NSI) are one of the ways to strengthen the innovative potential and innovative position of national economies. As a concept comprised of subsystems and links between them, the NSI determine innovativeness of the economy [Lundvall 2007]. Freeman [1987] defines them as "[...] the network of institutions in the public and private sectors whose activities and interactions initiate, import, modify and diffuse new technologies". In the publication edited by Lundvall [1992], national innovation systems are "[...] the elements and relationships which interact in the production, diffusion and use of new, and the proposed useful, knowledge....and are either located within or rooted inside the borders of a nation state". Another definition of the NSI states that it is "[...] a set of institutions whose interactions determine the innovative performance... of national firms" [Nelson 1993].

The level of innovativeness of economies may also be compared at the regional level. An example of such an approach is the Regional Innovation Score- 
board, based on the assumptions of the innovativeness measurement published by the European Commission under the Innovation Union Scoreboard. In the 2014 ranking, the analysis covered 190 regions of the EU, Norway and Switzerland. 34 of them were ranked as innovation leaders, 57 as innovation followers, 68 regions are moderate innovators and 31 regions received the status of modest innovators [European Commission 2014a]. During the initial period of publishing of the RIS, the analyses carried out were based on a limited set of indicators and applied only to a part of the European regions. This was due to the unavailability of detailed data at the regional level. The methodology applied in the RIS, like its equivalent at the level of the national economies - EIS/IUS, has been subject to transformations.

Regions, as units of analysis of the growth and economic development processes have gained importance in the recent decades. Various studies highlight their role in the economy, which they play as distinct, somehow autonomous, systems within the framework of the system of national economies. Therefore, innovativeness of regions remains related to both macro-economic innovativeness, which is its wider context, and micro-economic innovativeness. The factors which affect innovativeness at the meso-level and which should be considered as internal factors are: presence of research institutions, centers of knowledge, universities, consulting services related to knowledge management; presence of specific relationships with the external environment and specific relationships within the region; presence of specific interactions between enterprises in the region; creation of regional networks of educational and training institutions, research and development sector, technological consultancy, management, finance, risk capital, local authorities able to make developmentoriented decisions [Gaczek 2005]. The above-mentioned factors should not, however, be treated as the conditions necessary for the region to be considered innovative. Due to the differences in resources of individual regions that affect their innovativeness, each of them should be treated as a special case.

Within regions, positive effects are generated resulting from the proximity of economic entities. Geographical proximity is perceived as one of the elements determining the occurrence of innovation [Boschma 2005]. It is the individual regions, where conditions of innovativeness are created, which actively affect enterprises and their innovativeness. According to Jewtuchowicz [2009], the local environment should be considered as a primary factor of the development as well as innovativeness.

Just like in the case of the macro-economic level, also in the case of regions it is possible to distinguish specific innovation systems. Jewtuchowicz [2005] defines the regional innovation system (RIS) as a system of interdepend- 
encies and relationships between the sphere of science, $R \& D$, industry, and public authorities, supporting the processes of adaptation and collective learning. The RISs may perform many functions. These include: integration, information, social, innovative, educational and economic functions [Boguski 2010].

The evolution of regional innovation systems may take place through the development and implementation of regional innovation strategies. The objective of such an instrument is "to increase the regional potential with regard to innovation by strengthening cooperation between the research and development sector and the economy, which leads to increasing the competitiveness of enterprises operating in the regional and local markets" [Grzybowska 2012].

With regard to the meso-economic level of analysis, the innovativeness measurement may also apply to innovativeness of industries and sectors. However, it is not a widespread activity. Most often, the innovativeness measurement takes place in relation to high-technology industries [Grzybowska 2012]. In the case of this level of analysis, we are dealing with the so-called sectoral system of innovation and production. It is composed of entities that operate actively in terms of developing and producing products and technologies [Przychodzeń 2015]. In this case, it is worth understanding the reasons for which innovations are generated. It may be assumed that their emergence is a result of forces, the source of which may be cooperation or just the opposite - competition.

The last of the considered levels of analysis of innovativeness is the micro-economic level. The literature is dominated by a view that innovativeness of the economy is a result of innovativeness of enterprises located within its borders. They play a key role in the ongoing innovation processes. Their accumulation in space translates into innovativeness of the regions and, consequently, may lead to innovativeness of national economies. There are many definitions with reference to the concept of innovativeness of enterprises. Pomykalski [2001] states that it should be understood as their ability to permanently and systematically seek, implement and disseminate innovations.

In its studies dedicated to innovativeness, the Central Statistical Office (CSO) distinguishes two types of enterprises, in terms of their innovative activity. It does this based on the methodology drawn from the Oslo Manual. Innovative activity is described as "[...] engaging of enterprises into various research, technical, organizational, financial and commercial activities, which lead or are intended to lead to the implementation of innovations. Some of these activities are innovative, while others are not novel, but are necessary for implementing innovations. The innovative activity also includes the research and development (R\&D) activity, which is not directly related to the creation of specific innovation" [GUS 2014]. 
In the cited publication, the CSO distinguishes two types of companies: an innovatively active enterprise ("during the period analyzed, it has introduced at least one product or innovation process or implemented at least one innovative project, which has been interrupted or abandoned in the course of the period analysed (unsuccessful) or has not been completed by the end of this period (i.e. is continued)") and an innovative enterprise with regard to product and process innovations ("during the period analyzed, it has introduced into the market at least one process or product innovation (new or significantly improved product or new or significantly improved process)") [GUS 2014]. In the years 2012-2014, when compared to the years 2011-2013, the proportion of innovatively active enterprises in the sector of industrial enterprises increased from $18.4 \%$ to the level of $18.6 \%$. The proportion in the same category of enterprises, but in the case of the services, decreased from $12.8 \%$ to the level of $12.3 \%$.

The second type of enterprises - innovative enterprises, in the case of the industrial and service activity in the years 2012-2014 accounted for, respectively, $11.4 \%$ and $17.5 \%$ of the total number of those enterprises (an increase in relation to the years $2011-2013$ by $0.4 \mathrm{pp}$ in industry and the similar level in the case of services). In the years 2012-2014, the group of innovative enterprises was dominated by process innovations that were implemented in $12.9 \%$ of industrial enterprises and $8.4 \%$ of service enterprises. During the same period, product innovations were introduced in $11.7 \%$ of industrial enterprises and $6.8 \%$ of service enterprises. The cases in which there were both product and process innovations accounted for, respectively, $7.2 \%$ and $3.8 \%$ of enterprises. A different kind of innovations, namely organizational innovations were implemented in $8.4 \%$ of all enterprises in the case of the industry and in $9.7 \%$ in the case of service enterprises. In turn, marketing innovations were introduced in $7.6 \%$ of all industrial companies and $7.9 \%$ of all service companies [GUS 2015].

Innovative enterprises are characterized by a set of features thanks to which their innovativeness is shaped. This includes [Sosnowska et al. 2001]:

- ingenuity;

- exploiting the innovative potential in order to maintain a competitive position;

- forward thinking (predicting the future);

- keeping in touch with customers to learn their current and future needs;

- skillful selection of a team of creators and innovators who guarantee high innovativeness of the enterprise;

- having the proper scope of information, through which it is possible to accurately assess the market and competition;

- ability to adapt to changes and needs of the market. 
Innovativeness is a result of impact of many factors that emerge and are shaped at each level of economic aggregation. Innovativeness of the national economy is a result of innovativeness of its regional economies. These, in turn, are shaped by innovativeness of entities located within their borders. In this set of entities, the main role is played by enterprises. Innovations they introduce are dependent on a number of internal and external factors in relation to themselves.

The measurement of innovativeness, no matter if it concerns innovativeness of countries, regions, industries or enterprises, is subject to constant changes in its methodological aspect. Along with the growing importance of the issue of innovation and innovativeness, there is an increasing demand for providing data that are detailed and specific to a given area of analysis and necessary to conduct further studies. One may cite many postulates, which specify what changes of the statistics on innovation should be subject to. The development of new methods to measure innovativeness as well as the improvement of those used so far will certainly be served by a further constructive discussion on the conceptual sphere of the analyzed concepts.

\subsection{Importance of innovativeness in building competitive advantages}

The current conditions under which enterprises compete are subject to the impact of the globalization forces. In this situation, competing becomes a process which is even more multi-faceted than before. In order to meet the requirements of the ever-changing environment, enterprises must look for efficient ways to compete with their market rivals. A key area of operation in this regard is to dynamically pursue the innovative activity. Being an innovative entity, either at the micro-, meso- or macro-level, may prove of key importance in adapting to the ever-changing environment, as well as in determining the direction and forms of changes taking place in the market. Leading enterprises are those that set the tone in industries and sectors within which they do their business. They achieve it by overrunning their rivals in the largest possible number of areas of operation.

Innovation is a concept with reference to which there is no unambiguity in its definition. However, we may find common features among the approaches of various authors. Firstly, innovation is a change in the current state, for which the practical application must be found and which is referred to as intentional and beneficial. Secondly, this change in terms of its objective applies to products, processes, organization, management methods, market. Its outcomes are technical, economic and social benefits. In addition, innovations are considered as a measure to implement the development goals of a given organization and 
technical progress takes place through them (they are its driving force). It is also considered that innovations require appropriate knowledge (e.g. technical, economic, etc.) [Baruk 2002].

Numerous authors have differently perceived the importance of innovations. In classical economics, the issues related to innovations and innovativeness have been marginalized in favor of three key factors of production. In connection with that, criticism which has been formulated later on with respect to the achievements of classical economics focused, inter alia, on the issue of ignoring the role of other factors, whose nature is not material only [Grzybowska 2012]. The economists, whose achievements determined the main trends in economics, did not deal in a particular way with the importance of innovations in the economic development [Świtalski 2005].

The author, in whose works innovations played a significant role in shaping the economic growth, was Schumpeter. In his considerations, innovativeness and entrepreneurship were in the forefront as factors of economic growth. Technical innovations were the center of his interest, which is manifested by the manner in which he determined the so-called objective range of innovations. Innovation, according to Schumpeter, was the first application of a specific solution (while its dissemination was considered to be an imitation). For a very long time, many economists have not shared Schumpeter's views. Over time, Schumpeter's supply aspect of innovation was joined by Schmookler's demand aspect. Both aspects have been combined by Oppenländer, who at the end of the 1980s concluded that innovations and the economic growth are interrelated, interdependent processes [Grzybowska 2012]. The reasons for which Schumpeter's works have not been discussed for a long time by a broad community of economists may be found in the work by Tobin [1997, as cited in: Świtalski 2005], in which he stressed that due to the representatives of Keynesian economics there was a focus on the aspects of short-term changes in the economic system in place of an analysis of long-term changes.

Innovations are a factor subject to discussion in a number of other economic theories. These include, for example, theories regarding economic growth, in which we may distinguish exogenous and endogenous models as well as evolutionary theories. A particular role is attributed to innovations in the case of the new growth theory, in which technological progress plays a role of one of growth factors, which is in turn believed to be an endogenous variable [Grzybowska 2012]. It should be stressed that as late as in the 1980s, innovations became the core of considerations on the economic growth factors. Such a change was accelerated following the publication by Romer [1986, as cited in Świtalski 2005], in which the author stated that "the main driving force of economic 
growth is technical progress i.e. the improvement in knowledge about the methods of processing inputs into outputs".

Innovativeness is a concept related to innovation and, just like the associated keyword, does not have one universal definition. According to Mync [1998], innovativeness is the ability to create new things or ideas as well as the ability to absorb them in the process of their dissemination in practice. The importance of innovation and innovativeness as a subject of scientific studies has increased after formulating the paradigm of the knowledge-based economy. At the same time, the activities aimed at creating systems to support innovativeness were intensified [Okoń-Horodyńska 1999].

Innovations have an economic impact at each level. Firstly, with regard to the micro-level, they are a source of competitive advantage of enterprises. Secondly, at the meso-economic level, they generate benefits for the regional economy. Thirdly, when analyzing the case of the macro-economic level, they determine the economic development, economic transformations taking place and an increase in prosperity [Kowalski 2013].

Innovativeness is a feature that is conferred on a specific type of entities. In the currently dominant perspective on the issue of economic development, it is stated that there are three levels of economic development of national economies. According to the ranking of the World Economic Forum we may distinguish [World Economic Forum 2015]:

- factor-driven economies;

- efficiency-driven economies;

- innovation-driven economies.

In addition, the World Economic Forum distinguishes two transitional levels located between, respectively, the first and the second and the second and the third level of development. Therefore, the adjective assigned to the most competitive economies and also to those characterized by the highest GDP level per capita, is "innovative".

It cannot be stated that a relationship between innovativeness and the level of the economic development is a one-way relationship only. The more and more intense innovative processes certainly affect the development and social prosperity. However, on the other hand, along with the economic development, the factors and determinants of innovativeness tend to improve. Therefore, a relationship between them takes a form of a feedback, in which both elements influence each other.

Innovativeness is a concept juxtaposed with competitiveness in such a way that it is considered to be its main determinant [inter alia, Wojnicka 2004, Stankiewicz 2005]. It is also a factor, which is believed to play the key role in 
the development of entities at the micro-, meso- and macro-level, as well as at the local, regional and national level. According to Drucker [1992], in order to effectively operate within the market economy, we need to incorporate innovativeness into the enterprise management system and its culture.

Nowadays, innovations are considered to be a factor that in particular determines the position of national economies in the global economic system. Striving for an increase in innovativeness is present at every economic level, and in the case of national economies this purpose is achieved through, inter alia, designing innovation systems, the aim of which is to establish an efficient knowledge distribution system [Wojnicka 2004]. As a result of innovations being introduced and innovativeness that accompanies them, the objective of economic growth is achieved. This growth translates into an increase in the competitive capacity at the international level [Pangsy-Kania 2007]. In addition, the countries considered to be leading innovators are also the countries that belong to the group of the richest economies. The progressive economic growth in these countries is accompanied by deepening of the gap in the level of their innovativeness against the innovativeness of other countries.

A need to take up innovative activity stems from, inter alia, the changes that take place in the global economy. These in turn affect, directly or indirectly, the local and regional economies, which results in a change of the context of the ongoing processes of market competition.

Considerations over the competitive advantage have been conducted since the 1980s. Since that time, the scientific achievements in this area have been subject to transformations and the accompanying scientific discussion has been carried using the concepts anchored both in economics and management. In the history of the concept of forming the competitive advantage Bednarz [2011] distinguishes three approaches:

- classical theories in which the priority role is played by external sources;

- new concepts in which an emphasis is put on enterprise resources, i.e. internal sources;

- mixed approach, which takes into account both internal and external sources.

The classical theories, in which an emphasis was put on the marketoriented competitiveness factors, include, inter alia [Pierścionek 2007]: concept of cost competitiveness; quality leadership and quality control systems; competition based on the market power of an enterprise; marketing concept of competitiveness; cost leadership and differentiation. Porter is one of the authors of the classical theories. He proposed a set of three baseline competition strategies (cost leadership, differentiation, focus) corresponding to two forms of competitive advantage - low cost and differentiation [Porter 1998]. 
The evolution of the competitive advantage concept was taking place along with changes in the environment, which occurred with the arrival of the era of globalization. New economic reality has provided stimuli to expand the competitiveness concept by adding such elements as, for example, information and information systems, virtual organization forms and enterprise networks or learning and knowledge-based organizations [Pierścionek 2007]. The 1980s and 1990s were dominated by the so-called resource-based models of competitiveness of enterprises. Pierścionek [2007] stresses that their significant trait is the departure from shaping long-term advantages in favor of short-term advantages. The author distinguished the following resource-based models:

- time-based competition;

- capabilities-based competition;

- concept, in which a key role is played by the development and creation of core competences (core competences of the corporation);

- concept assuming a leading role of identifying the capabilities characterizing an enterprise and their adaptation to the area of activity (distinctive capabilities).

In these models, sources of the competitive innovative capacity such as higher quality or lower costs are embraced.

Porter [2001] concludes that the competitive advantage of enterprises results mainly from their ability to be innovative. Innovativeness should be constantly developed, therefore, their productivity will also grow. According to Grzybowska [2012], innovations are one of the most important tools to compete and achieve competitive advantage. Many theorists and practitioners share this view. Also, Hamel and Prahalad share the opinion on the leading role of innovations in developing the competitive advantage [Bojewska 2011]. In Schumpeter's theory of creative destruction, entrepreneurs play the role of entities, through which the economic development takes place. Due to the fact that new enterprises enter the game, the previously developed competitive advantages in the market are disturbed. Innovations, which are implemented, give rise to a series of events that can culminate in changes in the entire economic system [Schumpeter 1939]. Innovations are, therefore, a factor that introduces imbalance and is an impulse for development.

The theories that have emerged around the issue of innovations generated at the enterprise level may be divided into supply and demand theories [Noga 2009]. A key difference between them relates to the issue of where the impulse for innovation comes from. In the case of the demand theories, it comes from the market, thus the demand side while in the case of the supply theories it is within the enterprise where the forces determining the innovative activity are located. 
Innovations affect the functioning of enterprises in a very diversified way. They may improve their competitiveness. This happens when new or significantly improved elements of their offer are introduced on the market. Innovations may also refer to non-technological aspects of the functioning of enterprises. In this way, marketing or organizational innovations result in changes in the efficiency of manufacturing processes.

If the developed competitive advantage is to be sustainable, it is necessary to take the innovative activity which takes a form of a process rather than a form of a single event. In the context of the above, we should refer to the concept of the innovative process, which is defined in many ways. According to Penc [1999], the innovative process consists of a series of transformations ensuring the emergence of innovations, their development and putting them into practice as well as their further improvement. The innovative process is also the process of generating an innovative idea, its designing and implementation [Janasz 1997]. Through the innovative process, innovation should take place. It is desirable that implemented innovations are a factor, on a basis of which competitive advantage is being shaped. Appropriate management of this process may contribute to the fact that this advantage will be maintained or even increased.

Being aware of the importance of innovations and innovativeness for creating the competitive advantage is by itself not sufficient to be translated into the effects in a form of market success. It is also very important to have the appropriate resource facilities, whose elements will allow developing and implementing innovations essential for a given entity. In the case of innovativeness of enterprises, many authors have compiled the features that define innovative enterprises. Jasiński [1992] states that they include: conducting research and development activities or purchasing new products and technologies; allocating relatively high financial inputs for these activities; implementation of new scientific and technical solutions, that takes the form of a regularly performed activity; permanent introduction of innovations into the market.

Among the factors that affect innovativeness, we may distinguish those which are positive and supportive, and those with a negative, restrictive impact. Their set is not permanent and is subject to constant transformations. From the OECD studies on the role of innovations, we may conclude on their importance for a number of participants in the economic system. In the context of the functioning of enterprises, it should be stressed that innovative enterprises are more efficient. In addition, taking the macro-scale into account, they create more jobs that in turn are more productive. Thanks to them, social or environmental problems are solved [Kowalski 2013]. 
The fact that scientists and politicians shared and still share the view about a positive impact of innovation and innovativeness on the economy was translated into taking actions aimed at developing and implementing innovation-oriented policies. The promotion of innovativeness by the state may take place using a number of instruments. Przychodzen [2015] includes among them: legal, financial, institutional, infrastructural, structural and commercial instruments. Legal instruments are mainly actions leading to the creation of appropriate legal regulations. Another type - financial instruments - refers to the functioning of systems of awarding grants, subsidies, tax credits, but also other instruments that support the innovative activity in financial terms. Institutional instruments apply to, inter alia, the issue of establishing and supporting scientific centers. The group of infrastructural instruments includes: technology parks, business incubators, centres of innovation and technology transfer. On the other hand, structural instruments consist of working educational and research programs, while commercial instruments are, for example, trade agreements and various quasi- and non-tariff instruments.

The innovation-oriented policy that results in achieving the objective of increased innovativeness of enterprises and economies should be created and coordinated at multiple levels. It is not enough to establish a strategy at the supranational level, as it is in the case of the European Union innovation-oriented policies. In addition to actions at the EU level, it is necessary to develop national policies and then to create local and regional policies.

The reasons for which the innovative activity is undertaken are very diverse. Also, the methods to achieve competitive advantage by being innovative may vary. In the case of enterprises operating within a particular industry, obtaining the status of an innovative enterprise may take place through nurturing the activities in a form of cooperation with other entities. Alternatively, innovativeness is also achieved as a result of the intensified competitive struggle. One of the significant circumstances to intensify the innovative activity is the functioning of entities within cluster structures. Clusters, being geographic concentrations of enterprises and various organizations and institutions, enable the emergence of positive economic effects resulting from the proximity of these entities. In the year $2013-5.3 \%$ and in $2014-6.6 \%$ of industrial companies in relation to all innovatively active enterprises cooperated as part of a cluster initiative or other forms of formalized cooperation [GUS, Bank...].

Innovations are an important factor affecting the competitiveness of the economy, whose element is the developed competitive advantage. They are considered to be a determinant of the economic development of local, regional and national economies. One of the theories belonging to the canon of theories of 
economic development is the theory of diffusion of innovations. Under this theory, it is considered that innovative processes occur in a way characteristic of the diffusion process and the spread of innovations takes place in a form of a spatiotemporal process. The economic development is combined with some elements of innovation also in the case of the so-called theory of long waves, also referred to as the Kondratiev waves. This theory is dominated by a conclusion that "baseline innovations result in a sharp, cyclical increase in the rate of the economic development" [Szewczuk 2011]. According to Świtalski [2005], innovations and innovativeness are means to "increase the efficiency of management, build strong competitive positions and obtain economic benefits by enterprises, national economies and societies". What is more, innovativeness and competitiveness are not "the ultimate goal of enterprises and economies".

The environment, in which enterprises are to compete, is constantly changing. This fact opens new horizons for them, however not each of them is able to translate these changes into its own benefits. The more favorable position in this regard is occupied by innovative enterprises. The current conditions of doing business even more than ever require enterprises to operate flexibly. Therefore, creating the competitive advantage may not take place exclusive of the innovative activity that is a driving force for the development of enterprises, sectors, regions and countries. 


\section{Factors influencing development of innovations in the agri-food sector}

\subsection{Endogeneity and exogeneity of incentives for innovation development}

The firms' incentives to innovate and adopt new technologies are central for development of innovative activities in any sector. Some of the incentives can be general to the whole economy, and some of them can be sector specific. Usually two general types of innovations are distinguished, namely product innovations leading to creation of new goods and services; and process innovation reducing the cost of producing existing products. Drawing a clear line between the two types of innovation is not always possible but inducing both of them depends strongly on incentives, which can be divided into endogenous and exogenous ones. From a sectoral perspective as the endogenous incentives, we consider first of all market structure, patent licenses, and research joint ventures. In this context we will address the issue of adopting innovations, which also belongs to the endogenous factors of the development of innovation. The exogenous incentives are related mostly to the government activities, whose objective is to encourage innovation. They include patents, copyrights and trademarks, awards and government grants.

The market structure is a key incentive affecting the development of innovations. Modern studies on the impact of market structures on innovativeness were initiated by Schumpeter [1960], by stressing the role of economic agents in technological progress. He pointed to a positive relationship between the emergence of innovations and the market power, and in his opinion large companies were more innovative than small ones. Monopolies seem to be a natural environment for the research and development $(R \& D)$ activity and innovation, as the completely new information has a status of a public good whose demand must be supported by the patent system. Schumpeter stressed that innovations are more important than the price competition, because it is a more efficient measure to gain an advantage over competitors. On the other hand, Arrow [1962] stated that when innovation is protected using a perpetual patent, profit obtained thanks to it goes to a company which as the only takes up the research and development activity. Such a pure incentive for innovation is independent of strategic activities regarding pre-emption of innovations, or of costs of innovation. Thanks to innovation, it is possible to reduce unit costs of production of a given good. The amount which the company would be ready to pay for obtaining innovation depends on the market structure. Tirole [1988] compared the situation of a monopoly, competition and monopoly at risk of entry to the baseline situa- 
tion, in which incentives for innovation are equal to an increase in a net social surplus obtained through innovation. As the price shall be fixed at the level of the marginal cost, the costs before and after innovation are the same (c). The additional net social surplus per time unit is $v^{s}=\int_{c 1}^{c 2} D(c) d c$, and therefore at the constant interest rate $(r)$ a social incentive for introducing innovation will be: $V^{s}=\int_{0}^{\infty} e^{-r t} v^{s} d t=\frac{1}{r} \int_{c 1}^{c 2} D(c) d c$.

In case of a monopoly, incentives for innovation are: $V^{m}=\frac{1}{r} \int_{c 1}^{c 2} D\left(p^{m}(c)\right) d c$, where $\left(p^{m}(c)\right.$ is the monopolist's price being a function of its cost. Because $\left(p^{m}(c)>c\right.$ and $V^{m}>V^{c}$, so the monopoly pricing at each level of costs results in production deficiencies when compared to the social optimum. As a monopolist may not fully take over the social surplus, it has too few incentives for introducing new products, unless it is able to differentiate prices perfectly.

Let us assume that in the case of perfect competition, a company generating innovation receives a patent. When innovation is major, this company designates a monopoly price, and other companies cease production, while in case of secondary innovation, due to the competitive supply from other companies, the innovator collects the price equal to the marginal cost. It may be shown that a monopolist is gaining less from innovation than a competitive company, as it to a some extent replaces itself, when it introduces innovations, while a competitive company (in the case of major innovation) becomes a monopolist [Tirole 1988].

The increase in welfare as a result of innovation made by a monopolist $W^{m}$ is equal to the sum of $V^{m}$ and a change in the consumer surplus, while $W^{m}>V^{m}$ and $W^{c} \geq V c$, where $W^{c}$ and $V^{c}$ are increases in welfare due to innovation and incentives to undertake $R \& D$ activities in a competitive market, respectively.

It appears, therefore, that if companies do not have to worry whether other companies make innovations as the first, the competitive market provides less incentives for research (profits) than the social optimum but more than a monopoly. Even Arrow [1962] pointed out that in case of a competitive company profits on innovation are higher because they come from a greater number of entities than in a monopoly.

In addition to a situation in which through the patent protection it is possible to obtain the market power by means of innovations, it is also possible that companies with the market power may be able to stop the entry and imitation using defensive patents and retain the market power by introducing new products. In case of a monopoly threaten by an entry, we may consider two situa- 
tions $^{2}$. In the first, in the product market we have two companies, the first is a monopoly, and the other is a potential entrant with very high unit costs. As soon as a monopolist may obtain a new technology reducing the unit costs, we have a situation of monopoly and incentives for innovation for it are $V^{m}$. When a potential entrant is the only one which may obtain a new technology, we have a situation of competition and the value of innovation for an entrant is $V c$. Since $V^{c}>V^{m}$, innovation is worth more for an entrant than for a monopolist. In the second possible situation, none of the companies has a monopoly on innovation, e.g. the third company, which could not produce products in this market generates innovation and puts it for auction between two production companies. In this case, an existing company must take into account not only the benefits of innovation, but also what is going to happen, when not this company but its competitor adopts innovation. In turn, a potential entrant is not interested in whether a monopolist adopts innovation if it itself decided not to do so, and as a result, this does not affect the way in which it calculates the value of innovation. On the other hand, when a monopolist makes innovation, but does not introduce it, its profit is reduced by innovative entry. It appears, therefore, that innovation is more valuable for an entrant than for a monopolist. Finally, as the competition reduces profits, incentives for a monopolist to remain a monopolist are greater than incentives for an entrant to become a duopolist.

In particular, the issue which of two companies spend more on research (or which is more likely to make innovation) depends on the following two effects: performance-based and substitution. The first one occurs when due to the fact that in the market of homogeneous products a monopolist does not obtain profits smaller than those of cooperating duopolists, it always makes innovations before an entrant. The second concerns a situation when a current monopolist even before innovation earns monopoly profits, as a result of which it cares less about innovation. What is more, in order to prevent an entrant from competition, a monopolist wants to get ownership of innovation, even it does not use it, e.g. where a patent relates to a manufacturing technology, which is not better than that used by a monopolist or when product innovation does not differ from the product of a monopolist to an extent justifying the costs of introducing a new product. The substitution effect is a reason for which the marginal productivity from R\&D expenses for a monopolist decreases along with the initial profit. In

\footnotetext{
${ }^{2}$ When a company is a monopolist as regards the R\&D activity, we may talk here about a pure incentive for innovation. However, we usually deal with the competition in the R\&D area. It may be related to a patent race. Then, each company wants to accelerate its research programs and bears additional costs. Entrepreneurs compete for a rent which is partially wasted by additional costs borne during its acquisition.
} 
addition, we may not forget that in practice entrepreneurs, apart from making a decision on conducting the R\&D activity, must choose one from among several R\&D technologies (involving different techniques and levels of risk), learning occurs in the innovation process and allowing managers in a company to make decisions usually results in a lack of profit maximization due to the separation of ownership from control.

In conclusion, it may be noted that the issue what type of the market structure provides greater incentives for innovation depends on whether a patent race is possible. The related issue is the problem of selecting the optimal innovation time [Carlton and Perloff 2005]. When the demand is growing, the later innovation is introduced, the higher is the discounted value of earnings and, therefore, the optimal innovation time is when the present value of savings on innovation is equal to the current value of alternative earnings from an original investment i.e. innovation should appear when marginal revenue (from royalties) becomes high enough to cover marginal costs of the lost interest rate. This is a strategy which a monopoly strives for. In turn, competitive companies behave in a different way, as they race to be first. If innovation is made by a company in the competitive market, by patenting it, it will be possible to get royalties endlessly. In a competitive branch, it is highly probable that innovation will be made earlier, as a given entrepreneur would not want to wait for the other to make innovation before it does so. As a result, while a monopolist introduces innovation in the optimal time, in the competitive branch research is overinvested and innovation appears too early. Carlton and Perloff [2005] also pointed out that the moment of the emergence of innovation depends on many factors, such as cost and demand functions or the number of competitors. Kamien and Schwartz [1982] stressed that the moment of innovation in a competing company takes place immediately after the time of zero profit. It may also happen that innovation at a monopolist appears earlier. This situation takes place when a monopolist collects a higher price for its product and thus their distributions of benefits from innovation are different. However, in general, competitive companies make $\mathrm{R} \& \mathrm{D}$ faster than monopolists not involved in a patent race.

Finally, it is worth noting that in practice patents do not constitute a major measure to protect the competitive advantage. Carlton and Perloff [2005] indicate: secrets, time of introduction, quick movement of the learning curve downwards (gaining experience, which results in the lower manufacturing costs), sale of services in case of process innovations. When it comes to efficient ways to protect the competitive advantage, in case of product innovations only secrets are rated lower than patents. Product patents turn out to be particularly effective in case of inorganic chemistry, organic chemicals, medicines, plastic materials. 
Patent races are less likely for new processes and more for new products in the branches with a greater level of the R\&D activity.

The objective of a patent is to provide an investor with exclusive rights to a new and useful product, process, substance or project [Carlton and Perloff, 2005]. New products include machinery (mechanisms with movable parts) and industrial products (no movable parts) as well as tools. New processes and methods include processes of chemical treatment of metals or for the manufacture of medicines, mechanical processes of production of goods and electric processes. New substances are chemical ingredients and mixtures. The patent protection also applies to new species of plants and animals. New projects include the shape of products, whereby shapes are used for functional needs. For example, in the USA, where 5 million patents have been granted since 1790, the patent protection lasts for 20 years from the date of completing an application. In order to obtain it, it must be demonstrated that an invention is useful (especially new chemicals), new and non-obvious (it is not possible to slightly change something which is commonly known), it must explicitly describe innovations and, if possible, provide a practical model.

A rational innovator gets involved in expensive research until the expected marginal return on research is equal to the marginal cost. Patents allow investors to capture a large share in profits (to internalize externalities) associated with the production of knowledge by way of isolation from the competition. By guaranteeing the exclusive right by means of patents, the society encourages more inventions in certain branches. On the other hand, even if patents protect an inventor against imitation, obtained monopoly profit is smaller than the full social benefit (unless a patent holder may differentiate a price). As the estimated private rate of return on the R\&D activity is smaller than the social rate of return [Jones and Williams 1998, Mansfield 1998], although many people make inventions for their own good or in the service of humanity, without patents and government incentives, there will be too little research and innovations. Many entrepreneurs take up activity for cash prizes. When there are no patent protection or other incentives for investment, not only few innovations are created, but also anybody can copy them. Anyone may use the new information, and imitations of new inventions can be sold legally. Imitations being created imply an increase in the level of competition, which leads to reducing prices to a competitive level. Despite the costs incurred for research, an innovator does not obtain private benefits (economic profits). If inventors incur all private and social costs of research, but do not receive private financial benefits from their investments, a solution maximizing profit for them consists in not getting involved into re- 
search. As a result, without patents, consumers can buy innovations at competitive prices, but there are few innovations.

Resignation from socially desirable innovations is detrimental to the society because new production methods reduce production costs and allow to increase the production with the same amount of inputs, and new products increase the productivity or provide pleasure. By providing inventors with the patent protection, the society achieves two main benefits - greater incentives for additional R\&D and acceleration of innovations by means of disclosing inventions. Patent law encourages to disclose new discoveries, and disclosure is likely to increase the speed of inventions, because one inventor is based on the work of others. The existence of a patent does not constitute, in fact, any obstacle to similar investments, e.g. Xerox, which, after all, reduces the value of a patent of the first inventor. Also, disassembly in order to obtain the compatibility with given devices or to imitate the functions of other software is permitted. At the same time, a lot of patents and property rights are not enforced. Although patents increase the costs of imitation and delay the appearance of imitations in the market, copying of innovations may start quickly - competitors learn about R\&D programs in processing branches, on average, 12-18 months after their initiation, mainly as a result of the movement of employees between companies, formal and informal messages between engineers and researchers, reports of providers of means of production and customers or disassembly of new products. Mansfield [1985] and Levin et al. [1987] showed, however, that imitation costs increase as a result of the patents. On the other hand, some entrepreneurs consciously quit the patent protection to prevent their competitors from learning these patents, which, in case of patents, occurs more often than e.g. in case of secrets. In some countries, patents are blocked or inventors are prohibited from selling or licensing their technologies to everyone outside of the government, if it could put state security at risk.

Generally speaking, the stronger patent law is, the more difficult it is to obtain a new patent and the longer a holder of a current patent may earn monopoly profits. On the other hand, the less frequently patents appear, the less likely it seems to obtain a patent, which reduces incentives for engaging in research and disclosing innovations. Despite the lack of definitive evidence that the patent law contributes to increasing the level of the innovative activity, the majority of economists agree that robust patent law increases the number of innovations in the country [Nordhaus 1969, Gilbert and Shapiro 1990]. Certainly, however, patent systems influence in what branches the innovative activity appears [Carlton and Perloff 2005]. 
An entrepreneur receiving a patent acts like a monopoly and maximizes profits by determining the marginal revenue equal to the marginal cost. A patent is worth the value of the years it lasts multiplied by the annual value of the rights to sell a new good on a monopoly basis. A patent may be granted for an indefinite or definite period of time [Carlton and Perloff 2005]. In the first case, a patent holder obtains monopoly profits endlessly, which implies the fact that many companies struggle for a patent, which results in an excessive number of undertaken research projects. The current value of a patent may be calculated by dividing annual profit by percentage rate and is usually lower than the net social benefit, if the invention was sold at competitive prices. Every company has an equal chance to receive a patent, as a result of which the expected return for a company taking research is the value of a patent multiplied by the probability that a company makes a discovery as the first. An entrepreneur participates in a patent race as long as the costs of research are lower than expected benefits from winning the race. In turn, thanks to the shortened duration of patents, the government may reduce incentives for the excessive number of research. This is because the exclusive rights obtained only for a specific period of time contribute to reducing the present value of future monopoly profits. As a result, the expected private benefit for each company is lower and, therefore, fewer entrepreneurs get involved in research. In conclusion, as the number of $R \& D$ projects to be undertaken depends on the number of years for which we may get the patent protection, if the number of research is not to be excessive, a patent should be granted for an appropriate number of years. Moreover, the government has a choice - the longer a patent lasts, the greater are incentives for research, but also the higher are costs due to more research projects and the losses of a monopolist. Finally, the government should choose such duration for patents so as to maximize expected net social benefits, taking into account the monopoly pricing.

In practice, however, the number of years for which the patent protection is granted, is constant for all products, which means that the monopoly power for some is guaranteed for a period which is too short and for others - too long. As for certain products, before they are placed on the market, other licenses are also needed, the effective duration of a patent is reduced and for this type of products the duration of a patent is often extended by the duration of a delay. In turn, in the branches with a rapid speed of innovation, the duration of a patent does not matter, because the appearance of new products eliminates the demand for older ones, although they are covered by the patent protection. In some countries, durations of a patent are dependent on their holders, who need to pay fees for each year of duration. At the same time, there is a discussion with respect to the patent protection in developing countries, which, on one hand, helps increase 
incentives for entrepreneurs to create innovations, which increases the benefit for the consumer, and, on the other, as a result of a rise in prices restricts access of consumers to these innovations. Hughes et al. [2002] stated that the absence of the patent protection in a long term in developed countries will ultimately reduce benefits for the consumer.

The intellectual property protection forms, giving similar effects as in case of patents, are copyrights, trademarks and trade secrets. In case of the latter, innovation is protected by keeping the secret, e.g. the recipe for Coca-Cola. Copyrights are the exclusive rights of production, publication and sale with regard to art, dramatic, literary and musical works, e.g. articles, books, drawings, maps, music works, outstandingly designed items, photographs. They differ from patents in this regard that while patents protect the functions and purpose, copyrights protect artistic expression. The protection does not apply to ideas, procedures, systems, operation methods, concept, principle or invention, but, at most, the form in which it has been described, explained or illustrated. The exception in many countries is the so-called doctrine of fair use, in accordance with which it is possible to make copies short excerpts of a book for personal use. On the other hand, trademarks are words, symbols and other characters used to distinguish a good or service provided by one of companies from the market offer. A trademark may also be registered with the patent office. Interestingly, if the name of a product begins to be identified with a product of the entire industry, the trade mark protection expires, e.g. aspirin, linoleum, nylon, thermos, trampoline, jojo [Landes and Posner 1987]. Carlton and Perloff [2005] point out that although copyrights, like patents, encourage to create reputation, patents allow to achieve a greater exclusivity and monopoly power, it is also more difficult to obtain them.

Because imitators observe innovations with delay or do not have know-how necessary to copy them fast, patents and accompanying inefficiency associated with the monopoly power give companies appropriate incentives for innovation. At the same time, a disadvantage of the patent protection, copyrights and trademarks is just the fact that when close substitutes are not available, new products can be sold thanks to them at high monopoly prices. As a result, governments, in order to encourage the innovative activity, reach for research awards and contracts. If the government has the complete information, in order to induce the optimal level of research, by maximizing the net social benefit, the government may determine the amount of awards and announce research grants $^{3}$. After making a discovery, new products may then be sold at competitive prices, and the consumer surplus is maximized.

\footnotetext{
${ }^{3}$ It is also possible to subsidize the costs of research, e.g. by applying tax credits for R\&D expenses, tax breaks or special duty-free export zones.
} 
The award system is reduced to defining the project and providing a specified amount of money (award) to the first company which completes the project. After providing the award, innovation stops being private. Awards are encumbered with a low risk, because the government does not incur any costs if no one makes a discovery. If the government properly determines the amount of the award, the optimal number of companies will fight to win. With an increase in the number of research programs, social costs and expected social benefits are growing. With a small number of companies, adding another one significantly increases the probability of success, as a result of which expected social benefits at first grow rapidly. When social costs increase steadily, net social benefits (social benefits minus social costs) at first grow, then decrease, and their maximum is at the point where marginal costs cross the descending line of marginal social benefits. Thus, the award which is too high will result in an excessive number of research, because the competition disperses almost all rents from research and a net social benefit becomes very low (social cost is close to expected benefits). In attempting to receive the award, a company undertakes a research project if its expected win is at least as high as the costs incurred (we assume that it has a neutral attitude to risk). The optimal number of companies is, therefore, achieved in case of the award, where expected profits of each company are equal to research costs ${ }^{4}$.

The government may also provide the optimum number of research by providing such number of research grants to companies offering to conduct $\mathrm{R} \& \mathrm{D}$ data at the lowest cost. This approach is more centralized when compared to the patent system. From the award system it differs in terms of the fact that the government controls access to the research market, more specifically - the government selects a certain number of companies and signs with them contracts containing more details than in case of awards. The objective of concluding grants is to protect against the excessive reproduction of research costs.

The problem is that the government may select the optimum number of companies only when it knows actual research costs and expected benefits. When the award, research grant and duration of a patent are determined before learning the value of innovation and an innovator believes that innovation is worth more than stated by the government, a patent may result in more research than the award and government contract. Of course, when the duration of a pa-

\footnotetext{
${ }^{4}$ Expected profits are equal to the probability that at least one company makes a discovery by the number of companies multiplied by the value of the award and since with the optimal number of companies the costs are equal to the expected social benefits with the given number of competing companies, the award offered by the government should be calculated as a ratio of the expected social benefit to the probability that at least one company makes a discovery by the number of companies [Carlton and Perloff 2005].
} 
tent is very short, research awards and grants, even if too low, may be a better solution. In general, it is difficult even for a potential inventor to predict the value of innovation in advance. What is more, even after making an invention its value may be uncertain, because it is difficult to estimate the demand due to legal inaccuracies. Companies are better informed than the government about the feasibility of various inventions and about the demand for them, so the less centralized solution (as the patent system) is preferred. An advantage of the patent system is that monopoly profits are correlated with the social value of innovation. In practice, the price in the award system is determined after innovation takes place.

Another problem is the fact that the public and private sector interactions may become a cause of social loss, when public investments replace private investments and when relatively small private investments are a disturbance for government research programs. On the other hand, however, it appears that without government support companies would finance only up to $20 \%$ of research, conducted with support of the government [Mansfield 1984]. In turn, Lichtenberg [1987] stated that government R\&D expenses neither increase nor decrease the private sector expenses for this purpose, and the government should, in the first place, finance research that would otherwise be ignored by the private sector.

Finally, it is worth noting that one issue is to determine effectively whether companies get involved in too little or too much R\&D activity, while the other is to determine the optimal way to encourage them to or discourage them from R\&D. Although patents provide exclusive rights to innovations made and contribute to increasing the level of the R\&D activity, as opposed to awards and government research contracts they lead to distortions due to the monopoly pricing. As a result, they are less efficient than the optimal awards or research contracts, if only the government has the sufficient information to induce the optimal number of research. However, since the government has usually the limited information, patents still remain the most common method to encourage research in the world [Carlton and Perloff 2005]. Tirole [1988] notes, however, that in the industries where positive externalities in relation to other companies (spillovers) are high, government subsidies to the R\&D activity are a good substitute for the patent system, because the spillover effect results in reducing payment for a winner of a patent race and increasing its for losers who "steal a ride".

A patentee may manufacture a product or use new processes, or license, or allow others to manufacture in exchange for a fee hereinafter referred to as a royalty [Carlton and Perloff 2005]. Licensing enables the transfer of technology to other companies on a basis of a license, thanks to which new inventions 
may be disseminated faster. Licensing may take place only when it increases profits of both companies (and therefore also of the industry). It appears where an independent innovator (or a company specializing in R\&D) is not able to make use of a patent or where an innovator has processing capacity. Firestone [1971] notes that the majority of patents in the hands of corporations are used only by these corporations, and the majority of patents in the hands of independent investors are licensed to individual companies.

Tirole [1988] distinguishes three reasons for licensing. The first are product and market incentives, the second - small product and market competition, while the third - strategic licensing. The importance of product and market incentives is shown by the Rey-Tirole model and by the Farrell and Gallini [1986] and Shepard [1986] incomplete contract model. For example, in this first model, a processor of an intermediate product, when deciding on licensing, selects between reducing the monopoly power and increasing incentives. When it comes to the second reason, the product and market competition may be mitigated by 3 factors: product differentiation, production capacity restrictions and interim price collusions. As a result, cost savings of the industry related to high cost of the manufacturer using low-cost technology may easily exceed the loss of profits of the industry. It is also worth noting that the market position of a company is not affected by a license to another company serving a different geographic market. Moreover, we may notice that in addition to ex-post licensing, it may be also ex-ante licensing (before research). The objective of strategic licensing is to reduce incentives of a competitor to inventions such as initial innovation, and therefore the motivation is not saving on production costs, but rather saving on $R \& D$ expenses, that are wasted from the point of view of the industry. Ex-ante licensing brings less incentives for inventions, because its marginal costs are decreasing which makes innovation less desirable [Gallini 1984, Gallini and Winter 1985].

Various authors considered various forms of contracts between a licensor and a licensee. Kamien and Tauman [1983] examined two-part fees - at first, a licensee pays a fixed fee for access to technology, which is transformed into a variable fee or royalties per unit of final production manufactured with the use of intermediate technology. In Gallini [1984] and Katz and Shapiro [1985b], fees were fixed while Gallini and Winter [1985] admitted royalties only. In practice, there is the information or legal reasons for which contracts are limited to simple forms, such as a fixed fee or royalties. Katz and Shapiro claimed that, in certain circumstances, production of a licensee (or how much of this production is produced under a license) may not be observed by a licensor, therefore, it is impossible to base transfers on production, and a fixed contract fee is a good approximation of reality. Calvert [1964] and Taylor and Silberston [1973] 
showed that most licensing agreements are based on royalties. The second place is occupied by two-part tariff, or more complex arrangements, and the third - by a fixed fee.

When the market is competitive, all companies produce at a fixed cost (marginal and average) and sell at a competitive price. When one of them develops a new process, this process will enable the production of a good at a lower cost. When this company obtains a patent and decides to sell a product, it will be in a situation of a dominant low-cost company exposed to competition. The lowest price that it may charge is a price below which it would suffer losses, while the highest price is equal to a price obtained before innovation. Let us assume that the optimal solution for a dominant company is to charge a price slightly lower than a previous price so as to prevent competitors from selling. Profit from innovation is then a difference between old and new costs multiplied by the number of units sold (royalty). When a company considers licensing a concept to other companies, it charges this rate of royalty for the unit of production sold by another company [Carlton and Perloff 2005].

In case of secondary investment, which reduces manufacturing costs to a small extent only, the curve of demand for licenses is formed by deducting the new manufacturing cost from the curve of residual demand of a company holding a patent. As a result, the maximum value of royalty, which a competitive company wants to pay for the license shall be equal to the difference between a competitive price and a cost obtained after implementing a patented process. When the number of units sold is higher than before, the license value begins to fall to zero, because a competitive price is equal to a manufacturing cost in a new process. Profit maximizing royalty appears when the marginal revenue from selling another license is equal to the marginal cost of this license. This cost amounts to zero, and therefore royalty is determined by the point of inflection of the curve of the license's marginal costs towards the axis of volume. This point is located at the previously produced volume. As a result, profit maximizing royalty is equal to total savings from using new processes, which equals to profit achieved by a company when it does not license a product, but sells it on its own. In case of major investment, which results in a large decrease in manufacturing costs, the marginal revenue for demand for licenses is zero with the previous production volume. Consequently, the profit maximizing price is lower than the previous price, i.e. the royalty rate is lower than the reduced cost, and the number of licenses sold is greater than the previous production volume.

Therefore, it turns out that, firstly, if an innovator may produce as efficiently as others, it is all the same to it whether it will either sell a product or license it because competitive pressure will reduce monopoly in both cases. Li- 
censing is, however, more likely (and more profitable than the lack of licensing) when licensees have lower manufacturing costs than an innovator. Secondly, an innovator captures all social benefits in case of secondary innovation, but not in case of major innovation. In case of the former, consumers purchase the same quantities at the same price and an invention has no impact on them, while in case of the latter, prices are decreasing and the quantity increases and thus the consumer surplus grows, profit of an innovator is, therefore, lower than total social profit [Carlton and Perloff 2005]. Moreover, Katz and Shapiro [1985a] found that privately desirable licensing is also socially desirable. When the industry's production volume increases along with a reduction in costs by one of companies, the consumer surplus also grows and it is assumed that the industry's profit grows as well, which results in an increase in the level of prosperity. They also showed [1985b, 1986c] that licensing increases both the award from acquiring innovation and the award from losing a patent race. Incentives for taking $R \& D$ depend on how much of the common surplus may go to a licensor, which depends on the bargaining power of a licensor.

The reason for a small number of research with no additional incentives are externalities. In the absence of patent rights, any company interested in manufacturing a new product prefers to copy an invention of another company rather than to pay for the development of a new product. As a result, each company will wait until others incur costs and the number of undertaken research is not large. The method to avoid the problems of externalities are research joint ventures. They are agreements in which some companies agree to share expenses and benefits associated with a given research project. They become more and more common, especially in the area of technology, where R\&D costs are high.

Just like license agreements, these are contractual practices which significantly affect the level of $R \& D$ and the diffusion of innovations within the branch. They are also connected with licenses by the fact that although initially they relate to the input market (innovations), they may also involve auxiliary restrictions in the product market.

Apart from using the complementarity of the members' assets, joint ventures allow to coordinate research activities, e.g. they may prevent duplication of research strategies, and available resources may be better utilized. Grossman and Shapiro [1986b] and Ordover and Willig [1985] distinguished two phenomena caused by joint ventures and accelerating the emergence of innovations. First, when the patent protection is not fully effective and innovations create the spillover, companies conducting R\&D individually will not internalize positive externalities associated with innovation on their competitors. Instead, they will underinvest in R\&D from the point of view of the industry. Joint ventures agree- 
ments allow to adjust at least externalities among the members, thereby increasing their R\&D expenses. Secondly, fixed R\&D costs are often so high that companies do not want to incur them on their own. Joint ventures allow to acquire funds for using the growing economies of scale and $\mathrm{R} \& \mathrm{D}$, and in the concentrated industry they may help competitors avoid to compete in the R\&D market, especially when innovation redistributes profits rather than increases them. On the other hand, while joint ventures between non-competing companies or between several companies in the non-concentrated market seem to be socially desirable, they may also slow down research in concentrated branches [Tirole 1988].

However, joint ventures involve a couple of problems. First, companies are afraid that this type of activity may lead to anti-cartel charges. While entrepreneurs meet to agree on how to finance research and to share existing knowledge, control authorities can suspect that they collude in order to determine the price of a new product at the monopoly level. Another risk is that many companies have several patents on a single process, and single innovation may be worth nothing, and a better solution is to purchase a license to a patent under reasonable conditions. The solution in such cases are agreements taking account mutual cross-patents [Lerner and Tirole 2002], but this often results in exclusion or charging the monopoly price from companies outside joint ventures [Gilbert 2002]. Thirdly, it is not clear whether through joint ventures it is possible to finance the optimum number of research projects. Although they give an opportunity to avoid unnecessary duplication of research projects, except where it may function as a monopoly differentiating a price, the number of research undertaken by them is insufficient to cover the full expected social value. This happens especially when research may easily be copied by companies outside joint venture. As a consequence, joint ventures rarely generate significant research in such markets and, on the other hand, in some countries, patent collusions are allowed [Carlton and Perloff 2005].

At the level of companies, innovations take place also when new products and solutions invented by other entities are adopted by other companies in the market. The speed of adoption of innovations increases when companies expect the growth in demand and are unwilling to incur the costs of adoption before there is no sufficient demand, as well as where they may not expect a decline in the costs of adoption or in connection with the uncertainty with respect to technology. The standard diffusion path takes on the shape of the letter S - at the early stage, only a few companies adopt innovations, then this process speeds up when companies are learning about an invention, then the process slows down when most companies have already made adoption. Interestingly, in case of the diffusion of unpatented innovation in the concentrated branch, the costs of adop- 
tion are reduced over time, but more and more slowly, and no company wants to adopt at the zero time. In case of strategic adoption in a duopoly, companies may be tempted to adopt technologies early so as to delay or prevent adoption by competitors.

We may consider two opposite cases: innovation preventing imitation and quick imitation and delayed joint adoption [Tirole 1988]. In the first case, adoption of innovation by the other company does not bring any profit to this company, and the first company adopts this innovation earlier with a view to the acquisition by means of pre-emption of its competitor. The diffusion takes place either with a significant delay or never, while in case of early adoption the related monopoly rent disappears completely. In the latter case, adoption of product innovation results in immediate imitation and incentives for adoption are needed. Adoption is delayed and takes place in both companies at the same time. Therefore, we may say that the time of diffusion of innovation in the concentrated industry depends on the rate at which adoption is imitated.

The processes of adoption are accompanied by positive externalities. They may be direct (producer benefits from the fact that other producers belong to a given network) or indirect, which takes place due to the growing economies of scale in production - an increase in the network implies an increase in the number of complementary products that can be delivered at a lower price. It is also noted that the network size is specific to a particular company or branch. Externalities refer to both the demand and supply side. When it comes to the former, due to independent utility functions, users must predict what technology is to be widely used, as a result of which different users may have different preferences regarding which technology to coordinate. Consequently, two potential inefficiencies are created: excessive inertia (users wait to adopt new technology or to select from among several ones) and excessive momentum (consumers adopt worse technology in fear of being left alone) [Farell and Saloner 1985].

The supply side refers to the method of the selection and promotion of innovation. In the presence of externalities associated with networks, standards (the selection of given technology to be adopted by all) are often imposed (or agreed) by the government or private entities, such as e.g. associations of producers. Thanks to standardization, it is possible to avoid excessive inertia and to reduce the costs of exploration and coordination incurred by consumers and, on the other hand, it may be difficult and inefficient, when technologies change too often, it may reduce diversity. Usually, standardization results from the market, whereby standards are often set by a dominant company. Often, in order to gain a competitive advantage over competitors or to prevent competitors from gaining the advantage, product prices are reduced, and consumers are informed 
about the products before their commercialization. For strategic purposes, companies can choose to leave their products incompatible, reducing the network size, or they may achieve compatibility, individually or by entering into agreements with competitors [Katz and Shapiro 1985a, 1986a, 1986b]. Tirole [1988] points out that decisions of companies and users regarding whether to adopt specific technology may be considered through games of timing, wars of conflict, competitions for the right of pre-emption.

\subsection{Innovative impact of clusters}

There is a fairly widespread belief that the proximity of the presence of economic entities is conducive to their productivity and efficiency. The term proximity may be regarded as a general, umbrella concept covering many dimensions. The essence of proximity consists in reducing the uncertainty associated with economic activity, it contributes to solving the problem of coordination among various actors and supports interactive learning and innovations. By analyzing the logic and rate of the emergence of innovation, at least four functions of proximity have been identified [Engel and del-Palacio 2009]. Firstly, there is evidence that when companies operating in the same industry are located close to each other, they tend to innovate by creating an environment in which companies compete with each other in a positive sense. Secondly, the geographical proximity helps companies create an effective division of labor and coordinate their activities, thus developing their main suppliers and partners. Thirdly, there are external attributes of proximity available to all in a given region. They are associated with human resources existing in the region (workforce) and know-how. Fourthly, and perhaps most importantly, the proximity is important to initiate the transfer of knowledge and learning processes among various actors. In turn, Skawińska and Zalewski [2009] into the sources of benefits achieved by entities thanks to proximity include internal economies of scale related to the technique of production, benefits of location being a manifestation of the impact of the industry on individual entities, benefits of urbanization being a manifestation of the functioning of the economy as a whole and being external to companies and industries, as well as relationships among industries. In addition, Figiel et al. [2011] note that the proximity of companies allows them to achieve so-called agglomeration effects which may be associated with the close, in terms of location, functioning of companies with the same activity profile (effects of location) or of all entities (effects of urbanization).

A special form of the functioning of enterprises based on their spatial proximity and mutual penetration, allowing to achieve positive effects of com- 
petition and cooperation (coopetition), are clusters. The importance of clusters in increasing innovation was pointed out by Martin and Sunley [2003] and Porter [2001]. The former, among the basic benefits of the functioning within a cluster, in addition to a higher growth rate, higher productivity, improved profitability and competitiveness, increase in the number of new companies and jobs, mentioned also higher innovativeness. In turn, Porter pointed to the increased capacity to innovate, by discussing three groups of synergistic benefits from the functioning of entities within clusters. Companies are watching their behaviors, both in terms of production techniques and marketing, by observing new, more efficient solutions, and then improving their own activities based on these observations. As a result, new ideas, concepts and innovation spread faster, while experimenting and processes of joint creation of new solutions become less costly and risky. Entities complement each other, and the diffusion of innovations is faster and more efficient. Innovative solutions are introduced as part of the competitive struggle carried out to gain a competitive advantage in relation to other entities ${ }^{5}$.

The importance and popularity of the concept of a cluster and noticing the impact of clustering on the economic development started from the fact that Porter considered clusters as a source of building competitive advantages of nations [Figiel et al. 2013]. In addition to the proximity, a key feature of a cluster allowing to increase innovativeness is coopetition taking place among its participants, and being a combination of competition and cooperation. While the competition is the process in which market participants, striving for the implementation of their interests, try to provide offers more beneficial than those of their competitors (the benefit can refer to various types of characteristics e.g. price, quality, service conditions, etc.) [Przybyciński 2005], cooperation means just collaboration. Therefore, coopetition is a situation where competitors cooperate and compete with each other at the same time [Bengtsson and Kock 2000]. According to Jankowska [2009], coopetition, as a special case of regulation of behaviors is to lead to the harmony in economic processes taking place within their borders. In turn, Ketels [2003], in addition to the geographical proximity, among the key attributes of a cluster distinguished connections, defined as a focus on the com-

\footnotetext{
${ }^{5}$ The second group of synergistic benefits consisted in improving performance of companies and sectors within a cluster thanks to access to specialized inputs and labour, market and technical information, offered within clusters. Companies may be more effective in sharing functions, products they offer are more complementary, they may conduct joint marketing activities, access to institutions and public goods is better. In turn, the competition among companies within a cluster enables continuous comparisons and increased efficiency of action. Continuous contacts and cooperation reduce the risks and limit opportunistic behaviors. Instead, companies are oriented towards long-term cooperation, taking more care about their reputation. Thirdly, the cluster environment is conducive to the creation of new companies. Thanks to current access to information and interrelations, it is much easier to enter the market.
} 
mon goal, interactions taking place among entities and the number which boils down to the fact that interactions among entities must relate to the number of entities guaranteeing to achieve the so-called critical mass.

According to Sölvell [2009], clusters are subject to the life cycle. The emergence of a cluster may take place either as a result of the occurrence, in a particular location, of specific advantages in relation to the resources available in this location, or as a result of historical conditions and merits of a specific economic operator through which the process of concentration within a specific branch was initiated. At the next stage, there is an increase in the intensity of competition and cooperation processes, whereby an important role in this process is played by the environment which, according to the Porter's diamond model form the determinants of demand, determinants of factors of production, context of the strategy and competition of companies and related and supporting sectors [Figiel et al. 2013]. Some clusters enter the stage of maturity relatively quickly, for others the stage of the largest performance, at which the economies of scale are used, may last even for centuries. Over time, the processes taking place within the framework of cluster structures may lead to their decline. A final result may be the stage referred to as a museum or a renaissance of a cluster, for example, due to the fact that new companies entered the market or technological or institutional developments took place.

Clusters, in their form, adapt to the needs of the environment in the context of innovation, which are increasingly created as a result of the involvement of entities from many various industries and corners of the world. It may be noted that while the first direction of evolution is associated with structural changes, the other is a result of the processes of globalization. Consequently, innovation clusters, innovative cluster networks and innovation cluster networks are created.

Innovative clusters with the cross-sectoral range are usually of regional nature. They are also referred to as research or knowledge-based clusters [Nowakowska 2011]. An innovation cluster is the often observed concentration of interconnected organizations, including suppliers, service providers, universities, trade associations, etc., within which mutual benefits are achieved thanks to proximity as a result of the aggregation of expertise and highly specialized resources. Their key feature is to strive for exploiting the potential and business opportunities by means of supporting the research and development sector. In the spotlight, however, there are not only innovations but structural changes (new specializations) within existing sectors, which, consequently, become cross-sectoral. This approach is characterized by the actual functioning of the so-called triple helix among sectors of business, science and government. Among participants, we may find: scientific research units, universities, compa- 
nies able to create innovations and absorb new technologies, supporting institutions - science and technology parks, innovation incubators, technology transfer centers, industrial and service companies whose activity requires research and development, but also: economic chambers, chambers of commerce and industry, financial institutions, consulting companies, especially from the area of science and technology, banks, venture capital companies, business angels, law companies, particularly those specializing in the area of intellectual property rights, controlling institutions and standardization committees. Moreover, thanks to taking into account the educational element, it becomes possible to create a bridge between ideas and economic reality [Gołębiowska-Tataj 2013]. As a result, entities cooperating with each other jointly implement programs that integrate research, development and implementation activities into educational programs and commercialization. In this context, we are talking about the multilayering and switching processes.

According to Engel and del-Palacio [2009], in innovation clusters other benefits of agglomeration prevail, defined not by sectoral specializations, but by the stage of development and by innovations, and a key feature of these benefits is the mobility of resources - capital, people, information, including know-how and intellectual property, which facilitates rapid innovations based on new projects, experiments, increase in scale, and even errors. They state that an agglomeration of companies within the branch did not explain the nature and specificity of some clusters, and in particular did not explain the capacity of some regions to support the process of the continuous emergence of new companies with high growth opportunities, independent from other companies with a similar industry orientation. As the basic competence of innovation clusters, they indicate entrepreneurship and the early emergence of global strategic thinking. In particular, the dynamic development of entrepreneurship between the $R \& D$ sphere and business sphere is determined by a significant increase in the mobility of students. Entrepreneurship is also a prerequisite in the face of competition and restricted resources. The existence of these clusters is, therefore, evidenced by the fact that companies from new industries, which do not benefit from externalities related to the agglomeration, appear in their territory ${ }^{6}$. Through the emergence of new companies, innovation is to some extent increased and accelerated.

Among two key processes taking place within these clusters, we may distinguish both exploitation - the efficient use of assets and capacities which is determined by maintaining the stable organizational structure, clear and unam-

\footnotetext{
${ }^{6}$ According to Lindqvist [2009], they are: transfer of skills and inventions, development of auxiliary and supporting branches, economies of scale in case of joint use of specialized machinery, development of the local market of qualified staff.
} 
biguous standards of operation, as well as exploration - development of new capacities, which, in contradiction, is determined by loosening the structure. As these processes take place not only in the interinstitutional context such as research institutes, universities or industrial laboratories, but also in the nongovernmental sector (social innovations), administration (institutional innovations) and among users (user-driven innovation), these clusters are not only an interinstitutional partnership, but an open environment within which social processes of the production and diffusion of knowledge will take place [Gołębiowska-Tataj 2013].

In terms of what is focused on, among innovative clusters we may distinguish the following types of clusters [OECD 2001]:

- knowledge-based clusters - access to basic research, public research institutions and universities;

- clusters based on economies of scale - connection with technology institutions and universities, own research conducted by companies on a small scale;

- $\quad$ specialized suppliers - much intensity of R\&D work, product innovations, small distance from each other, from customers and users;

- clusters dependent on suppliers - import of technology in a form of capital goods and intermediate products, interaction with suppliers and after-sales services.

The effects of the functioning within innovation clusters are: increase in the capacity of entities to absorb, produce and diffuse innovations, easier creation and exchange of new ideas, concepts, information, life-long learning and rapid spread of knowledge and information, current monitoring of the sector/branch and benchmarking against competition, of key importance is the exchange of market information and tacit knowledge, but not commercial relationships, creation of new companies so-called spin-offs based on innovations created within a cluster. Innovation clusters also affect positively the attraction of foreign investments, generation of new knowledge in the area of technology, development of venture capital funds, international exchange of personnel, increased effectiveness of the R\&D sector, increased innovativeness of economies, especially those less developed [Nowakowska 2011].

Within innovative cluster networks, national and even supranational initiatives are mostly promoted. The objective is to increase innovativeness by supporting the research and development sector and structural changes, the identification of new specializations and new, emerging industries. Innovative cluster networks are nothing but innovative networks, whose members are clusters. The common denominator of most definitions of enterprise networks is to em- 
phasize the importance of cooperative connections, which are usually informal [Skawińska and Zalewski 2009]. Jewtuchowicz [2001] considers as a network a set of selected links with selected partners, matching market relationships of enterprises. These relationships include collaborative and competitive links. It should be stressed that in case of network structures there is no condition of the spatial concentration of economic activity. In the general sense, the network is defined as a group of cooperating market entities [Manley 2003].

Networks may take many forms. If we take into account the nature of links among network participants, on the one extreme we have completely formalized links which are based on agreements precisely governing all aspects of cooperation, on the second just the opposite - links may be informal and difficult to determine in terms of their nature or time horizon [Fisher 2001, Freeman 1991]. If, in turn, we take into account the purpose of creation, it may be: joint acquisition of raw materials, cooperation as part of the production process, training of staff, exchange of know-how, entering new markets, joint creation of innovations [Manley 2003]. In the area of innovation, cooperation may be used to facilitate the commercialization of concepts, carrying out the entire innovation process (conducting research or outsourcing basic, applied and implementation research) or only the sharing of knowledge and experience [Dobski 2005].

When it comes to innovative networks, they are most often specified as loose (entities react to their activities while remaining independent from each other all the time) and informal (not based on long term agreements) links among entities, as a result of which an innovative network is characterized by the ease of changing the structure by decomposition (removal of entities) or recombination (changing relationships and links among entities) [Landsperger and Spieth 2011]. On the other hand, however, the innovation process requires longterm, multi-faceted relationships based on trust [Manley 2003], which rules out the ease of transformations within the network. Each network participants enriches it with unique skills and know-how, and the essence and main benefit from the functioning within its framework is a possibility of acquiring knowledge from other entities [Stuart 2000]. It is also important to acquire their resources or use their unique skills [Zaheer and Bell 2005].

The network is created by entities which joined it on a voluntary basis, in order to achieve their objectives. Therefore, these entities will not passively execute orders while management of these entities should be rather reduced to supervision in the area, for which the network has been set up. Among the major challenges set before the major entity is, therefore, such influence on various members so as they created innovations together, without the superiorsubordinate relationship. This way of management is called the network orches- 
tration and it is a group of intentional activities of a central enterprise aimed at creating and using the value created within the network of enterprises [Dhanaraj and Parkhe 2006]. There are three areas of the network orchestration [Pierański 2013]: knowledge flow management, determination of rules of cooperation among network participants and ensuring the network stability. The central entity may also affect the functioning of the network by deciding what entities may operate within the network. Networking consists of the following elements: membership in the network, defining the structure of the network and the position of the central enterprise within the network. The network orchestration is an extremely complex process, which requires the central enterprise to be able to keep the balance between ensuring the proper innovation process and discrete influencing entities within the network. Without a doubt, the overriding objective of all activities, however, is to ensure the stability of the network defined as a condition under which network participants want to be its members. The stability grows along with the belief of participants in benefits from the membership. In turn, the basic benefit from establishing of and functioning within the network is access and possibility of using knowledge belonging to the network members, which allows to create innovation [Pierański 2013].

In addition to the orchestration issue, also the importance of cohabitance and leadership is stressed in networks. Cohabitation itself may be defined as self-organizing, inter-organizational networks, which are characterized by the dependency among organizations. Interactions within these networks resemble a game both based on the trust and governed by the rules on which participants agreed. Leadership, in turn, always raises conflicting connotations. It is easy to underappreciate its importance, but it is also just as easy to over-appreciate the role of leadership, giving leaders total confidence, thus refreshing their perception as talented visionaries, who as the only create a strategic course of action for their colleagues [Eriksson 2011]. In the development of the network, dynamic skills are also strongly underlined [Eriksson 2011]. These skills play a special role in creating the competitive advantage based on strong innovation skills and specific areas. They are defined as an ability to integrate, build and reconfigure internal and external competences so as to face the rapidly changing environment. In connection with the above, the dynamic skills are perceived as a reflection of the network ability to achieve new innovative forms of competitive advantage. The dynamic skills strengthen governance skills and unique combinations of resources that combine various functions. 
Another form of innovative structures are innovation cluster networks ${ }^{7}$. The reasons for their creation include the impact of international corporations, fragmentation of industries, extraordinary mobilization of knowledge, people and other factors of production on a global scale, but also the appropriate economic policy. This is accompanied by human migrations whereby brain drain has been replaced by so-called brain circulation. The mechanism is as follows emigrants from developing countries graduate from prestigious universities located within innovation clusters, then find employment there, get absorbed by the entrepreneurial culture, learn about the mechanisms of joint achievement of objectives and operation of flat management structures, mobility culture, individualism, teamwork. They learn how start-ups work and how to turn these start-ups into global players, including using own background and contacts in the regions from which they come. They acquire skills to use opportunities, combine local and global knowledge, thus creating a new value, gain a broader perspective and unique experience. After years, they return to their home countries, where they adopt this knowledge hidden in the new institutional environment, using formal and informal networks of contacts with partners from an innovation cluster - they know the local market, cooperate with research institutes and venture capitals, which results in a significant reduction in their transaction costs. Thanks to them, in their countries, new start-ups and innovation clusters are created, which is accompanied by a process of the emergence of global networks of innovation clusters [Saxenian 2006].

The innovation cluster network connects individuals, start-ups, universities, research centers, associations, mature corporations and other organizations, which are globally oriented and which excel in rapid innovations, experimentation and commercialization. These are networks of individual and institutional relationships, while the major role is played by individuals, companies and the relationships among them - national, international, formal and informal, often within the framework of social groups that are easily observable and evidence the existence of a much broader network of contacts. Network organizations are

\footnotetext{
${ }^{7}$ The best example is an American network of innovation clusters formed around the American Silicon Valley. This specialized and compact cluster of innovation, by taking advantage of the economies of scale and positive externalities, attracts capital and talented people not only from the USA, but from all over the world. What is more, although it might seem that its followers do not achieve similar successes, it turned out to be otherwise. For Japan, China or India the cost advantage was not enough and they are now world leaders in the areas of finance, design, or high technologies. Beijing or Shanghai are becoming strong centers of innovation and creativity with an increasing number of patents. Israel and Taiwan are not inferior to them, with the growing number of technology start-ups and venture capitals which are the greatest after American ones. As a consequence of the interaction of those innovation clusters, a network of interaction clusters was formed [Saxenian 2006].
} 
formed as informal groups of professionals so as to develop into strong, strictly oriented organizations. Some networks bring together representatives of one nationality, beginning their activity from local support of global corporations [Engel and del-Palacio 2009]. The global network of clusters in the IT jargon may be defined as a global cloud with formal and informal relationships which enables and accelerates the innovation process and the formation of new companies as part of innovation networks around the world [Saxenian 2006].

Interestingly, innovation clusters within networks may be significantly distant from each other, but this does not discourage owners venture capitals from seeking investment opportunities. Also start-ups show a remarkable mobility, taking advantage of the presence in various networks in order to obtain financing, use opportunities and resource security [Engel and del-Palacio 2009]. As stressed by Doz et al. [2001], in these contacts the religion, origin, place of residence, membership to a particular country, group or region do not matter. Engel and del-Palacio [2009] divided the linkages within innovation clusters into four types:

- $\quad$ strong - family, close, friendly;

- weak - the most common, created by mobile people by networking or individual contacts; work, joint business; sharing information, frequent direct contact with people from the same industry or related industries;

- $\quad$ stable - created from weak linkages as a result of more frequent establishing of contacts, sharing information, technology and services; they also take place among entities from various innovation clusters; they are accompanied by numerous, supporting weak linkages, which effectively prolong their duration; dynamic and liquid;

- atomic - permanent connections and multidimensional network of weak connections act as electrons and create permanent connections; they appear when relationships are stable and strong, and elements of two clusters become interdependent and operate in a coordinated manner, e.g. when individual actors play at the same time important roles in many entities and locations; the benefit is to increase the mobility of resources, to reduce the costs of innovation, acquisition of resources and customers, production, after-sales support.

Engel and del-Palacio [2009] stated, moreover, that in case of the continuing formation of various atomic linkages in two or more innovation clusters, a product created in this way may also be called an innovation cluster. The emerging image of the linkages among innovation clusters has been shown in Figure 2.1. The first and second innovation cluster form an innovation supercluster, when the following conditions are met: 
- they are connected by means of atomic linkages, and hence entities participating therein are interdependent;

- are mutually interconnected;

- they have common companies, knowledge creation processes, network structure, know-how in the field of management;

- they search for similar benefits and adopt incentives applied.

Figure 2.1. Potential linkages between innovation clusters and their implications*

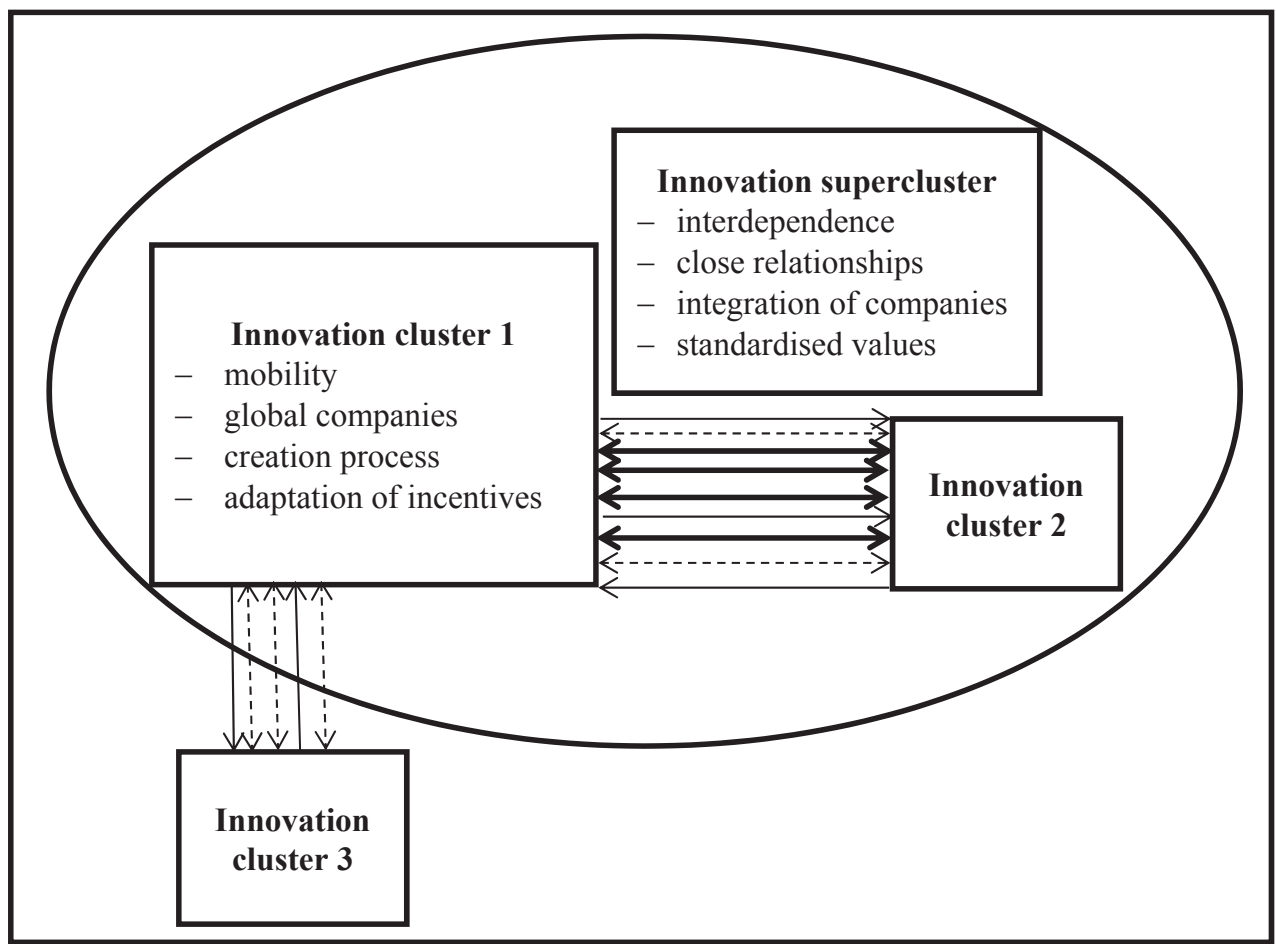

* Solid line - permanent linkages; dashed line - weak linkages, bold line - atomic linkages. Source: Own elaboration based on Engel and del-Palacio [2009].

As an example of a supercluster, we may provide the history of cooperation of the American Silicon Valley and Israel, which are currently considered to be a permanent element of the global network of innovation clusters.

Among the obstacles that stand in the way of the development of innovative cluster networks and innovation cluster networks, we may mention [Huggins 2000]:

- difficulties in collaboration resulting from different organisational structures, management styles, organizational culture, language barrier; 
- lack of skills of cooperation, defining and distribution of tasks, clear determination of responsibilities and share of entities in profits;

- high level of complexity of an implemented project;

- lack of an adequate level of knowledge required.

In particular, in case of innovation cluster networks, the most important problems include the low level of immigration and differences in legal and economic systems, as well as religious differences, concerning the system of values and attitudes [Saxenian 2006]. Too close cooperation is also risky, which may lead to isolation and closure of a network to external resources. Problems within a network may result in a lack of trust and resignation from participation in a network or limitation the commitment by individual entities [Dhanaraj and Parkhe 2006]. A threat may also be the diversity within a network. Although, on one hand, it contributes to increasing the probability of the emergence of innovation, it may also pose a threat of conflicts arising from the different way of the functioning of network participants.

\subsection{Innovative trends in the food products markets ${ }^{8}$}

Emergence of a new breed of consumer in the first decade of this century influencing a spectrum of business and economic decisions becomes a key factor driving the consumer demand. New consumers, more educated, affluent and well informed, are creating a more diverse and fragmented society [Shaw 2002]. The changing consumer preferences are embedded in consumer trends reflecting aggregated dominant consumer wants and wishes. The trends themselves can be viewed as changes in style and taste, which have been going for a long time [Vejlgaard 2008]. The underlying sources of consumer trends are significant social, economic, political and technological changes, which are coming slowly, but they make profound impacts on our lives. Most of the presently observed trends is associated with the change from the industrial to the post-industrial era characterized with an increasing role of knowledge and creativity as well as with an empowerment of employees.

The so-called megatrends shaping nowadays consumer behavior are as follows: gerontologization of society, rejuvenating society, luxurisation of consumption, lifestyle design, distanced (conscious) consumption, lazy (convenient) consumption, increasing mobility of people, centralization of consumption, information society or cybernetic consumerism (resulting from social media, virtual consumption and multitasking), experience marketing, and avatarization of

\footnotetext{
${ }^{8}$ This part of the book is based on publications by Figiel [2016] and Figiel and Kufel-Gajda [2017].
} 
consumption. Megatrends are connected most of all with changes regarding life expectancy, level and distribution of income, value systems of consumers, structure of employment, environmental concerns, as well as with rapid development of information technologies [Figiel and Kufel 2016].

One of the most significant event recently influencing consumer trends was the 2007-08 financial crisis. Since then, buying things has not been so strongly placed in the center of human activity any more. Households had to limit their consumption whilst becoming more conscious that capitalism and mass production may rely also on overexploitation of workers, animals, and natural environment. Consequently, purchasing decisions started to be made in a more responsible way, whereas before the crisis consumers were more individualistic and egocentric. They enjoyed buying and owning tailor-made products, through what they built their ego, and believed that an idyllic world of consumption should have ensured a good mood.

There is a vast body of literature addressing the issue of current consumer trends. A comprehensive synthesis regarding this topic can be found in work of Zalega [2013]. The following eight main post-crisis consumer trends are discussed: anti-consumption, conscious (ethical, responsible) consumption, collaborative consumption (mesh, sharing economy), freeganizm, intelligent (innovative) consumption, smart shopping, cocooning (home centralization), and non-stop. Of course, these trends have profound impact on food consumption. Changing attitudes toward food consumption are a part of this new consumer perspective as well. There are two key dimensions of this phenomenon, namely:

- the way we eat (increased number of smaller and richer households implies consumption away from home and convenience),

- and what we eat (better educated societies are more concerned about nutrition and health implications of food. i.e. low calories, slow food, ego food, etc.).

Consequently, food demand can no longer be viewed as dependent only on prices, income and population of consumers. Therefore, a stylized food product demand function, as pointed out by Antle [1999], should take the following form:

where:

$$
F_{D}=f(P, I, N, C, N P)
$$

$F_{D}$ - a food product demand,

$P$ - product and other relevant output prices,

$I$ - income,

$N$ - population,

$C$ - characteristics of the consumer population, $N P$ - non-price attributes of a product. 
The non-price attributes of a product, from which consumers derive utility or disutility, may include nutritional content, safety and convenience characteristics. Also, they may represent how the product was produced, the environmental impact of production, and production processes and inputs like pesticides, irradiation and genetically modified organisms.

Food producers are supposed to respond to global consumer trends by offering products consistent with the consumer expectations increasingly related to consumer population characteristics and non-price product attributes. One of the ways to meet this challenge is introducing innovative products. Variety of such products reflecting producer trends can be noticed in the contemporary food markets. Gaps between the consumer and recent food product innovation trends in the context of potential business opportunities have been examined on the worldwide basis by Figiel and Kufel [2016] who found that certain demands for food products have not been fulfilled yet. Both types of trends are sort globally intertwined but probably neither consumers behaviors, nor producer responses are identical in every geographic location.

We present results of an analysis of producer trends based on the study performed by XTC innovation. This study consists in segmentation of each food product launched in 2014 and 2013 in 40 countries. Each new product is precisely described regarding innovative features and then positioned on the XTC trends tree, which includes 5 axes within which 15 innovation trends in food products are extracted. The discerned axes are pleasure, health, physical, convenience, and ethics. Innovative products developed in various countries are assigned to different trends within each axis according to their attributes and prevailing utilities. The axes comprise the following trends:

- pleasure (induced by enticing quality, often emotionally charged) - four trends, such as sophistication, variety of senses, exoticism, and fun;

- health (expressed by health benefits and risk prevention) - three trends, such as natural, medical, and vegetal;

- physical (driven by attention to appearance, body shape or state of mind) three trends, such as slimness, energy, well-being, and cosmetic;

- convenience (based on efficiency of use and adaptation to new lifestyles) three trends, such as easy to handle, time saving, and nomadism;

- ethics (focused on solidarity, concern for others and the environment) - two trends, such as solidarity, ecology.

Table 2.1. contains a brief description and examples of products features and quality attributes for all 15 food product innovation trends (FPIT) appearing in the world markets. In this table, also the most crucial consumer needs, which are supposed to be met are descriptively pointed out. 


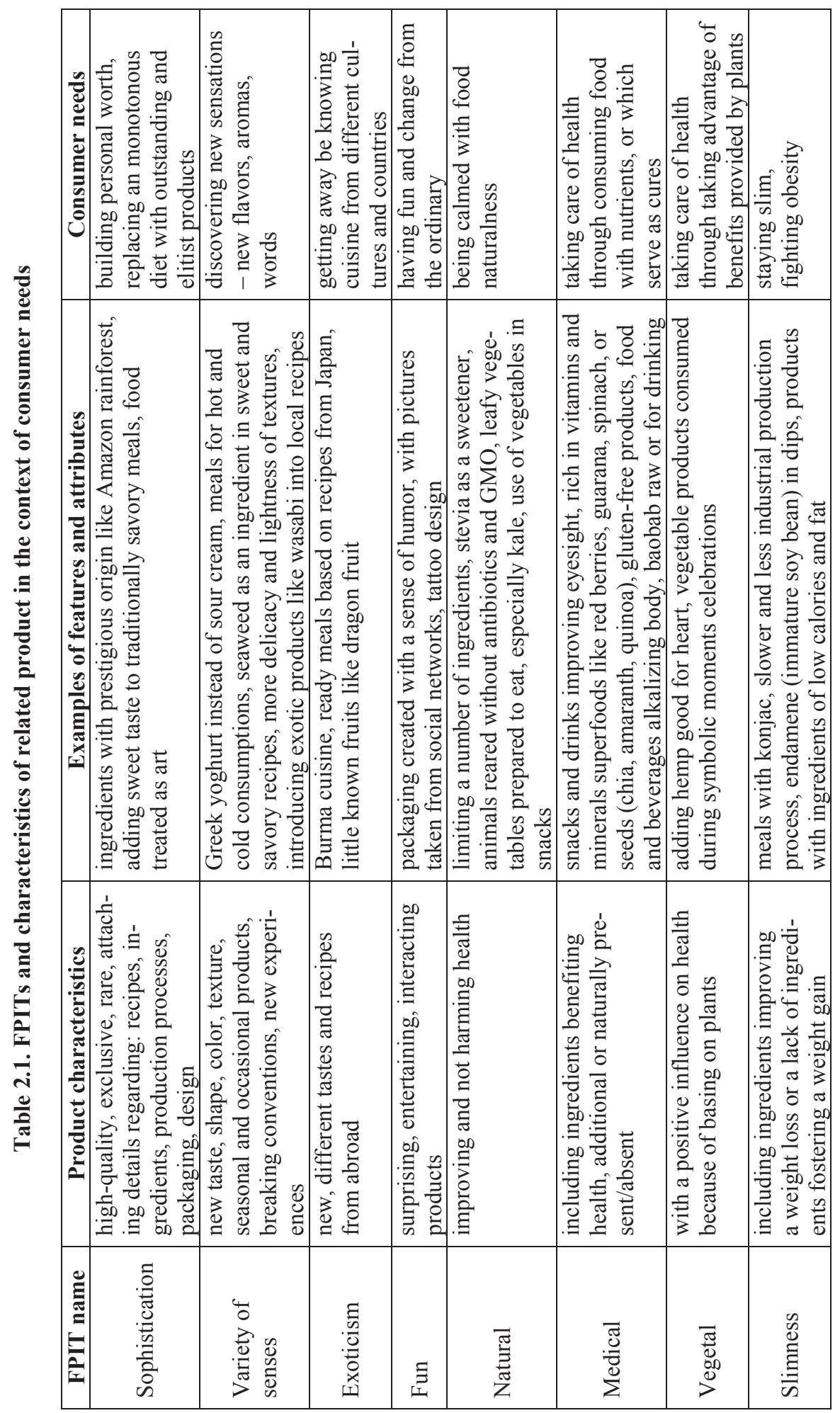




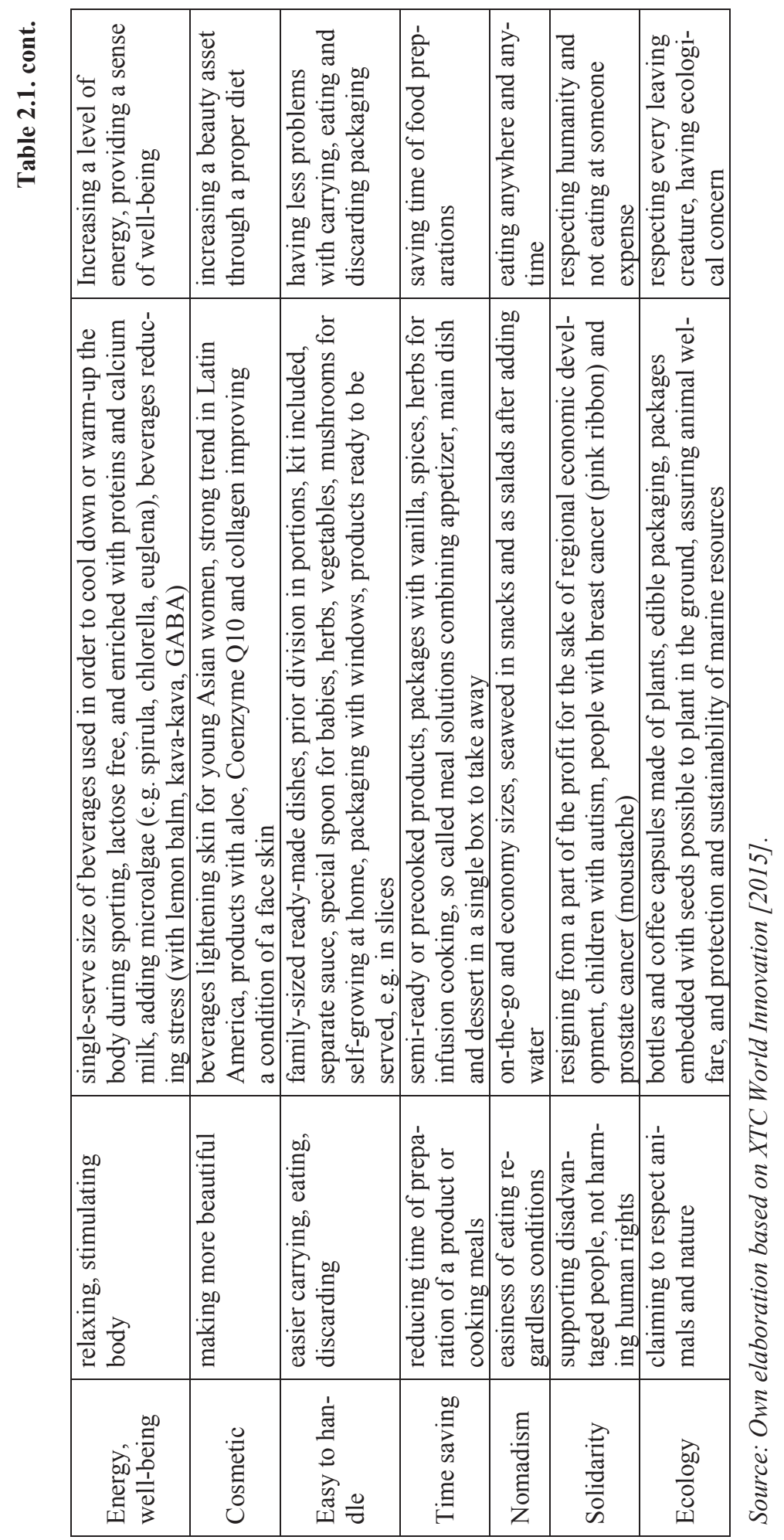


Development of food product innovations is supposed to be in line with consumer preferences, which are changing over time being influenced by various factors. One them is globalization of food markets increasingly influenced by international companies offering products of similar nature no matter where particular marketplaces are geographically located. But, behavior of consumers is also determined by their needs and expectations rooted in social and cultural environments differing across countries and the world regions. Consequently, marketing strategies of the food companies are likely to differ depending on the region of the world. So, it seems obvious that diversity of the food consumption patterns should be reflected by specific responses of food producers including product innovations introduced into the markets.

How the occurrence of the recent food product innovation trends differ across the world regions can be seen in Table 2.2. containing percentage values representing shares of each FPIT in the overall number of food product innovations, which appeared in a particular region.

Table 2.2. Intensity of occurrence of the food product innovation trends in the analyzed world regions $(\%)$

\begin{tabular}{|l|r|r|r|r|r|}
\hline \multicolumn{1}{|c|}{ Trend } & \multicolumn{1}{c|}{ Asia } & Europe & $\begin{array}{c}\text { Latin } \\
\text { America }\end{array}$ & $\begin{array}{c}\text { Middle East \& } \\
\text { North Africa }\end{array}$ & $\begin{array}{c}\text { North } \\
\text { America }\end{array}$ \\
\hline Variety of senses & 41.75 & 29.80 & 32.40 & 28.20 & 30.30 \\
\hline Natural & 4.10 & 9.60 & 11.50 & 4.50 & 16.80 \\
\hline Sophistication & 13.60 & 19.25 & 10.60 & 21.30 & 12.20 \\
\hline Easy to handle & 7.40 & 12.10 & 7.60 & 12.40 & 6.55 \\
\hline Fun & 2.00 & 4.50 & 3.10 & 2.00 & 1.85 \\
\hline Time saving & 2.20 & 4.40 & 5.80 & 5.00 & 2.60 \\
\hline Medical & 14.85 & 7.40 & 13.85 & 12.90 & 15.40 \\
\hline Exoticism & 1.40 & 3.15 & 0.60 & 2.50 & 2.20 \\
\hline Energy, Well-being & 2.35 & 1.40 & 2.05 & 4.50 & 2.15 \\
\hline Nomadism & 1.30 & 1.65 & 1.75 & 1.50 & 1.00 \\
\hline Slimness & 5.55 & 4.35 & 7.60 & 4.00 & 4.50 \\
\hline Vegetal & 0.85 & 0.90 & 1.25 & 1.00 & 2.45 \\
\hline Solidarity & 0.10 & 0.55 & 0.15 & 0.00 & 0.55 \\
\hline Cosmetic & 2.35 & 0.15 & 0.55 & 0.00 & 0.15 \\
\hline Ecology & 0.25 & 0.65 & 1.25 & 0.50 & 1.30 \\
\hline
\end{tabular}

Source: Own elaboration based on XTC World Innovation [2015].

The variety of senses trend dominated in all regions. Its intensity of occurrence was in the range of $28.20-41.75 \%$. The second most intensively occurring trend was sophistication (between 10.6-21.3\%). Relatively often observed were also food product innovations representing the medical, the easy to handle, and 
the natural trends. On the contrary, the least intensively occurring trends were the solidarity, the ecology, and the nomadism.

At first glance, comparing regional patterns of the intensity of the FPITs' occurrence, there seem to be considerable differences between regions. However, indices of the percentage similarity (PSI) calculated for the pairs of the regions appeared rather high, ranging from 0.76 to 0.89 . This means, that in general the observed patterns of the intensity of the FPITs' occurrence can be considered similar (PSI from 0.6 to 0.8 ), or very similar (PSI from 0.8 to 1 ). The least similar in that respect are Europe and Asia, whereas the most similar are Europe and the Middle East \& North Africa. Second highest value of the PSI (0.88) was found for Latin America and North America. So, it can be stated that geographic proximity clearly matters as a factor determining differences in the intensity of occurrence the FPITs across the world regions.

Table 2.3. provides an insight into differences between the world regions regarding intensity of occurrence of the food product innovation trends grouped into the general axes.

Table 2.3. Intensity of occurrence of the food product innovation trends grouped into the general axes in the analyzed world regions (\%)

\begin{tabular}{|l|r|r|r|r|r|}
\hline \multicolumn{1}{|c|}{ Axis } & Asia & Europe & $\begin{array}{c}\text { Latin } \\
\text { America }\end{array}$ & $\begin{array}{c}\text { Middle East \& } \\
\text { North Africa }\end{array}$ & $\begin{array}{c}\text { North } \\
\text { America }\end{array}$ \\
\hline Health & 19.75 & 17.95 & 26.60 & 18.30 & 34.60 \\
\hline Physical & 10.30 & 5.90 & 10.10 & 8.40 & 6.80 \\
\hline Pleasure & 58.75 & 56.70 & 46.70 & 54.00 & 46.60 \\
\hline Convenience & 10.90 & 18.25 & 15.15 & 18.80 & 10.15 \\
\hline Ethics & 0.35 & 1.20 & 1.40 & 0.50 & 1.80 \\
\hline
\end{tabular}

Source: Own elaboration based on XTC World Innovation [2015].

As it can be noticed, in all world regions food product innovations representing trends belonging to pleasure axis were by far the most numerous. Fairly intensive was also occurrence of the FPITs included in the health axis. Next, in terms of occurrence were the FPITs constituting the convenience and physical axes. The FPITs belonging to the ethics axis were hardly noticed, what may mean that food companies have paid little attention to the development of that type product innovations so far.

A high similarity of the intensity of the FPITs occurrence in world regions does not necessarily mean that in relative terms they were equally important in every region. In order to find this out the percentage shares, representing intensity of the FPITs' occurrence in a particular region, have been normalized with reference to their maximum values in the regions compared (i.e. the highest 
share in all regions takes the value 1 and the other lower shares take the values proportionally smaller). The results of these calculations for each region are presented in Figures 2.2-2.6.

Figure 2.2. Importance of the FPIT categories in Asia relative to other regions

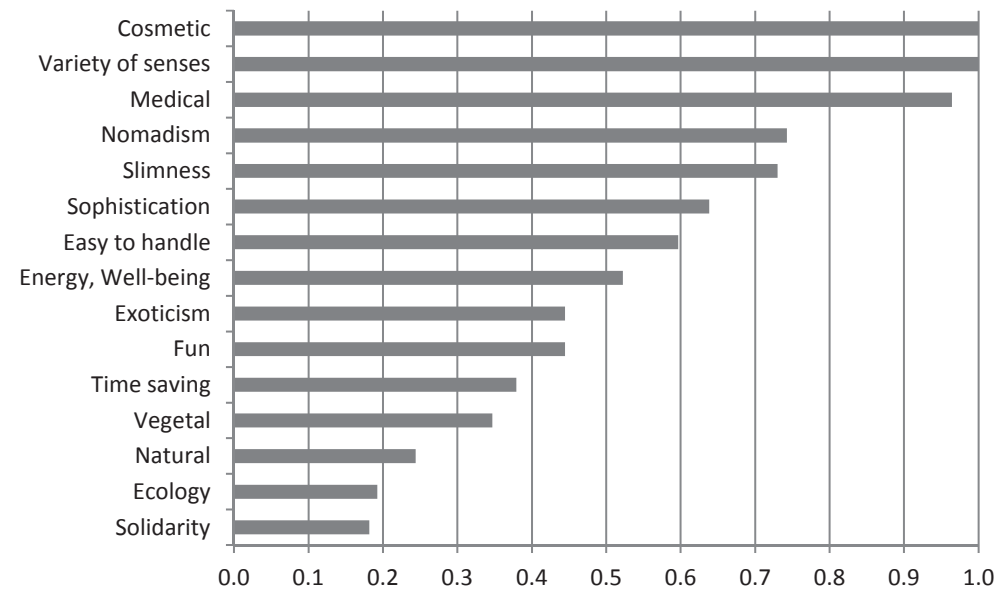

Source: Own elaboration based on XTC World Innovation [2015].

Figure 2.3. Importance of the FPIT categories in Europe relative to other regions

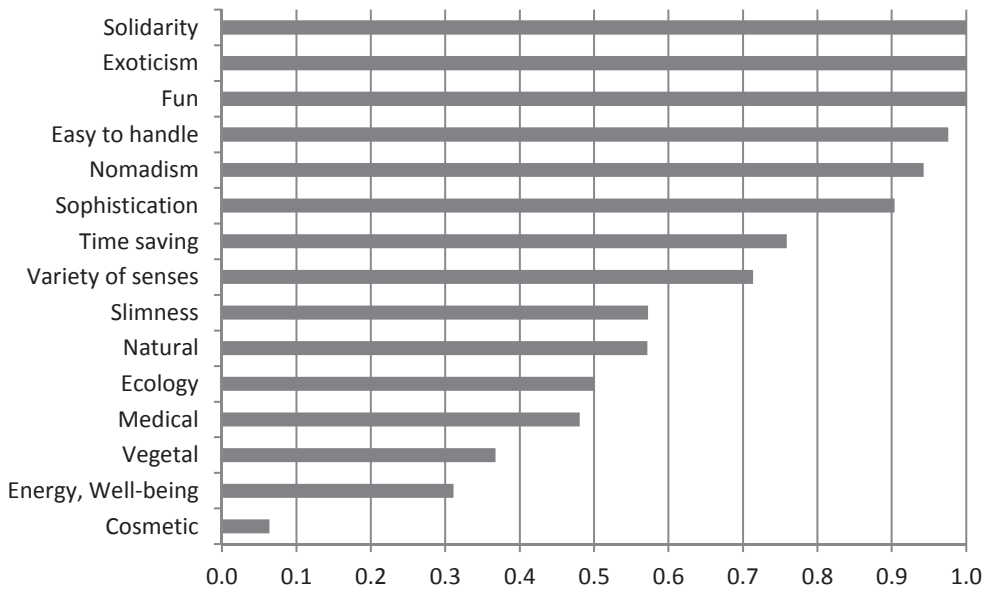

Source: Own elaboration based on XTC World Innovation [2015]. 
Figure 2.4. Importance of the FPIT categories in Latin America relative to other regions

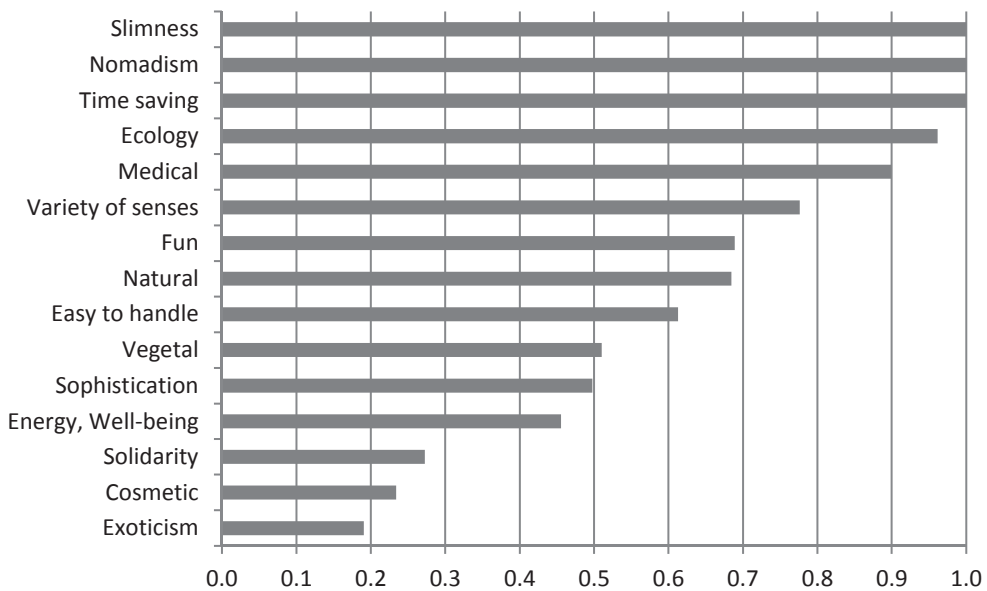

Source: Own elaboration based on XTC World Innovation [2015].

Figure 2.5. Importance of the FPIT categories in the Middle East and North Africa relative to other regions

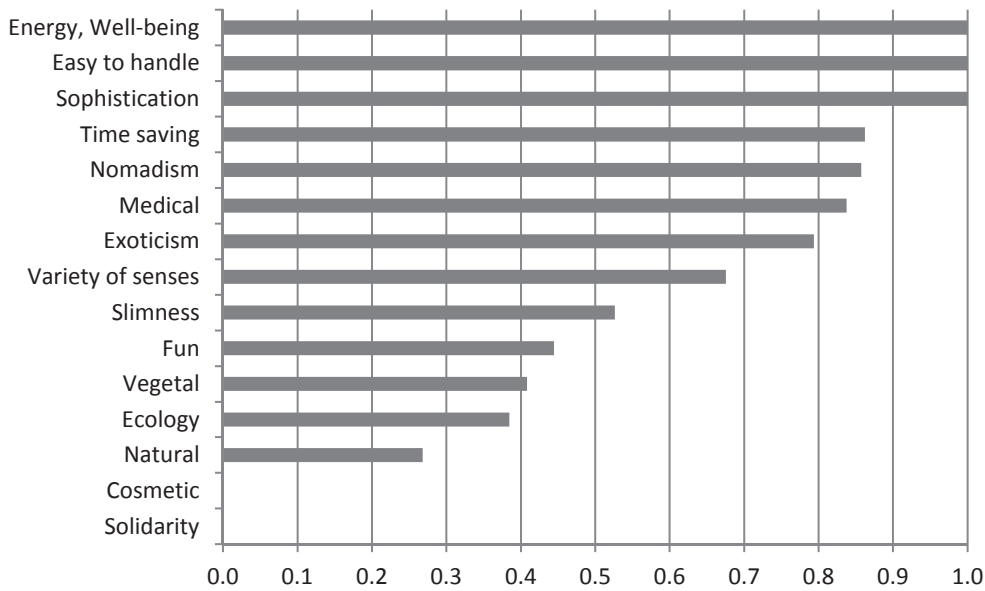

Source: Own elaboration based on XTC World Innovation [2015]. 
Figure 2.6. Importance of the FPIT categories in North America relative to other regions

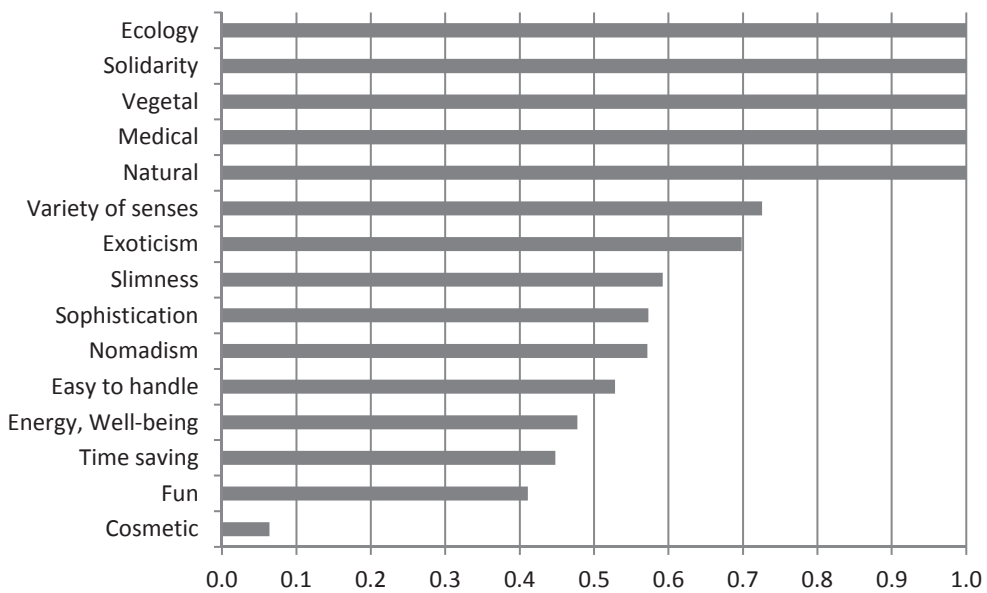

Source: Own elaboration based on XTC World Innovation [2015].

It can be hypothesized that there are world region specific factors, which should have a noticeable impact on relative importance of each FPIT considered on the regional basis. This appeared to be truth when comparing the normalized values of the intensity of FPITs occurrence across the regions. The cosmetic and the variety of senses trends occurred the most frequently in Asia. Food product innovations representing the solidarity, the exoticism, and the fun trends were observed the most in Europe. In Latin America this refers to the slimness, the nomadism, and the time saving trends. The Middle East and North Africa is the region on the top place with such FPITs as the energy, well-being, the easy to handle, and the sophistication. North America was ahead of the other regions in the case of the ecology, the solidarity (the same value as for Europe), the vegetal, the medical, and the natural trends. In general, the observed differences suggest that the relative importance of the FPIT categories in global food markets is to a certain extent determined by the world region specific factors influencing orientation and priorities of food producers regarding characteristics of food product innovations.

Global food markets are driven by consumer behaviors, which evolve over time and form observable trends. Food producers in order to stay competitive need to look for new business solutions including introduction of product innovations, which are supposed to meet to consumer expectations. Comparing the intensity of occurrence of the food product innovation trends (FPITs) in Asia, Europe, Latin America, Middle East \& North Africa, and North America it was found out that the observed patterns are similar. The variety of senses trend 
dominated in all regions. The second most intensively occurring trend was sophistication. This leads to a conclusion that the process of development and diffusion of food product innovations is globally driven, and hence its outcomes are quite uniform in the all world regions considered. A degree of similarity is especially high for the regions in closer geographic locations, like Europe and the Middle East \& North Africa, and Latin America and North America.

Another finding refers to potential consumer adoption of food product innovations as relative importance of the analyzed FPITs differed across the regions. Simply some of the FPITs were much more noticeable in one region than in the other. For instance, food product innovations representing the solidarity, the exoticism, and the ecology trends were much more visible in Europe and North America than in the rest of the regions. This may mean that in spite of a strong impact of globalization forces there are world region specific factors influencing food producers responses in terms of product innovations.

As it was found out by Figiel [2016] and Figiel and Kufel-Gajda [2017] consumer incomes seem to play an important role. They looked for the relationship between the intensity of the FPITs' occurrence and the GNI per capita levels in the following 14 countries: Brazil, Canada, China, France, Germany, Italy, Japan, Mexico, the Netherlands, Poland, Spain, Switzerland, the United Kingdom, and the United States. In Figure 2.7. values of correlation coefficients calculated for these two variables in the analyzed countries are presented.

Figure 2.7. Correlations between the FPITs' occurrence and the GNI per capita levels

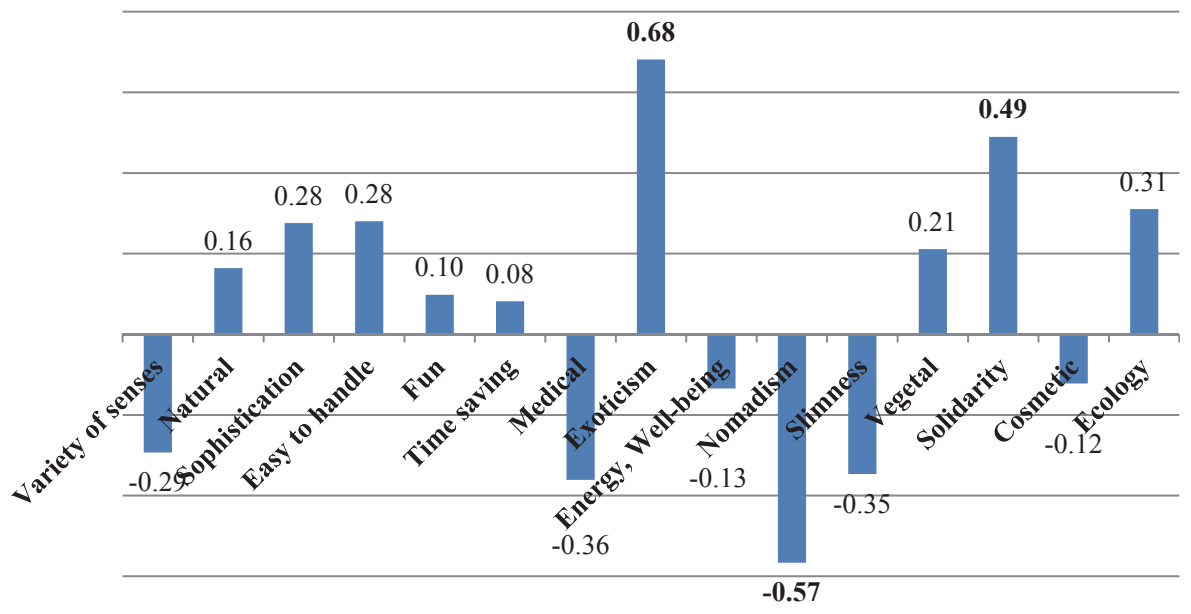

Note: Results statistically significant at $\alpha \leq 0.1$ marked in bold.

Source: Figiel and Kufel-Gajda [2017]. 
As it can be noticed 9 coefficients have positive signs and 6 negative ones. Ignoring statistical significance one can claim that the higher income of a country is, the more intensively some of the FPITs occur. This refers to exoticism, solidarity, ecology, easy to handle, sophistication, vegetal, natural, fun, and time saving. On the contrary, such FPITs as nomadism, medical, slimness, variety of senses, energy and well-being, as well as cosmetic seem to be relatively less occurring when a country income increases. The highest absolute values of correlation coefficients were obtained for the exoticism, nomadism, and solidarity trends, while the lowest for the time saving, fun and cosmetic trends. Unfortunately, only for 3 FPITs, i.e. exoticism, nomadism and solidarity, the relationships were found to be statistically significant. 


\section{Institutional determinants of innovation transfer in the Polish agri-food sector}

\subsection{Rationale for public intervention in the light of innovativeness of the Polish food processing sector}

When considering the issue of institutional support for the transfer of innovation must be first and foremost kept in mind the fact that it can be a form of state interference distorting the market processes. From the theory of prosperity, it is clear, however, that the market economy is inherently efficient [Feldman and Serrano 2006; Mas-Colell et al. 1995; Herbener 1997]. The existence of a market economy in the European Union should therefore lead to the widespread use of innovation as a source of performance [Aghion and Jaravel 2015; Arrow 1962; Thirtle and Ruttan 1987]. In this case, support the transfer of knowledge and implementation of new innovative solutions should be superfluous and even leading to deterioration in efficiency. This can in fact be considered as a form of interventionism, which is not conducive to improving efficiency [Ajefu and Barde 2015; Cordato 1980; Grand 1991], if these activities are directed only to a specific group of companies.

The economic literature indicates, however, the existence of market failures [Stiglitz 2004], which is a source of inefficiency. Therefore, we can believe that imperfect competition, asymmetric information and other market failures are limiting to a certain extent the use of innovation as a source of efficiency. An example of this is large diversity of innovative economies of the European Union [European Commission 2014a] and the fact that the policy of support for the transfer of innovation not always causes an adequate growth of economic innovation [Arundel et al. 2013]. In practice, the country's economic growth - at least in the short term - is not necessarily due to the transfer of knowledge to industry and services sectors. Its source may be the low price of labor factor, the availability of cheap raw materials and favorable conditions in the world market [Kasperkiewicz 2008]. According to Kasperkiewicz [2008], Polish economic growth in recent years has also resulted primarily from the use of these factors. Underestimation of the importance of knowledge transfer has led, however, to maintain, and even the rise of the technological gap between Poland and the most innovative economies of the European Union.

Limited use of knowledge as a factor of development and economic growth may concern the entire national economy and its individual sectors [Gotsch et al. 2011; Pavitt 1984; Malerba et al. 1997]. All sectors, including food processing sector, are exposed to it. One of the main reasons for limited 
innovation are existing structural conditions of a particular sector in a particular state. It can be exemplified by the implementation of organizational innovations related to new methods of human resource management in Serbia [Ratković 2015]. According to Ratković [2015], the implementation of these innovations was conditional upon both the size of the company and form of ownership. The specificity of the structure of the food industry in Poland [Mroczek et al. 2014] may also determine the specific institutional arrangements for promoting innovation transfer. The specific structure of the sector can be a barrier to the transfer of innovation to be taken into account when planning policy of support for this process.

The internal structures of a particular sector are tied to a certain extent market failures. Example may be the unreliability of competition and information asymmetry. The severity of specific market failure is linked in turn to the degree of utilization of knowledge as a factor of efficiency improvements. This in turn may lead to institutional changes in the area of knowledge transfer, as exemplified by various policies oriented to support this process. Currently, one of the main trends of dealing with the role of the institution is the New Institutional Economics. With reference to the relationship between competition and knowledge transfer one of the leading representatives of this trend, namely North [2005] states that companies, political parties, and even higher education institutions in the face of competing organizations must strive to improve efficiency. According to the author muffled competition limits the motivation of organization to invest in new knowledge and, consequently, does not cause sudden institutional changes. On the other hand, strong competition accelerates institutional changes. In these considerations, the author concludes, therefore, that the cause of improvement of the effectiveness is generally the competition, and the measure for this is raising the level of knowledge.

Assuming the occurrence of dependences indicated by North [2005] it can be said that the support of the transfer of knowledge, e.g. by pursuing specific policies should take into account the competitive environment in which the organization operates, i.e. the company. If competition is negligible, the support for entrepreneurship through subsidizing the transfer of knowledge can bring marginal results, because companies will not be motivated to use it. Whereas the opposite effect will be in a highly competitive environment. From the above relationships, it also appears that some policies to support economic activity, as a form of assistance that utilize transfers of funds to selected companies, can cause the elimination of competitive companies in the long term to limit the willingness to invest in new knowledge, due to the lack of sufficient competition. So in designing institutional support for the transfer of innovation should 
be taken into account the interactions that may occur between the hitherto functioning forms of business support, and the new that should be considered for public support for transfers of innovation. Under certain conditions, however, policies may complement each other. Such a situation appears when in the conditions of zero competition financial transfers will contribute to the creation of new businesses, which will motivate existing businesses to improve efficiency, e.g. by implementing new innovative solutions. Institutions supporting the transfer of knowledge could then make a big difference for those companies that cannot cope with its acquisition on market principles. The consequence may then form an even more competitive environment. The scale of this support and the conditions, under which it is granted, however, should be defined in such a way as not to eliminate companies from the market using a particular policy.

In practice, Poland is now a country with a relatively low level of innovation in the economy. According to the report of the European Commission [2014a], a synthetic innovation indicator of the Polish economy amounted to 0.279 , which put Poland in the group of countries with moderate innovation. In fact, Poland was ahead in terms of innovation to only those European Union countries, such as Bulgaria, Latvia and Romania. Reasonable seems to be speculation that one reason for this may be unreliable transfer system of innovation in the sector engaged in research and development to manufacturing and services. The increase in innovativeness of the economy is, however, one of the priorities of European Union policy for 2014-2020. Under this policy, Poland should receive from structural funds the amount of EUR 82.5 billion, much of which can and should be used for the development of innovation.

In the period 2014-2020, it is possible to use EU funds in order to strengthen the institutional system of innovation transfer. The question is whether the elements of the system need such support, and in which cases it will be justified by efficiency. In addition, the importance of certain sectors of the economy as a whole would be minimal or increase in their competitiveness on the European market may not be possible. In such cases, encouraging innovation may prove to be ineffective. There may also be sectors that perfectly cope with the implementation of innovations without public support. Considering this a question arises whether support for development of innovation in the Polish agri-food sector can be really effective and economically justifiable.

The food industry is a very important sector for the Polish economy, especially due to its competitiveness in the international markets. It seems, however, that it owes its success primarily to low labour costs, and no innovative solutions. This is confirmed by studies in the field of industrial innovation (Figure 3.1). 
Figure 3.1. Innovative activities of the Polish enterprises in 2014-2016

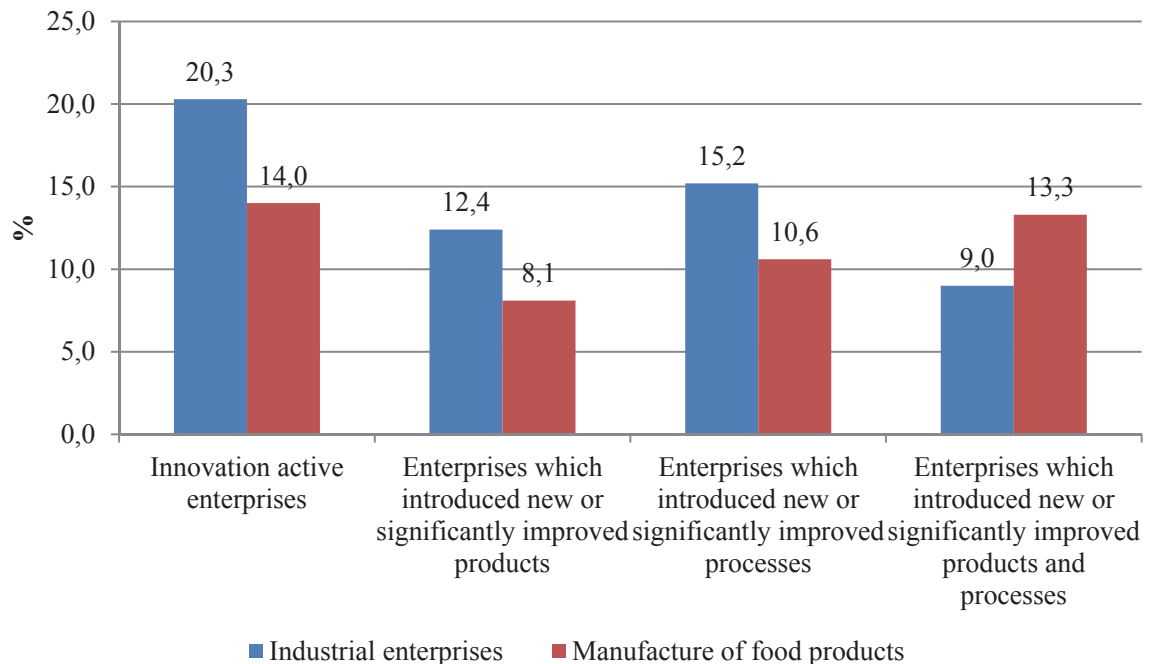

Source: Own calculations based on data from the Central Statistical Office.

The research shows that $14 \%$ of enterprises engaged in manufacture of food products in 2014-2016 are innovation active. Throughout the industrial sector there were 6.3 percentage points more of such enterprises. In the agri-food industry there were relatively fewer companies than in the whole industrial sector, for both product innovation and process. Differences in the implementation of different types of innovation, however, were developed at a similar level. This means that the improvement in innovation of agri-food processing can be associated with significant changes in both the technology used in production and organization of the production process. This observation is confirmed by the fact that $13.3 \%$ of companies in this sector both implemented the two considered types of innovation.

Level of innovativeness in the food processing industry is, therefore, quite low. In the long term, low labour costs may not be sufficient to increase, or even maintain its current competitiveness of the sector on domestic and foreign markets. Lack of innovation can show up particularly strongly in the case when the expansion have to be taken into markets outside the European Union countries. Then the Polish food processing industry will be forced to compete both with countries with much higher levels of innovation, as well as with countries with lower labour costs. There is, therefore, the need to point for entrepreneurs in this sector potential hazards, in order to motivate them to become more involved in 
the exploration and implementation of innovative solutions that will even expand into the global market.

Awareness of the need to implement innovative solutions is not the determinant of taking actions in this direction by entrepreneurs. The company may in fact not have the human resources that will be able to find and implement solutions appropriate to the scale and profile of production. The barrier can also be the amount of capital that the enterprise will be able to invest in the acquisition of new knowledge and the propensity of entrepreneurs to take risks. It also seems that some limitations in the growth of food processing sector innovations can result from dominant currently in Poland supply-side approach to create innovative solutions. This in turn implies a situation in which entrepreneurs are not able to find innovation, the implementation of which will enable existing in enterprise structures or with minor changes to these structures.

Significant in this regard is the opportunity to cooperate with the wider business environment. Such cooperation may in fact bring about tangible benefits in both macro scale, i.e. at the level of the entire economy, as well as the scale of individual businesses and business environment organizations. Among the organizations of that environment, in accordance with the Oslo Manual [2008], from the study of innovative activity are separated following types of partner institutions:

- other companies belonging to the same group of companies;

- suppliers of equipment, materials, components and software;

- clients;

- competitors and other companies in the same field of activity;

- consulting companies (consultants), commercial laboratories, private research and development institutions;

- scientific institutions of the Polish Academy of Sciences;

- research institutes;

- foreign public R\&D institutions;

- universities.

On the side of the environment that encourages business innovation are mentioned many institutions both public and private, with which the company can work together to gather information about the availability of new solutions, the conditions of their acquisition, the benefits resulting from the implementation and the process of adaptation and use in the enterprise. Because of such cooperation should occur a reduction in unit costs implementations. With these contacts, also derive tangible benefits for the environment. In the case of public sector units it is the ability to obtain information about the demand for innovative solutions, what can lead to a gradual transition from supply on demand 
model of creating innovation. In the case of private sector, institutions there are measurable financial benefits resulting from the sale of its solutions or intermediary in the transfer of innovation.

The study shows that food processing is not only very innovative, but also reluctant to take cooperation for the acquisition and implementation of innovative products and processes (Figure 3.2).

Figure 3.2. Enterprises which participated in innovation activities co-operation as the share of innovation active enterprises in the years 2014-2016

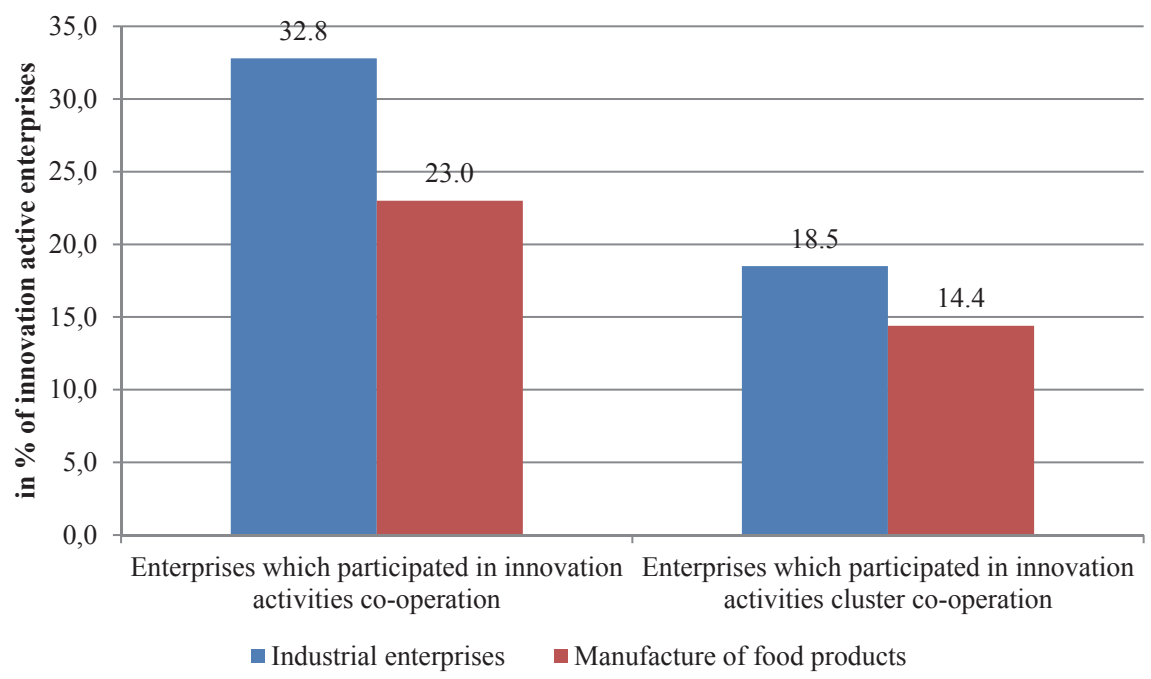

Source: Own calculations based on data from the Central Statistical Office.

Less than one in four innovation active companies of this sector undertook any cooperation for the implementation of innovations. Throughout the industrial sector there were 9.8 percentage points more of such enterprises. Equally, food processing companies are reluctant to use clusters to improve their level of innovation. The percentage of such enterprises in 2014-2016 amounted to only $14.4 \%$ and was lower than the industry average by more than 4 percentage points. What emerges is a need to diagnose, in the course of further research, the causes of limited cooperation between business and the environment. Identifying these causes, occurring both in the companies and institutions belonging to the environment, in confrontation with applicable law and the policies to improve innovation in the economy should consequently lead to increase the efficiency and effectiveness of government involvement in economic processes, especially occurring in the agri-food sector. 


\subsection{Innovation policies and regulation adjustments in Poland}

The relationships between law and politics are usually bi-directional. Conducting a specific policy must in fact take into account existing legal requirements. However, the policy may also imply making certain adjustments in the area of the existing legal solutions. These relationships are reflected also in respect of the policy to support the transfer of innovations to the Polish economy, including the food-processing sector. Considering the institutional conditions of this transfer should be, however, firstly considered the priorities of this policy, both at EU level and at national level. Implementation of the solutions proposed under this policy had already resulted in some changes in the existing law and should expect further adjustments in this area.

Improvements in innovation in recent years have gained great importance not only in Poland but throughout the European Union and has become one of the priorities of a common policy. It is expressed primarily in the Europe 2020 growth strategy, in which the European Union has defined three main policy priorities:

- smart growth; developing an economy based on knowledge and innovation;

- sustainable development; promoting a more resource efficient, greener and more competitive economy;

- socially inclusive growth (supporting the economy with high employment, delivering social and territorial cohesion).

The adopted in the strategy priorities allow the use of various instruments including financial, aimed to improve the transfer of innovation. Moreover, the implementation of the first priority can contribute to the implementation of other priorities, especially to improve the competitiveness of the economy. However, there can, therefore, occur several risks like:

- in the case of directing public funds only to a specific group of beneficiaries could be limited competition, which stimulates market conditions, the acquisition of new knowledge as a source of efficiency improvement;

- implementing new, innovative technologies may be associated with a reduction in employment (under such conditions, achieving a high level of employment will have to involve an increase in the number of companies operating in the sector or other sectors, e.g. business services with high-tech);

- supporting innovation in other countries may limit the benefits of the Polish economy due to lower labor costs;

- directing support on research and development activities - without taking into account the stage of transfer of innovation and demand for specific solu- 
tions of innovative nature - could lead to the dominance of the supply system of innovation, which is not adapted to market demand;

- focusing support on the public sector, which is in the case of Poland dominant in the creation and transfer of innovation, can reduce or even eliminate from this activity the private sector recognized in theory as more efficient;

- subsidizing the conventional private sector activity may reduce the effectiveness of the instruments used to promote the transfer of innovation, resulting in a decline in interest in investing in new solutions.

In consideration of the need to raise the level of innovation in the economy, the European Union defines the primary objective, which is increasing spending on R\&D to $3 \%$ of GDP. This objective should be considered justified, but provided that support this activity will be focused not only on the stage of development of innovative solutions, but also their transfer and implementation. The resulting new products, technologies, methods of company's organization and marketing solutions should in fact be reviewed in the sphere of production and services. In addition, it will be important to maintain mentioned relationships between supply-side and demand-approach to innovation. Research and development needs to a greater degree than is currently to focus on the needs of the market and not only develop own ideas of innovative solutions. There will be also a need to undertake research and development activities in hitherto nonexistent in the country areas of economic activity. It should be also expected that the majority of implemented innovations would be a process innovation that even while increasing the scale of production, may lead to a reduction in employment. This in turn can prevent the achievement of another overriding aim of the European Union which is to increase employment in the group aged 20-64 to 75\%.

The strong focus of EU policies on improving the innovation of economies of the Member States is also expressed in the establishment of one of the seven flagship initiatives, namely "Innovation Union". This project according to the authors should be focused on improving the "framework conditions and access to finance for research and innovation so as to ensure that innovative ideas can be turned into new products and services, which in turn will contribute to economic growth and job creation". Implementation of this project could, however, be associated with the formation of the previously discussed threats. To some extent, the support for improvement of private R\&D proposed in the Strategy may counteract to this. In this context, it is thus possible to use public funds to support not only private research activity, but also it seems possible and reasonable to support the transfer of innovation from the research sector to businesses with the participation of private companies belonging to the business environment. This approach also makes possible to increase the scale of support 
due to the applied within the framework of EU aid rule of the need to involve a relatively higher own funds for private beneficiaries than in public. In addition, if in the case of the private sector is more likely higher efficiency in the use of these measures, of course, provided that the total aid is not the result of the phenomenon of seeking pension by the beneficiary or consequence of an action of interest groups.

The involvement of the private sector in the process of improving innovativeness of the economy, including food-processing sector, should contribute to the implementation of the project "Innovation Union". At the EU level, the European Commission undertakes to:

- complete creation of the European Research Area, to develop a strategic research agenda focused on challenges, such as energy security, transport, climate change, resource efficiency, health and aging, environmentally friendly production methods and land management, and to enhance joint planning with Member States and regions;

- improve framework conditions for innovative business to (i.e. to create a single EU Patent and a specialized Patent Court, modernize the framework of copyright and trademarks, improve access of SMEs to protect intellectual property rights, accelerate the development of interoperable standards; improve access to capital and make full use of demand side policies, e.g. through public procurement and smart regulation;

- create European Innovation Partnerships between the EU level and in the Member States to speed up the development and deployment of the technologies needed to solve specific problems. The first such partnerships will include the following: building the bio-economy by 2020, development of key enabling technologies to shape Europe's industrial future, and technologies to allow older people to live independently and be active in society;

- strengthen the role of EU instruments to support innovation (e.g. the Structural Funds, rural development funds, R\&D framework programs, the Framework Programme for the Competitiveness and Innovation (CIP), the SET-Plan), including through closer cooperation with the EIB and streamlined administrative procedures to facilitate access to funds, especially SMEs, and introducing innovative mechanisms incentive to investment related to the market for carbon dioxide emissions, especially for entities rapidly developing;

- promote partnerships in the area of knowledge and strengthen links between education, business, research and innovation, including through the European Institute of Innovation and Technology, and to promote entrepreneurship by supporting Young Innovative Companies. 
Particularly noteworthy is the fact that the project envisages strengthening the business environment in terms of their innovative activity. In this context, assumptions should promote the development, especially private entities that will shape the flow of information from science to business practice. Moreover, the project takes into account and gives great importance to improving the innovation of small and medium-sized enterprises, which plays in Poland fairly important role in creating jobs. At the EU level there are also taken action to strengthen intellectual property rights, which in the case of Poland can help to strengthen research activities. The effectiveness of the European Commission in the implementation of the project, however, will depend largely on adequate adaptation measures at the national level. Such strengthening of intellectual property could, in Polish conditions, not lead to any changes. Too strong barrier in this regard may be a parametric evaluation system of scientific research, which in its current form absolutely does not reward activity on the creation and implementation of new innovative solutions. Support from the European Union will not be able, however, to compensate for financial losses arising from any partial reorientation of research activities for development one. Nevertheless, the Europe 2020 strategy also sets trends that in connection with the implementation of the project "Innovation Union" should appear on the level of individual member states. According to accepted guidelines these states must:

- reform national (and regional) systems for conducting research and development and innovation activities in order to foster excellence and smart specialization, reinforce cooperation between universities, research society and business, implement joint planning and also to improve cooperation in areas where the EU can offer value added and adjust national funding procedures accordingly, to ensure the diffusion of technology across the EU territory;

- provide a sufficient number of graduates of science, math and engineering graduates and to introduce into school programs elements of creativity, innovation and entrepreneurship;

- prioritize expenditure on knowledge, including using tax incentives and other financial instruments to promote greater private investment in research and development.

Implementation of the strategy by Poland can, therefore, and indeed should be associated with changes in the evaluation and methods of financing research activities. Otherwise, the implementation of the project "Innovation Union" may fail due to the limited involvement of these units. However, the increased involvement of these units in the process of raising the level of innovation, combined with an increase in the number of graduates in science and raising the level of public awareness in the field of economic sciences, can bring 
tangible economic outcomes for both food processing and for the wider rural economy. In addition, investments in improving knowledge are investments in public goods. They should not, therefore, disrupt the market. With specific guidelines for member states it also results that to subsidize the creation, transfer and implementation of innovations should not be the only instrument to support. Involvement in the process the repayable financial instruments or fiscal policy can improve the effectiveness of the aid measures.

To the issue of improving the innovation in the food processing sector also refers proposed in the Strategy flagship initiative "An industrial policy for the globalization era". In this project, the European Commission will be obligated to:

- establish an industrial policy that allows creating the best environment to maintain and develop a strong, competitive and diversified industrial base in Europe and supporting the transition of manufacturing sectors to greater energy and resource efficiency;

- develop a horizontal approach to industrial policy using various instruments (such as the so-called smart regulations, public procurement adapted to the new conditions and competition rules and standard setting);

- improve the business environment, especially for SMEs, including through reducing the transaction costs of doing business in Europe, the promotion of clusters and improving affordable access to finance;

- promote the restructuring of sectors in difficulty towards future oriented activities, including through quick redeployment of skills to new, high growth sectors and support from EU State aid regime and/or the European Globalization Adjustment Fund;

- promote technologies and production methods that reduce use of natural resource, and increase investment in the EU's existing natural assets,

- promote the internationalization of SMEs;

- ensure that transport and logistics networks enable industry throughout the Union to have effective access to the Single Market and the internationals markets;

- develop an effective space policy to provide the tools to address some of the key global challenges and in particular to deliver Galileo and GMES;

- enhance the competitiveness of the European tourism sector;

- review regulations to support the transition of service and manufacturing sectors to greater resource efficiency, including more effective recycling; to improve the way in which European standard setting works to leverage European and international standards for the long-term competitiveness of European industry (this will include promoting the commercialization and take-up of key enabling technologies); 
- renew the EU strategy to promote Corporate Social Responsibility as a key element in ensuring long term employee and consumer trust.

The implementation of these guidelines by Poland should also encourage the transfer of innovation to the food-processing sector, particularly units included in the sector of small and medium-sized enterprises. In the longer term, support to the development of internationally should also lead to increased competition, which will oblige businesses not only active in the field of food processing, but from the entire sector to invest in acquiring new knowledge. However, the development of the business environment should be flexible to adapt to emerging needs. In other words, this environment should systematically obtain information about these needs and look for new solutions, both regarding production technology, organization of production processes and marketing and as regards the financing of investment in new knowledge. Note, however, that the support of the policies related to the identification of needs for innovation, and increasing awareness of the businesses of the need to take such measures should not be used to consolidate the existing structure of the industry. Market eliminates inefficient companies, which should not be funding by public funds.

Projects "Innovation Union" and "An industrial policy for the globalization era" refers to National Development Strategy 2020. Important in improving the innovativeness of the Polish economy should be the implementation of the second objective of this strategy, in which it is assumed to incur the level of value-added per 1 employee and increase the share of services sector in GDP. It should be expected that from support will benefit the business environment, including those related to food processing. Under this objective, action will also be taken to improve competitiveness and modernization of the food and agriculture sector. However, this strategy does not set specific objective, under which will be supported food processing. As a result, it will be treated as other industrial activities.

The country's development strategy also includes the growth of economic innovation as a separate objective. In Poland the increase in expenditure on $\mathrm{R} \& \mathrm{D}$ to $3 \%$ of GDP is not expected, as in the Europe 2020 strategy, but only a "substantial increase in spending", which is quite imprecise term. However, the measures are expected to be taken to increase demand for innovative solutions among entrepreneurs. Among the instruments that are geared to achieving this objective are mentioned:

- tax instruments;

- loan guaranties;

- revolving instruments.

In addition, this strategy involves the development of the financial market serving enhancing innovation. On the other hand a special role to play have: 
- capital funds;

- loan or guarantee funds;

- leasing companies.

In the National Development Strategy until 2020, it is assumed also the change in the system of parametric assessment of scientific units and the introduction of the jury system of transferring funds for research. By implementing these changes should however be borne in mind that R\&D activity is a continuous process and producing some solutions cannot always be shut down within 2-3 years, which usually corresponds to the term of the projects. It seems that in this form could be carried out studies that would respond to demand from entrepreneurs. However, recognizing the actual needs of enterprises depends largely on the development of the business environment and mainly of intermediaries in the transfer of innovation. The strategy also provides for increasing the degree of commercialization of research and the promotion of collaborative research with enterprises. The question is whether the granting of public support will be effective in the case of emerging solutions for one or a limited group of companies. In the case of the involvement of intermediaries can be made aggregation of needs and development of innovative solutions to a much broader audience. However, it is also assumed the improvement of the transfer of knowledge through the implementation of contract research.

The National Development Strategy provides a good base to take various measures to improve the innovation of economy, including food processing. The conducted study shows, however, that the Europe 2020 strategy gives greater importance to the private sector in the area of research and development. The development of this sector may in fact contribute to better match of the scope of research to market needs. In Poland it is necessary to develop it from scratch. Such activity already exists and is to some extent supported. The conducted field research shows that companies in e.g. biotechnology sector work in conjunction with enterprise incubators.

The National Development Strategy also addresses the problem of intellectual property protection. Strengthening this property in conjunction with the change of the system of parametric assessment of scientific units can be a powerful stimulus for enhancement activities aimed at creating solutions for a inventions. Creating an efficient and fair system of patent protection, however, will be a quite difficult process in Polish conditions. Research activity is in fact largely financed from public funds. The society ought to therefore be afforded with the opportunity to benefit from the effects of the activities, which they financed. There should not be given too much importance to innovation in the strict sense, i.e. understood as inventions used in business. Their economic importance in 
the short term will be quite limited. Yet, too restrictive patent protection may prevent their dissemination.

An important document defining the framework of Polish innovation policy, which implementation will lead to institutional changes in the business environment, including belonging to the food-processing sector is the Strategy for Innovation and Economic Efficiency "Dynamic Poland 2020". It is a specification of the National Development Strategy with regard to the improvement of innovation. In this strategy was presented a fairly detailed definition of innovation, which should be the determinant of the actions taken, e.g. in the operational programs. According to this definition, innovation should be understood as "the ability and motivation for operators to continuing exploration and exploitation in practice the results of research and development, new concepts, ideas and inventions. Innovation also means the improvement and development of existing production, exploitation and related to services technologies, introduction of new solutions in organization and management, improvement and development of infrastructure, especially relating to the collection, processing and sharing information. In relation to the public sector innovations are defined in many ways, including as the introduction of new services or fundamentally altered ways of organizing and providing these services for citizens and businesses - with high quality - in particular in order to meet the challenges of globalization and demography" [Albury 2005].

Used definition determines the direction of innovation policy. Its approach to this issue is very broad, which carries with it certain risks leading consequently to the ineffectiveness of the policy. As one of the threats should be recognized the possibility of identifying the concept of "innovation" in the meaning of "modernization". However, the same modernization of the economy, or the food processing sector can also be motivated and lead to the economic development of the country, it can be done on the basis of new solutions from the point of view of e.g. the company or a particular region, but coming down out of the market across Europe and the world. The benefits of the changes can then be short-term or only superficial. In the long term, e.g. the technological gap may increase.

The strategy "Dynamic Poland 2020" defines four basic policy objectives, namely:

- objective 1 - Adapting the regulatory environment and financial needs of innovative and efficient economy;

- objective 2 - Stimulating innovation by increasing the efficiency of knowledge and work; 
- objective 3 - Increase in efficiency in the use of natural resources and raw materials;

- objective 4 - The increase in the internationalization of the Polish economy.

Measures taken under Objective 1 will, therefore, shape in the greatest extent the institutional environment of innovation transfer. Soft institutions that will undergo modifications, should affect by not only the process of creating innovative solutions, but also the flow rate of these solutions and information between the scientific research sector and business. At the same time institutional system should provide a set of instruments for financing the various stages of the transfer of innovation, taking into account the increased risk of these investments. From studies conducted dossier results that pursued policy should go in this direction. Under the first objective there were set the following specific tasks:

- adjusting the system of economic regulation to the needs of effective and innovative economy;

- the concentration of public spending on pro-development and innovation activities;

- simplification, ensuring consistency and transparency of the tax system, having regard the need for effective and innovative economy;

- facilitating access to capital by companies in all phases of their development, with particular emphasis on venture capital and the SME sector.

Implementation of all these specific objectives is very important for improving the innovation of economy, however, it will require a very broad involvement of the public sector and the private one in the process of reviewing and revising existing regulations. This is due to the fact that even in the case of economic regulation system to adapt to the needs of effective and innovative economy is expected:

- enacting a law to improve the conditions of business, including simplifying the law and reducing regulatory costs;

- develop and implement solutions to conduct economic analysis of economic law;

- preventing bankruptcies and policy of new opportunity.

Actions in this areas seem to be necessary. This applies to particular cases in which legal regulations increase the risk of the business. An example is the insufficient flexibility for tax administration to adapt the recovery of duty to the company's financial situation, caused by external factors, including those arising from defective regulations. Taking into account the enterprise, which is obligated to pay their dues in relation to the state treasury under the conditions of occurrence of financial congestion, while implementing venture capital investments, which are innovative investments, should be expected imminent bank- 
ruptcy. Risk reduction however, can promote not only the change of the regulatory system, but also an introduction to the organizational system of innovation transfer facilities, especially in the area of financial, tax, insurance and investment advisory. Such an arrangement, however, suggests that an important element of the business environment, and special of micro, small and medium-sized enterprises should become private consulting companies. Public consulting is mainly oriented to issues of technology, product or marketing, not business relationships with the environment. These relationships may, however, be a serious obstacle in the implementation of innovative products or processes. Greater involvement of the private sector could be stimulating for growth in the scale of expenditure on pro-innovative activities.

Strategy for Innovation and Economic Efficiency also foresees the construction of a new system of fiscal incentives for units creating or implementing innovative solutions. Until now functioning incentives are not sufficient. There can occur, however, the barrier of the use of the instrument, especially by small and medium-sized enterprises. The use of them may indeed require professional knowledge, they do not have employees of the company and the available financial resources make it impossible to employ the right people. In this sphere there is also the opportunity to engage private consulting advisory companies. That would allow effective use of this instrument, and simultaneously minimize the risks arising from inappropriate interpretation of the rules. A similar role these companies could play in facilitating the company's access to capital in all stages of development, which is also the direction of the activities assumed by the strategy. Of course, such a commitment will generate additional costs to improve innovation, but this is the price for reducing the risk. An additional benefit of such a system may also be an increase in employment in the business environment sector. The increase in employment is, however, an equally important objective of both the National Development Strategy and the Europe 2020 Strategy. Implementation of innovation can, as we have previously noted, lead to a reduction in employment. The development of the private sector consulting services can therefore contribute to achieving both objectives at the same time. Such a situation is observed even in the service sector for corporate business.

To summarize the assumptions for the policy that flow from this strategy, should be stated that none of them directly does not apply to food processing. There is also a national strategy for industrial development. The possibilities of using instruments offered in the context of its policy to improve the food-processing innovation and economic activity of rural areas should be mainly seen in their accessibility for small and medium-sized enterprises. The conducted documentation study also shows that national strategies attach too little atten- 
tion to the importance of the private sector at the stage of transfer and brokering innovative solutions. The private sector is treated mainly as a recipient of these solutions. However, the Europe 2020 strategy is not limited by such a policy direction to improve the innovation economy. The condition is assumed in strategies adaptation of regulatory and financial environment not only in relation to companies developing or implementing innovations, but also the intermediary in this process. Especially that the intermediation itself may be innovative in nature and at the same time contribute to GDP growth.

In connection with the implementation of the objectives of the described development strategies aimed at improving innovation in the economy, some steps have already been made in aligning legislation. This is reflected in the Act of 25 September 2015 on the change of certain acts in relation to the promotion of innovation ${ }^{9}$. This Act amends for conducting research and development activities and implementation of its effects, particularly in relation to:

- the Act of 26 July 1991 on income tax from individuals ${ }^{10}$;

- the Act of 15 February 1992 on corporate income tax ${ }^{11}$;

- the Act of 4 March 2005 on National Capital Fund $d^{12}$.

The Act also introduces some changes in relation to higher education and other research and development units and scientific units, but these changes generally will not affect the development of the private sector in the business environment that may be involved in the process of transfer of innovation. Somewhat important seem to be changes in the above acts. In the acts on income tax have been introduced definitions of scientific, research and development activities. According to them, the legislator assumes that natural persons and legal entities may conduct these activities in the following areas:

- $R \& D$ understood as creative activities including research and development work undertaken on a systematic basis in order to increase the stock of knowledge and use it to create new applications;

- scientific studies including:

- basic research - original, experimental or theoretical research undertaken primarily to acquire new knowledge of the underlying foundations of phenomena and observable facts, without approach on the direct commercial application;

- applied research - research works undertaken to acquire new knowledge, focused primarily on the application in practice;

\footnotetext{
${ }^{9}$ Journal of Laws 2015, item 1767.

${ }^{10}$ Journal of Laws 1991, No. 80, item 350, as amended.

${ }^{11}$ Journal of Laws 1992, No. 21, item 86, as amended.

${ }^{12}$ Journal of Laws 2005, No. 57, item 491, as amended.
} 
- industrial research - research to acquire new knowledge and skills in order to develop new products, processes or services or introducing significant improvements to existing products, processes and services; These studies include the creation of components of complex systems, construction of prototypes in the lab or in an environment simulating existing systems, in particular to evaluate the usefulness of these types of technology, as well as the construction of necessary for these studies, pilot lines, including to obtain evidence in the case of generic technologies;

- development works, which mean the acquiring, combining, shaping and using of existing scientific, technological, business and other relevant knowledge and skills for the purpose of producing plans and arrangements or designs for new, altered or improved products, processes or services, except work involving routine and periodic changes made to products, production lines, manufacturing processes, existing services and other operations in progress, even if such changes may represent improvements, in particular:

- development of prototypes and pilot projects and demonstrations, testing and validation of new or improved products, processes or services in an environment which constitutes model terms of the actual operation whose primary purpose is to further technical improvement of products, processes or services whose final shape is not specified;

- development of prototypes and pilot projects that can be used for commercial purposes, where the prototype or pilot project represents the final product ready for commercial use, and its production solely for demonstration and validation purposes is too expensive.

The importance of this act in the context of improving innovation stems primarily from the fact that private individuals, both physical and legal, may deduct the cost of eligible R\&D activities from their taxable income. However, this is only selecting those costs in the maintained accounting records and that they meet the eligibility conditions. According to the Act, these costs include:

- receivables from social insurance, in part financed by the contribution payer, if these claims and premiums affecting workers in order to carry out research and development activities;

- purchase of materials and supplies directly related to their research and development activities;

- expertise, opinions, advisory services and equivalent services, and the acquisition of research results, provided or performed under contract by the scientific unit;

- payable use of scientific-research equipment used exclusively in the research and development; 
- depreciation write-offs of fixed assets and intangible assets used in research and development activity, with the exception of passenger cars and structures, buildings and premises which are separately owned.

The amount of eligible costs must not exceed:

- $30 \%$ of those costs in respect of social security contributions;

- in relation to other costs:

- $20 \%$ of the total amount, if the taxpayer is a micro-, small or medium-sized enterprise within the meaning of the provisions on freedom of economic activity;

- $10 \%$ of the total amount in the case of other taxpayers.

The act thus reduces the tax burden for companies conducting research and development activities. It also creates better conditions for entrepreneurs operating in the business environment. Companies conducting research and development may in fact deduct from their taxable income the cost of consulting services related to the study. Despite the not very strong emphasize the involvement of the private sector in research and development in national development strategies; introduced system of tax incentives can expect an increase in its role in the innovation process. There are not introduced such incentives for private companies, which could be involved in the process of commercialization of the results of these studies. It would be advisable however, because not all of these companies will be in a position to disseminate the results to the extent necessary business profitability.

Relevant for action to improve the innovativeness of the economy, including food processing and the broader economic activity in rural areas should also be changes in the National Capital Fund. The legislature defines the primary goal of the Fund as "to support the economic policy of the Council of Ministers in stimulating the economic development of a state based on innovation and competitiveness of the economy". Achieving this goal are to serve among others the following instruments:

- providing financial assistance to entrepreneurs and investors as defined by separate laws, either directly or through equity funds, to which the National Capital Fund provides financial support;

- make investments in businesses by taking issued by them in shares, warrants, bonds or participating as a shareholder in companies operating in the form of partnerships;

- granting of loans, guarantees and sureties as defined by separate regulations;

- creating or co-creating capital funds; 
- provision of services related to the management of the investment portfolio and risk management;

- act as an entity implementing financial instruments or fund of funds.

The National Capital Fund can guarantee the availability of repayable financial instruments for the innovation transfer process. Of course, the condition will be adopted specific provisions in the criteria for granting assistance, which will take into account the high risk of investing in innovative solutions. Repayable instruments should, however, help to improve the effectiveness of these investments. However, they will eliminate innovation with the highest level of risk. In order to make the transfer of the most advanced, innovative solutions to business, which did not receive the repayable support because of the level of risk, can be used non-repayable financial support in the form of subsidies or grants. It should be noted, however, that the use at the same stage of innovation transfer of the same criteria for access to the different instruments will result in competition between these instruments. The repayable instruments have an advantage in this competition.

Increasing the scale of repayable financial support to the disadvantage of non-repayable support should bring yet another tangible benefit for the economy. Companies undertaking to implement innovative solutions, especially those in the sector of micro and small enterprises will be forced to a greater extent to use external consulting services, e.g. the services of financial tax or marketing advisors and accountants. Limited financial resources make it impossible for these companies to employ their own experts with appropriate qualifications. As a consequence, it should lead to an increase in employment in business services. The fact that companies, especially in the early stages of development, are willing to use paid services provide interviews conducted in enterprise incubators. However, from these interviews also results that companies of the food processing industry do not use almost none of the support offered by incubators. As the main reason for this was indicated specificity of this sector, which determines not very innovative nature. The beneficiaries of this form of support are mainly companies from the new information technologies industry. The development of this industry does not have to be limited to urban areas, but can also be the direction for the development of the rural economy.

Started changes, in terms of regulations relating to the taxation of R\&D and finance the transfer of innovation, are not sufficient to succeed in improving the innovation of the rural economy and food processing. In the shortest possible time should be taken legislative action to eliminate congestion and to make financial system of recovery of receivables to the state treasury more flexible, Nowadays, even the banks do not always initiate bankruptcy proceedings 
against debtors, and often renegotiating contracts with them or conclude settlement agreements. This approach is rarely seen in the case of duties towards the state treasury. Furthermore, changes in regulations is also required by the issue of an assistant of taxpayer in the tax office. His/her guidelines for the taxpayer should also be mandatory for fiscal control. An important issue that requires rapid undertaking of legislative activity is also protection of intellectual property. These changes should ensure the protection not only at the national level, but also in international relations. At the same time must be ensured equitable sharing of benefits between the inventor and research funding body, especially when public funds are used for this purpose. Patent protection cannot, however, constitute a barrier to the dissemination of inventions.

\subsection{Organizational structure of the innovation transfer system}

Innovativeness of an economy is determined not only by the actions of entrepreneurs themselves, but also of people, institutions and state and local government authorities, making the business environment of each entity. However, innovative economy is not simply the sum of the elements comprising it, but kind of (emergent) synergy as a result generated in their broader collaboration and cooperation based on relationships developed network [Łobejko 2013]. In fact, innovation processes take place in a specific system of relationships including business networks, research institutions and NGOs and the government, public administration and civil initiatives ${ }^{13}$. At the same time the growing role plays correlations occurring between the dynamics of the creation and development of innovative enterprises, and the organization of the regions and the availability of specialized financial instruments [Matusiak 2008]. Often transfer of innovation and technology transfer terms are used interchangeably, often is used the same term for innovation and technology transfer or innovation and knowledge transfer. In semantic terms can be pointed the difference in defining these terms starting from the definition of the concept of innovation. The concept is very broad today [Zastempowski 2010]. It can be understood as [Schumpeter 1960]:

- introduction of new products or improvement of the existing ones;

- the introduction of new or improved production method;

\footnotetext{
${ }^{13}$ In total, one can talk about Inter-Organizational Network, where in addition to enterprises, there are units supporting business-related innovation activities. And the inter-organizational network can be defined as a system created voluntarily by a group of economic actors - companies involved in a similar field of activity, institutions both public and private, that support their activity, associated with relationships, interacting with the environment and set up to achieve common objectives [Barczak and Białkiewicz 2012].
} 
- opening up new market;

- the use of new raw materials or semi-finished products;

- a new format for selling or purchasing;

- the introduction of new production organization.

Transfer of innovation is of particular importance in terms of the functioning of the so-called knowledge-based economy (KBE), where, first of all, knowledge, not labor, raw materials or capital, is a key resource. When formulating KBE policy objectives must be taken into account the following facts, which significantly determine the process of transfer of innovations [Korenik and Szostak 2006]:

- rising costs of scientific research and development activities;

- shortening the life cycle of specific products and technologies;

- the increasing complexity of science and technology;

- that the first results of scientific studies in progress are usually after 5-8 years.

The idea of this is not yet innovation, because transform it into innovations is associated with incurring expenditures and risks. Hence, such an important role of the centres supporting business innovative projects. The spatial distribution of innovation is unequal - there are large disparities between countries and regions. It is also the result of problems with the transfer of innovation and effectiveness of the centres for the transfer. This shows how important element affecting the innovation of regions and countries, are business institutions, directly involved in the transfer of innovation.

This chapter focuses on characterizing the basic institutions directly involved in the transfer of innovation or to support this process, namely:

- colleges (universities, polytechnics, research units etc.), in particular in the context of the transfer of innovations there was discussed the issue of the creation of the so-called spin-offs and spin-outs by Polish universities and other specialized units set up in Polish universities, for example technology transfer centers, business incubators;

- non-university units (although in many cases associated with Polish universities), such as: technology parks and incubators and capital providers (venture capital, seed capital funds, etc.).

The aim of the study conducted was to evaluate the different organizations (actors) of innovation transfer process and to indicate the broad lines of the whole system of innovation transfer.

Institutions involved in the innovation transfer and/or directly supporting this process can be divided according to different criteria. One of them is the criterion of belonging to a particular sector - whether public or private, or so 
called third sector, represented by NGOs. However, an unambiguous determination of a specific institution belonging to a particular sector (whether public or private) may not be possible due to the fact of cooperation between the two sectors and the creation of joint ventures (institutions). For example, non-governmental organizations involved in the transfer of innovation can be created by both the public and private, and including the partnership represented by these two sectors simultaneously. Another separation line can be established according to the criterion of nature of providing services that support the entire process or a selected area of innovation transfer (e.g. support for transfer using financial instruments or non-financial, for example counselling, mentoring).

One of the most important actors involved in the process of transfer of innovation are public institutions of higher education (e.g. universities, polytechnics). This fragment of the public sector ${ }^{14}$, should play a special role in the transfer of innovation from science to enterprises. In particular, innovation transfer policy takes place through the establishment of specialized units at Polish universities, such as technology transfer centres, business incubators etc. This happens due to change in the perception of the role of universities, they have to play in the socio-economic development. Up to two previously carried out by these institutions functions, namely teaching and research, are increasingly added to the transfer function of new ideas and technologies to the economy. Of course, the exchange between scientific and economic sphere has been held for a long time, but now we have to deal with the change of the point of gravity. So far, the commercialization was perceived by universities as interesting, but side effect (activity, which was more tolerated than supported).

Currently, the universities perceive the commercialization of research results, as its main task as important as the research and education [Oliński 2009]. Speaking of centers of innovation and technology transfer or academic business incubators, usually intended to mean recognized in a whole economic complexes (primarily based on the real property or real estate), aimed at supporting the development of start-ups and offering them (apart from the basic, consisting of delivery, usable are) number of services such as: assistance in obtaining financial resources, associating with business partners, financial, tax, legal advisory (including patents), and many others. Of course, the units can be divided into various subgroups depending on the adopted criterion. For example, to one of these subgroups (undoubtedly having its own specificity, business belong business incubators created and conducted within the framework of the existing uni-

\footnotetext{
${ }^{14}$ One should not forget about private schools that also play a positive role in the transfer of innovation and link between science and business, but the potential in the form of research infrastructure is incomparably greater in public entities.
} 
versities - both public and private - frequently referred to as the Academic Incubators of Entrepreneurship). Among the differences in the functioning of the academic incubators of entrepreneurship are mentioned, among others, access to [Matusiak 2006]:

- university laboratories and research equipment;

- technological assistance and patent advising;

- knowledge of scientists and students in the provision of consulting and training services;

- databases for researchers and inventors, ideas, patents and technologies.

Generally, however, there are two main roads of innovation and technology transfer from research institutions to the economy:

- both free and paid transfer of results of research (e.g. in the form of patents, know-how, expertise rendered to business practice, projects implementation etc.);

- the creation of knowledge-based businesses (e.g. company spin-offs, spinouts).

Both ways of transfer of innovation should be considered valuable, but more and more attention is paid to the second way, which in Polish conditions is more difficult to implement, so that less frequent ${ }^{15}$, but at the same time bringing the "hard and measurable" results, proving success in conducting technology transfer on Polish universities. Very often the terms: company spin-offs and spin-outs are used interchangeably. However, these terms, even though they have a lot in common, are not synonymous. Spin-off and spin-out companies are different by one major issue, which is easily seen by analyzing the following two definitions:

- the term spin-off frequently defines the new company, which was founded in by employee/student (staff/students) and other persons directly associated with university, using the intellectual resources of that institution, so the spin-off companies have a ventures nature beyond the control of the parent organization;

- spin-out is a new company, which was founded in by employee/student (staff/students) and other persons directly associated with university using the intellectual and material resources of that institution. spin-out companies are financially or operationally related to the parent organization.

\footnotetext{
${ }^{15}$ The participation of scientists in economic life by exercising expertise to the practice, opinions about innovation, participation in numerous projects and internships in enterprises is now a common phenomenon (of course varied as to the field of science represented by individual scientists).
} 
So, there is the fundamental difference between these terms - it is a question of independence. Of course, both types of enterprises have grown up under own parent organization and both types are linked to each other, but essential meaning unlike the two types of companies is the nature of that relationship.

As it has been shown (Figure 3.3), for the effective transfer of innovation through the creation of spin-offs and spin-outs must be fulfilled four conditions: ideas, new technologies, inventions, people properly motivated (potential entrepreneurs), clear and friendly regulations, sources of financing of such initiatives and non-financial support.

Figure 3.3. Conditions for the establishment and functioning of the spin-off and spin-out companies

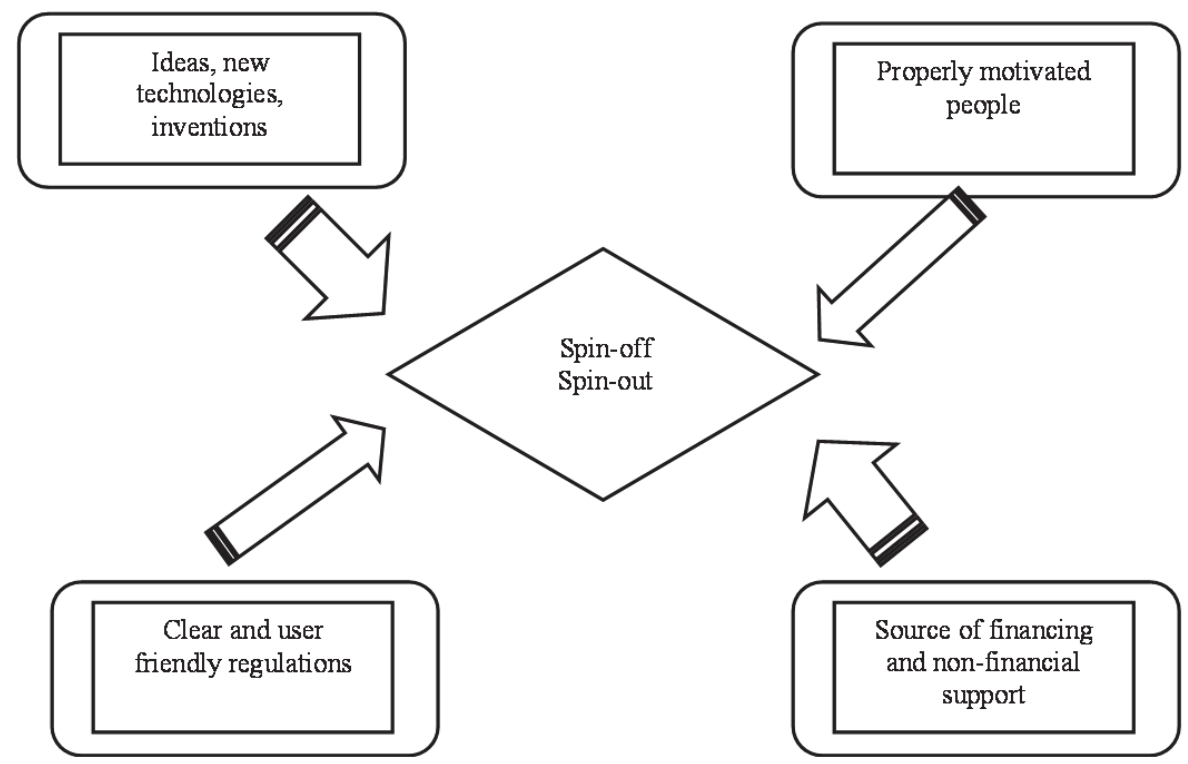

Source: Own elaboration.

In the Polish universities there are many innovative ideas and inventions generated. Unfortunately, many of them do not end up with transfer (commercialization). The problem with the commercialization of knowledge is a broader phenomenon, characteristic not only for Poland, but for the whole Europe - it is called European paradox (i.e. less effective than the US and Japan's ability to use the research results of the national scientific base), or simply put many ideas and inventions never reaches the "materialized form" even in the form of a spin-off or spin-out companies. In addition to the supply of new ideas and inventions, they must also find a properly motivated people - potential entrepreneurs. 
When it comes to clear and friendly legislation, although there can be noted some progress, but it still felt a certain deficiency. The main regulator of activities related to the innovation transfer and the academic creation of spin-offs and spin-outs is the Act of 27 July 2005 law on higher education, which in Article 86 [Journal of Laws 2005, No. 164, item 1365, as amended], it assumes that in order to better use of intellectual and technical potential of the colleges and the transfer of research results to the economy, universities can lead academic business incubators and technology transfer centers (where, academic business incubator created to support business or the academic staff of universities and students who are entrepreneurs), and technology transfer center is created for the purpose of sale or transfer free of charge the results of research and development works to economy. Therefore, these are institutions that assist in the transfer of technology for people wishing to set up spin-offs and spin-outs. What is more, next to the provisions on technology transfer centers and business incubators there have been saved directly articles relating to the creation of spin-offs and spin-outs. Thus, Article 86a of the new Act, says that the university, in order to commercialize indirectly, can create a one-man limited company, subject to hereinafter referred to as "special purpose entity" (SPC).

The university, through paid or unpaid contract, may entrust SPC the management of the rights to the results or to know-how. There can be seen clear progress and paying closer attention to transfer of innovation, as a result of research, by companies created not only by the staff or students of the university, but also the possibility of acquiring by the universities shares in such companies. The last condition is the infrastructure that provides the capital for the development of spin-off/spin-out companies. As already mentioned - a good option in this regard is effective and extensive network of venture capital funds and socalled business angels. Venture capital (VC) has become in recent years the issue often appearing in the economic literature relating to the promotion of innovation and technology transfer by creating spin-off/spin-out companies (although this form of financing is especially developed for the US financial market).

One of the most important non-university institutions for innovation transfer are technology parks. This does not mean that parks are not associated with research units. Despite the separation of these organizations, many parks work closely with research units. Parks (or rather companies located in the parks) that are located next to the thriving research institutions, benefit from a sort of "proximity pension" ${ }^{\prime \prime}$. At the beginning of 21 st century, followed by the world's re-

\footnotetext{
${ }^{16}$ This is confirmed by scientific research, while this is the case not only in Polish conditions, but also in other countries with developed economies that are leaders in transfer of innovation (e.g. Lindelöf and Löfsten 2004).
} 
vival of interest in the creation of technology parks, in the context of the regional innovation policy. It is connected with the exploration of the regions of effective instruments for the transformation of industrial economies based on knowledge [Matusiak 2011]. In the Polish legislation the notion of a technological park was clarified in 2002, as a cluster of separate buildings with technical infrastructure, created in order to make the flow of knowledge and technology between research institutions and enterprises, which are offered to companies which use modern technologies, consulting services in the creation and development of enterprises, technology transfer and converting the results of research and development in innovation, and also allows to use the real estate and technical infrastructure on a contractual basis [The Act of 20 March 2002 ... ${ }^{17}$ ].

Technology parks (also referred to as "science and technology parks"), are in the current Polish conditions, one of the most spectacular organization, dealing with the transfer of innovation. The reason for this is the "investment boom", which in recent years we had to deal with in Poland, and that was due to the support and the possibility of obtaining support from EU funds for such investments $^{18}$. But it should be kept in mind that the functioning of technology parks should not come down to a lease on favorable terms, or access to modern infrastructure (Internet, laboratories, etc.). In the park should work competent staff for managing the entire infrastructure, but above all the park should be "surrounded by" other specialized organizations and people who, through their experience and contacts bring added value to the functioning of the park (Figure 3.4). If it is assumed that the system of transfer of innovation, must function as Inter-Organizational network, in particular, it applies to the technology parks, which due to its human resources scale (in parks in Poland is already working many thousands of people - of course, including not only workers employed in parks, but also the owners and employees of park enterprises) and infrastructural, should play a specific role of hubs ${ }^{19}$, or network leader (focal firms ${ }^{20}$ ), and perhaps the best term in the described situation would be to adopt the role of or-

\footnotetext{
${ }^{17}$ This Act was repealed by the Act of 6 December 2006 on the principles of development policy, (Journal of Laws 2006, No. 227, item 1658).

${ }^{18}$ In Poland there are 42 science and technology parks at present, according to Book of Lists [2015].

${ }^{19}$ The Hub is a unit embedded in the concrete form of network structure and plays a central role in it, making it possible to optimize flows across the network, the hub powers derive from its position [Czakon 2015].

${ }^{20}$ Focal firm is called focal unit, in addition to the exercise of management functions and strategic (partly organizing work in other companies), so-called focal firm shapes and stimulates the creation and transfer of knowledge between setting up cooperating entities [Dembinski 2009].
} 
chestrator $^{21}$ of such a network. The creation of technology parks is in fact essential from the point of view of use of synergy effect [Rudzka and Góralski 2012].

Figure 3.4. Technology parks, as orchestrator of Inter-Organizational innovation transfer network

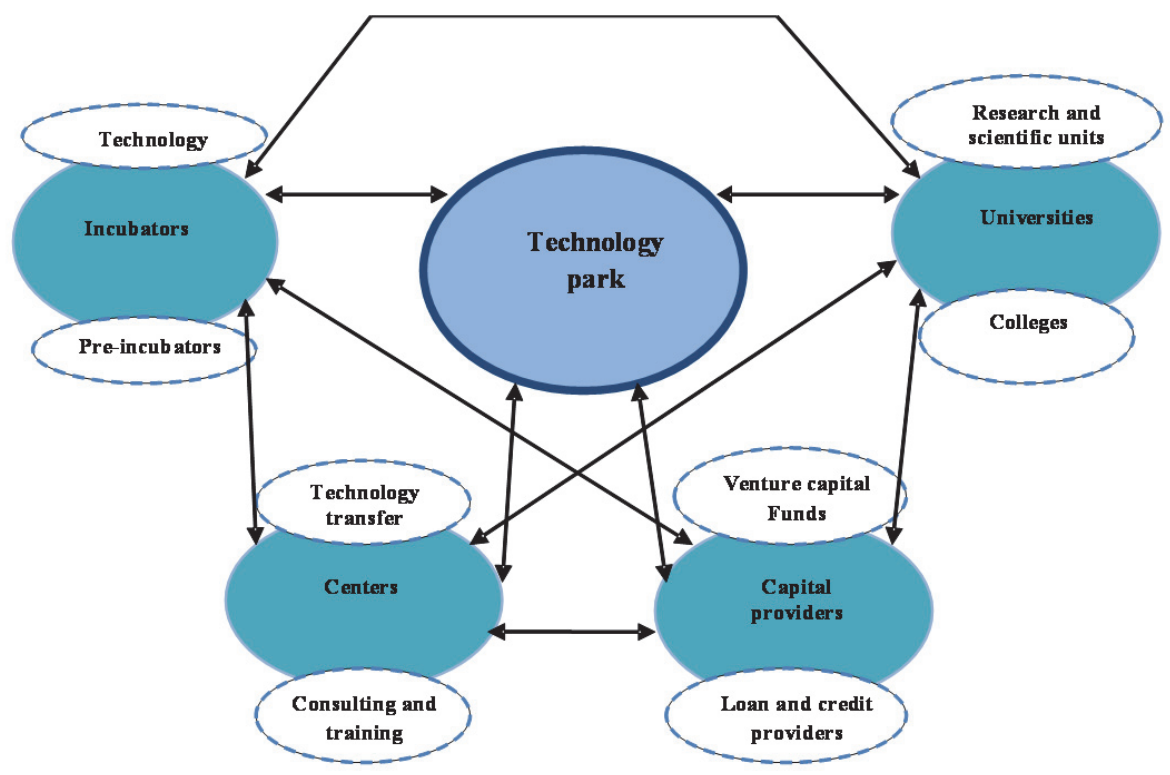

Source: Own elaboration.

This role parks can also play not only because of its size (in comparison with other entities dealing with the transfer of innovation, they are often considered to be very big), but also because of the diversified activities in which they lead. For example, many technology parks as part of its structure, lead technology incubators. Incubators of this kind are an instrument geared to the creation of new, modern enterprises. Unlike conventional incubators, cooperation with scientific institutions and transfer of innovation in this case is an added bonus, intended to ensure the newly formed company an attractive and unconventional business profile, increasing the chances remain on the market and further development [Krzak 2011]. Next to incubators (whether technology or generally called business incubators) can be distinguished so called pre-incubators.

\footnotetext{
${ }^{21}$ Network orchestration is a set of deliberately targeted actions to be undertaken by central entity, with a view to creating more value in the network and take part of that value for itself. Orchestrator function in the implementation of knowledge management requires knowledge of network structure (number of participants and their importance, the density of networks, network stability, the degree of centralization), and the relationship in the network it consists of: the number, nature and strength of the relationship [Chodyński 2012].
} 
A separate category of institutions promoting the transfer of innovation is financial institutions. For the aforementioned venture capital, private equity and others, "universal" 22 sources of funding can be added, such as banks, loan and guarantee funds, leasing companies and others. Specific forms of financing are related to the different stages of the development of innovative projects. They have an impact as intermediate bodies at different stages of transfer of innovation reflecting the needs and possibilities of funding. In this context analogies are often sought between life of a company and the life of a living organism, highlighting: birth, growth, maturity, and end-of-life. Another frequently used division distinguishing the different stages of transfer of innovation (and thus from concept to implementation) is a phase of: start-up, growth phase, expansion phase and phase of maturity. In accordance with the principle that innovative entrepreneurs need support in the early stages (including at the stage of formation of the idea), the whole process can be divided into the phase of preincubator and incubation phase (Figure 3.5).

Figure 3.5. Stages of transfer and commercialization of innovations - from knowledge creation to its implementation

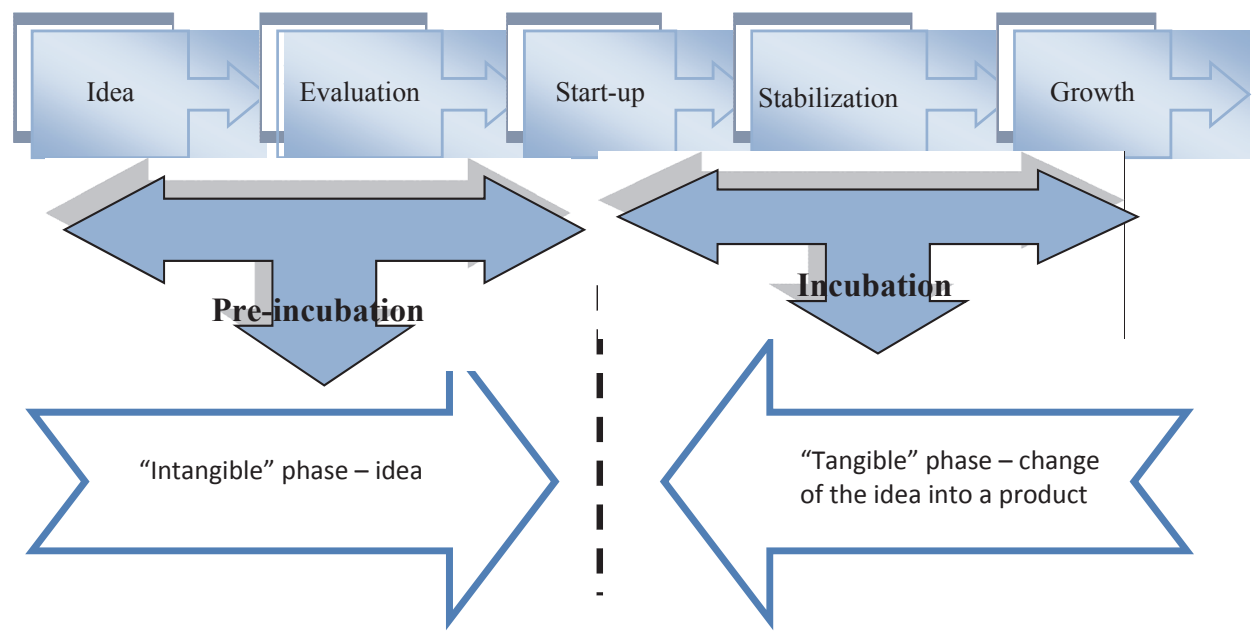

Source: Own elaboration.

The first stage of the so-called "material" phase is a start-up. As for the capital needs in this phase of development, it should be mentioned that this phase includes funds related to the occurrence of an idea on the market (e.g. a trial batch of products). It should be emphasized that without borrowing,

\footnotetext{
${ }^{22}$ This means directed not only to innovative projects, which does not mean that these institutions do not also finance such projects.
} 
the overwhelming majority of innovative business ideas cannot reach the growth phase, which is the next stage in the process of commercializing of innovation. This stage is characterized by a rapid increase in the income generated by selling of services/products. That is why many launching ideas do not enter into this phase, bankrupting or closing the registered company.

Entry into the growth stage is a confirmation of success - the fact that offered "value added" has been accepted by the market. This does not mean, however, that at this stage there are no specific capital needs. Although in this phase we often have to deal with exceedance of the threshold of profitability - there are so revenues that cover the operational costs associated with the production of the product - it does not mean, however, that at this stage there are no capital needs. Rather contrary, if a company wants to move to a phase of expansion, must initiate appropriate investment processes. Therefore, paradoxically, this phase may be accompanied by financial strains, up to the possibility of loss of financial liquidity.

The next phase in the process of transfer and commercialization of innovation is the expansion phase. This phase requires additional, significant capital expenditures (not just those associated with the product/service - as it did in the stage of starting, but primarily those associated with a number of other major projects (spending on marketing and image building/brand, expansion of distribution channels and many others).

The subsequent phase, which is characterized by different capital needs is a phase of maturity. This phase is the period during which is generated a surplus of current receipts over expenditure. Besides, this phase should enable "recovery" of the initial inputs of the enterprise functioning. In this phase must be made decisions about the future of our products/services, i.e. whether improve them further (differentiate from the competition), or enter new markets with new products. Decisions taken in this phase - as long as they were relevant - will help avoid the "death of the company". An extremely important issue is to bring concrete solutions in the provision of capital to a specific stage. In a series of transfer and commercialization of innovations, we can see a pattern. Typically, with the development of the company, its capital needs grow. However, equally important is the fact that changes in the financing of development of the company, is accompanied by a change of the type of funding. Just in various stages of development some forms are more relevant and tailored to the needs of entrepreneurs than others, and besides, not all forms of financing are available in the various phases of development. Possible sources of funding, depending on the development phase of the company are shown in Figure 3.6. 
Figure 3.6. Possible sources of funding depending on the development phase of the company

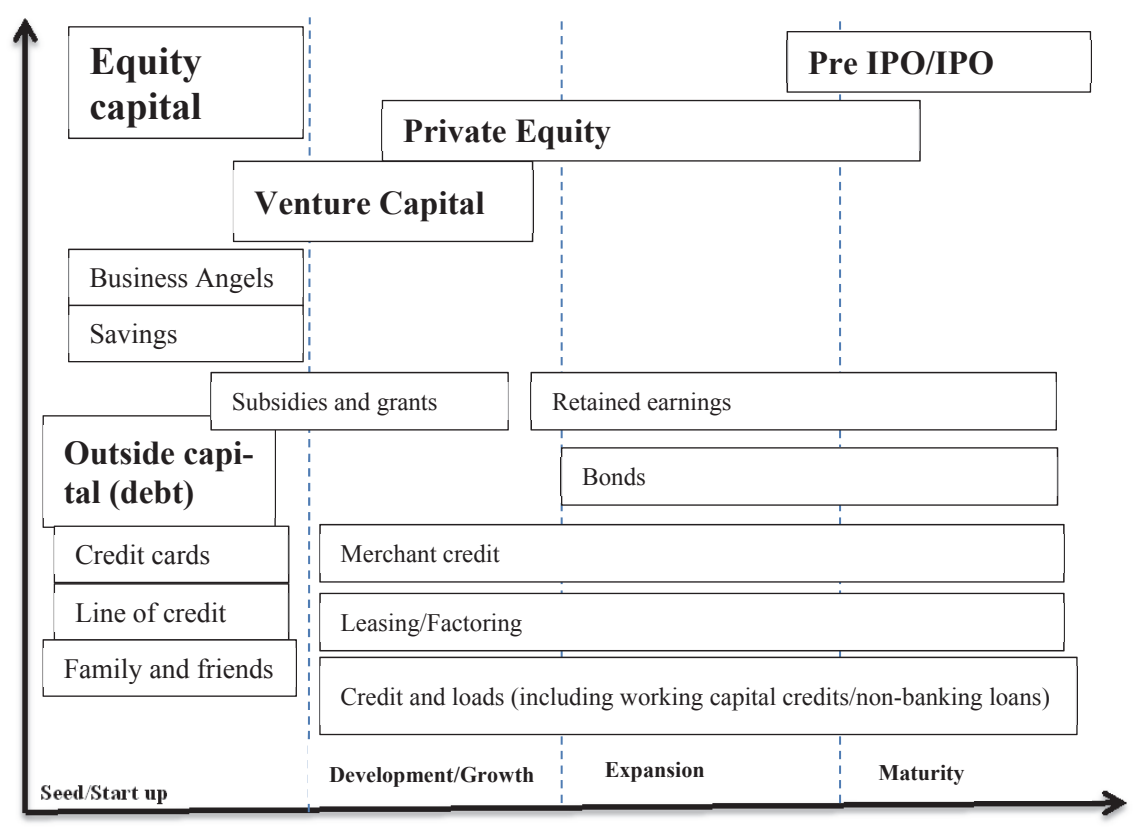

Stage of Enterprise Development

Source: http://innowacyjnypomysl.eu/źródt-finansowania-etapy-rozwoju-przedsiębiorstwa (Accessed: 15.11.2015).

Regarding the first described phase, the so-called start-up, it should be noted that this step involves expenditure and zero revenues. It is very difficult at this stage to raise capital. Most ideas of innovation "die" at the beginning. This area in the life cycle of innovation is called the "valley of death", that is why many experts say that reducing the negative impact of this phenomenon is the main challenge for policy. Despite numerous declarations and already running certain forms of assistance, this problem is still keenly felt in Polish realities. In this phase is very hard to use the credit. In the economic literature on the problems of the operation start-ups, is often highlighted difficult access of the companies in this category to foreign capital. First of all, it draws attention to the barriers faced by start-ups in obtaining a bank loan (insufficient guarantees and security for the loan, no credit history small businesses, lower than in relation to large enterprises, the creditworthiness, etc.). The same thing is presented regarding the leasing and factoring. So, practically we can speak of the so-called the principle of "bootstrapping". 
Another solution could be here venture capital funds or business angels. Looking at their rapid development in recent years, it is hoped that these forms of financing will serve companies in the starting phase an increasingly important role. Loan from the loan fund is practically possible and formalities associated with it are not complicated - but you need to meet the basic condition - reliable guarantors, and in the case of start-ups is not always possible.

As it can be discerned from the information contained in Table 3.1, already in the next phase of development (growth stage), the number of possibilities significantly increased (which is confirmed by the fact that the project left the so-called "valley of death").

Table 3.1. Sources of funding and company's development stage

\begin{tabular}{|l|c|c|c|c|}
\hline Specification & Start-up & Growth & Expansion & Maturity \\
\hline Equity & + & + & - & - \\
\hline Loan Fund & 0 & + & + & + \\
\hline Credit & - & + & + & + \\
\hline Leasing & - & + & + & + \\
\hline Factoring & - & - & + & + \\
\hline Business angel & + & + & - & - \\
\hline Venture capital & + & + & - & - \\
\hline Capital market & - & + & + & + \\
\hline
\end{tabular}

Source: Own elaboration.

In this phase, the real is in fact getting a loan from a loan fund or a bank loan. Similarly, leasing and factoring. The company also has some limited access to the capital market, for example: NewConnect ${ }^{23}$. The same applies to the next two phases of development (i.e. the expansion stage and maturity). Practically rarely in these phases we have to deal with the financing of companies with private equity of the owner (although this is possible), although some activities are financed through the profits made and/or depreciation. On the other hand, for the business angels type investors or venture capital funds right time for investments has already passed (given that, these forms of financing are intended for people whose main "asset" is the concept of business).

\footnotetext{
23 Alternative trading system NewConnect was launched in 2007 by the Warsaw Stock Exchange to enable the acquisition of financial reinforcement of the equity to greater number of operators. NewConnect alternative market regulations take into account the needs and expectations of small and medium size enterprises for which due to the procedures and costs regulated market is difficult to access.
} 


\subsection{Strengths and weaknesses of the innovation transfer institutions}

In Table 3.2 the main strengths and weaknesses of individual institutions dealing with or promoting the transfer of innovation are listed ${ }^{24}$. When it comes to technology parks, one of the advantages of these institutions is a close link with universities. The existence of such relationship, provides even participating interests - practically universities as often as local governments units are shareholders of companies with share capital managing technology parks. Because of numerous investments in laboratories, in many technology parks appeared the most modern, world-class equipment that can be used by both businesses and researchers [Bąkowski et al. 2014]. Although as many as $48 \%$ of parks are not equipped with laboratories - there is quite large variation. The worst situation is in the area of cooperation with financial institutions. Risk funds in the region are not supported by over $58 \%$, and at the national level of $64 \%$. With loan funds at the regional level there is no cooperation in $48 \%$ of the parks [Mażewska, Tórz 2015].

Among the strengths of technology incubators, a wide range of services for a range of thematic guidance and trainings as well as pro-innovation services should be mentioned. The technology incubators at the end of 2013 worked 334 entities, most of which are technology companies, so developing companies, producing and selling goods and services that embody a significant component of modern science [Bąkowski et al. 2014]. On the other hand, as many as $25 \%$ of examined technology incubators did not provide in 2013 even one of the proinnovation services. Only one-third of incubators cooperate with business angels, seed capital funds and VC funds, and only one in four incubator offers mediation in contact with the guarantee funds and in obtaining subsidies or a grant. The co-operation in the field of credit intermediation virtually no exists [Tórz 2015].

With respect to the Academic Business Incubators establishing a network of incubators in the Foundation of Academic Business Incubators it should be emphasized as a strength. Thanks to the funding, the network has become the world's largest network of incubators with hundreds of dynamically developed and existing enterprises.

\footnotetext{
${ }^{24}$ The identification of the analyzed institution were used in periodically issued reports such as Bąkowski and Mażewska [2015] and research by Bąkowski et al. [2014]. There were omitted, however, business institutions of universal character (i.e. not focused solely on the transfer of innovation, such for example as consulting-training centers, loan funds, or guarantee funds). However, in this section we pointed to the positive role that these institutions can and should play in the innovation transfer process.
} 
Table 3.2. Strengths and weaknesses of particular innovation transfer institutions

\begin{tabular}{|c|c|c|}
\hline $\begin{array}{c}\text { Type of } \\
\text { organization }\end{array}$ & Strengths & Weaknesses \\
\hline $\begin{array}{l}\text { Technology } \\
\text { parks }\end{array}$ & $\begin{array}{l}\text { wide range of services (condu- } \\
\text { cive to playing the role of the } \\
\text { network orchestrator); } \\
\text { direct links with universities } \\
\text { (possibility of commercializa- } \\
\text { tion of research); } \\
\text { developed infrastructure. }\end{array}$ & $\begin{array}{l}\text { a large variation in the potential (not all } \\
\text { parks are able to cope with the role of the } \\
\text { focusing units); } \\
\text { initiatives of the public authorities unfa- } \\
\text { vorable to making rational business deci- } \\
\text { sions; } \\
\text { some gaps regarding laboratories; } \\
\text { poor cooperation with funds providing } \\
\text { capital. }\end{array}$ \\
\hline $\begin{array}{l}\text { Technology } \\
\text { incubators }\end{array}$ & $\begin{array}{l}\text { wide range of services in the } \\
\text { majority of incubators; } \\
\text { focus on creating highly inno- } \\
\text { vative spin-offs and spin-outs. }\end{array}$ & $\begin{array}{l}\text { some incubators do not provide pro- } \\
\text { innovation services; } \\
\text { most of incubators cooperate with busi- } \\
\text { ness angels, seed capital funds and VC } \\
\text { funds, and in addiction poor cooperation } \\
\text { in the field of credit mediation. }\end{array}$ \\
\hline $\begin{array}{l}\text { Universities - } \\
\text { pre-incubators } \\
\text { and Academic } \\
\text { Business Incu- } \\
\text { bators }\end{array}$ & $\begin{array}{l}\text { within this category is a very } \\
\text { active, extensive network of } \\
\text { AIP (about } 50 \text { incubators); } \\
\text { direct access to creative young } \\
\text { people; } \\
\text { explicit segment - pre- } \\
\text { incubation. }\end{array}$ & $\begin{array}{l}\text { restrictions in infrastructure; } \\
\text { about } 20-30 \% \text { of incubators with very } \\
\text { weak results in the so-called "Core busi- } \\
\text { ness" that is in incubation of the compa- } \\
\text { nies (including high-tech); } \\
\text { limited scope of external cooperation } \\
\text { (in principle, cooperation at the regional } \\
\text { level); } \\
\text { no implemented standard of the AIP func- } \\
\text { tioning. }\end{array}$ \\
\hline $\begin{array}{l}\text { Technology } \\
\text { Transfer } \\
\text { Centers }\end{array}$ & $\begin{array}{l}\text { the proximity of the scientific } \\
\text { community; } \\
\text { improving the ordering princi- } \\
\text { ples of copyright management. }\end{array}$ & $\begin{array}{l}\text { too low number of centers operating with- } \\
\text { in special purpose companies; } \\
\text { a large share of public funding; } \\
\text { poor networking; } \\
\text { lack of contacts helping in obtaining spe- } \\
\text { cial funding for innovative projects. }\end{array}$ \\
\hline $\begin{array}{l}\text { Seed Capital } \\
\text { Funds }\end{array}$ & $\begin{array}{l}\text { specializations of funds (focus- } \\
\text { ing on the "industries of the } \\
\text { future"); } \\
\text { strong negotiating position } \\
\text { against the originators seeking } \\
\text { to raise capital; } \\
\text { extensive control in companies. }\end{array}$ & $\begin{array}{l}\text { the need to achieve the imposed top-down } \\
\text { indicators; } \\
\text { weak monitoring of the needs of entre- } \\
\text { preneurs. }\end{array}$ \\
\hline
\end{tabular}

Source: Own elaboration.

As to the weaknesses of Academic Business Incubators, it should be noted that quite a large units share (because about 20\%) cannot show even one of the newly established company, and 30\% of the AIP has not left any 
single graduate [Bąkowski 2015] - although these figures do not relate to the aforementioned network.

It is significant that does not increase the number of technology transfer centers functioning in the form of special purpose companies. Although commercial companies professionally engaged in the commercialization of technology are the organizational and legal structures, improving efficiency action [Bąkowski 2015]. Besides, Technology Transfer Centers continue to be (this trend is continuing for a long time) primarily financed from public funds. Increasing the share of private funds, would be the best proof of the gradual increase in transfers to enterprises (which is the essence of the activities of these units). However, as research indicates that $90 \%$ of the financing of the Centers comes from public funds [Bąkowski 2015]. Not much better is shown the cooperation of technology transfer centers as members of the network. Most units are involved in the operation of the cluster, but it is only $37 \%$ of respondents of examined Centres [Bąkowski et al. 2014]. Another element which should improve cooperation with capital owners - such assistance is offered (it is at different, often an insufficient level) by about half the units. A growing number of universities are implementing their own regulations laying down rules for the management of copyright and related rights and industrial property rights (this is an important tool for their business. Such regulations were implemented by $93 \%$ of the Technology Transfer Centres [Bąkowski 2015].

Seed Capital Investment Fund (FOCs) by financing the initial stages of company development, pay a significant risk of failure of the project. Therefore, the primary means of minimizing the risk is the knowledge of the field and used in it solutions. For this reason, funds specialize in certain industries in which they undertake investment activities. The choice of the industry in this case means that FOCs have access to specialists in the field. With the vast majority of industry specialization declared by the surveyed funds is a response to the current needs of the global economy [Lityński 2015]. The increase of the innovativeness of the economy is one of the priorities of European Union programs. No doubt the possibility of obtaining EU financial support paved the way to create seed funds [Brzozowska 2008], it should be taken into account that FOCs implement projects funded by public institutions, which requires the achieving of assumed result indicators and must, therefore, make the declared amount of capital investment during the project. Under these conditions, FOCs at risk of failure to achieve the indicators may decide to support projects overvalued and promising not achieving the expected business parameters, but allowing settlement of the project [Lityński 2015]. 
Summarizing analysis of the strengths and weaknesses of innovation transfer institutions, the attention should be paid to several issues. First of all, insufficient cooperation of non-financial institutions with institutions providing capital. It is not just about close ties with capital owners financing the project with a high load of innovation (such as those mentioned seed capital funds), but also other capital owners - those universal, as banks, loan and guarantee funds, business angels and others. More that the situation as regards the size of capital available in these institutions underwent in recent years systematic improvement. For example, at the end of 2014 loan funds, which are members of the Polish Association of Loan Funds with a total capital of PLN 2 billion 537 million 844 thousand. This envelope can already play a significant role in the overall system of powering business sector with external capital [Alińska et al. 2015] and the guarantee capital, only 45 funds grouped in the National Association of Guarantee Funds amounted at the end of December 2014 to about PLN 1.17 billion [Gajewski et al. 2015].

Other possibilities of obtaining financing, more directed for financing risky and innovative projects can be added to this list. Among these capabilities, can be even listed the so-called business angels. In Poland, in comparison with other developed countries this type of activity is less widespread, but the last few years are characterized by a large increase in popularity of the activity of business angels. There started to be formed special business angel networks, which in some ways resembles more formalized supply of venture capital for young companies. Examples of business angels networks, which as in Polish standards achieved quite "substantial" sizes are: Lewiatan Business Angels (LBA), INVESTIN, the Capital Fund of the Pomerania Development Agency (ARP S.A.), ARP S.A, Amber Business Angels Network, Business Angel Seedfund (BAS), Oxford Innovation (OXIN) and Oxford Investment Opportunity Network (OION), Poland Business Angels Network (PolBAN), Łódź Regional Development Agency (ŁARR S.A.), a network of private investors SATUS and others.

The above description was limited only to selected examples and data, but there are much more possibilities (e.g. the so-called technological credit ${ }^{25}$, mezzanine $^{26}$ and many other forms). Therefore, institutions supporting the transfer of innovation in terms of content, should be somehow "clustered" with the institutions that provide capital (Figure 3.7).

\footnotetext{
${ }^{25}$ The credit is due to the intervention of the state is granted on very favorable terms.

${ }^{26}$ Mezzanine is a way of financing of projects using the so-called projects hybrid instruments. It is a form of financing that enables equity funding - ideal in situations where a company does not want dilution of the ownership structure (e.g. due to a further increase in equity).
} 


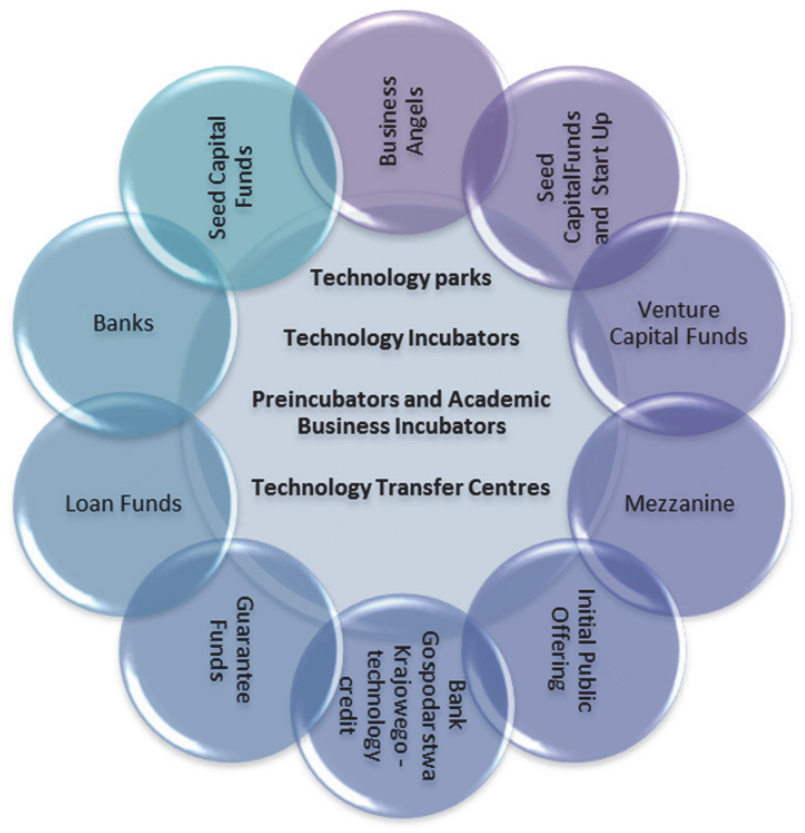

Source: Own elaboration.

Efforts should be made to make the system of transfer of innovation (including units supporting this process), operating in a manner typical for inter-organizational networks. The system of inter-organizational relationships within the organization network allows interrelated entities to conduct a collective strategic plan, which could raise the total efficiency [Stańczyk-Hugiet 2012]. Therefore, well-functioning inter-organizational networks increasingly prejudge the effectiveness of the entire system - this also concerns (and perhaps primarily) innovation transfer system in which there are various actors.

The main instrument of transfer of innovation, both at regional and national level, is the creation of a regional (or national) innovation system - RIS and NIS respectively, which is a collection of diverse entities (actors) that affect innovation processes and links (relationships) between them. It is a system of entities, interactions and events that as a result of the synergy are created in a particular territory and lead to enhanced absorption and diffusion of innovation.

We described different types of institutions engaged in promoting innovation and their transfer. The quality and effectiveness of individual institutions often depends on the success (or failure) of individual projects (implementations), and thus the dynamic increase (or fall) of specific companies. However, to be able to talk about properly functioning system of transfer of innovation and 
its impact on a substantial number of companies (and thus the macro-economic effect in terms of both regional and national level), it is necessary to build a network of these institutions. Creating a network structures, contributes to mutual learning and to maintain access to knowledge resources, which base is growing and is difficult "to grasp" by individual entities. In this way, the effect of specialization (so called core business, which deal with individual institutions), a "network effect", allowing to achieve different kinds of pensions (e.g. relational pension, Penrose pension, Ricardian pension, Schumpeter pension, entrepreneurial and others ${ }^{27}$ ). Diagnosis of what transfer system of innovation is in the current Polish conditions, most efficient and effective, is the key issue, decisive largely about the development of the Polish economy in the coming years. To avoid in Polish economy the so-called "Trap of average income"28, it is necessary to create a comprehensive system (rather than individual institutions) of the innovation transfer.

Apart from the historical analysis of the development of universities in Europe, according to the professor J.G. Wissema, it can be stated that we are now in the so-called second transitional period, between the Humboldt's university, and so called university of "third generation" [Wissema 2005]. Understanding the upcoming changes will be crucial for the development of Polish universities. Somewhat at many institutions of this kind there are already seen distinct changes (e.g. trimmed matters related to intellectual property, the creation of technology transfer centres and incubators caring for the first phases of the emergence and development spin offs and spin outs, changes in legislation on higher education etc.). However, to ensure adequate momentum and "depth" of change, Polish universities must establish a proper relationship of the two-way nature. That is, both the direction science-practice and practice-science.

The first direction is very desirable because it allows creatively shaping the environment by scientific institutions. This means that its proposal for such

\footnotetext{
${ }^{27}$ These examples of pensions are characterized in numerous economic publications, for example, Niemczyk [2013], Stańczyk-Hugiet [2012].

${ }^{28}$ So when the average developed countries in the process of catching up with the developed countries clearly slow down after crossing about USD 17 thousand [World Bank 2010] because of depletion "model imitative" and not crossing in a timely manner to the "model of innovation". Many countries have managed to get out of poverty, but they failed to reach the next step, i.e. a high level of affluence. Considerations on "trap of middle income" is beyond the scope of this study (i.e. the effect of "middle income trap" economists have researched from various scientific institutions in the world, for example, Agénor and Canuto [2012], Eichengreen et al. [2013], and in Poland - Ciesielska and Radło [2014]). The problem here is only indicated in the context of the need to establish an effective system of innovation transfer. Thanks to this fact, the Polish economy will be more competitive and will be making up faster for the civilization gap to developed countries.
} 
types of values about which customers do not have yet an idea (is expressed in surprise and recognition of the potential recipient who did not consider the possibility of the proposed solutions). The second direction of the practice-science, is reporting needs of the business practitioners with the expectation of meeting them. Relationship has an adjustment nature (i.e. helps businesses to adapt to the demands of the environment). According to the theory of adaptation, the ability to adjust to changes in the environment, is the main determinant for the survival of the organization. Accordingly, both these directions should be developed, that they can simultaneously strengthen each other (e.g. to offer more original solutions to the company in the course of solving a particular problem). 


\section{Prospects for the growth of innovativeness in the agri-food sector and rural areas in the light of the analysis of the Regional Innovation Strategies}

\subsection{Historical outline and implementation of the Regional Innovation Strategies in Poland}

The essence of innovativeness is not only the creator of a new idea, but also the effect of the interaction between the creator's environment and institutions supporting or inhibiting its creative activity. The emerging innovation systems, functioning in the national, regional, industry and technology dimension (e.g. ICT), are often interrelated and overlapped due to the interactions taking place among participants in the innovation process [Weresa 2014]. The Regional Innovation Strategies (RIS) should strengthen innovation systems, by helping regional authorities and other regional development organizations in defining and implementing these systems [OECD 2010] $]^{29}$.

The Regional Innovation Strategies have been existing in Poland for more than ten years. However, as it results from analyses, most of them are just at the beginning of building support for innovativeness in our country. According to the latest Regional Innovation Scoreboard [European Commission 2015], Poland is still at the end of the list of "moderate innovators" and is ranked after Spain, Hungary, Greece, Slovakia, Croatia and before Lithuania.

In this chapter we evaluate the existing RIS and their impact on the development of innovativeness of the agri-food sector and rural areas. An analysis was carried out on a basis of secondary sources contained in the documents and studies developed in the process of implementing the RIS in the European Union and in Poland.

The strategy is usually understood as a direction and scope of activities to be adopted by an organization/country/region in the long term, in order to achieve its objectives and ensure the long-term survival and development [OECD 2012]. An innovation strategy is, therefore, a general concept of the functioning of the innovation system in the future. It is not identical to the policy which includes impact tools aimed at achieving defined objectives. Sometimes, the boundaries between the innovation strategy and the innovation policy become blurred when the strategy identifies specific instruments that will be used to achieve the defined objectives [Weresa 2014].

\footnotetext{
${ }^{29}$ Regional innovation system - private and public entities operating in a given region and having impact on each other, which deal with the creation, modification, transfer and diffusion of new technologies on a regional, supraregional or international scale [Freeman 1987].
} 
According to the OECD recommendations, the implementation of the RIS should be carried out at six following stages [OECD 2010]:

- launching dialogue about innovativeness in a region so as to achieve consensus with respect to the proposed vision and to identify actors to be included into the regional innovation system;

- analysis of innovative needs and potential in a region, by evaluating the strengths and weaknesses;

- creation of the RIS including all possible stakeholders, making use of a discussion in a public forum, in order to clarify the challenges and options for the innovation policy;

- selection of priorities to support innovation, i.e. a choice among many options and budgetary possibilities;

- implementation of the strategy, creation of a series of action plans, pilot projects, initiatives. These activities should be closely coordinated with implementing authorities and assigned objectives, competences and budget;

- creation and use of a RIS monitoring and evaluation system.

It should be stressed that the activities aimed at stimulating innovations in the regions were initiated in the EU as early as in the 90s, pursuant to the Single European Act introduced in 1986. The concept of a strategic approach to innovativeness, which emerged back then, resulted in allocating the Structural Fund resources for supporting innovation. Those activities were associated with the then priorities of aligning the economic level among the regions and an attempt to indicate endogenous potentials of the regions, which may contribute to their further development [European Commission 2014b].

The idea has been subject to a series of evolutions. The first Regional Technology Plans were implemented in a linear manner, at the science-industry level. In turn, the Regional Innovation and Technology Transfer Strategies were added an additional element which was the transfer of technology. At the next stage, i.e. in the Regional Innovation Strategies the network approach, involving many actors, was already visible.

The process of building the RIS in Poland was initiated in 2001-2002 in five voivodeships: Wielkopolskie, Opolskie, Śląskie, Zachodniopomorskie and Warmińsko-Mazurskie, thanks to the funds from the EU 5th Framework Programme for Research and Technological Development. In 2003, the process of creating the RIS was also continued in other voivodeships, using funds from the Scientific Research Committee and Marshal's Offices. This allowed to create the innovation strategy at the NUTS II level (voivodeships). In 2005, all voivodeships, with the exception of the Mazowieckie Voivodeship, already had 
their Regional Innovation Strategies approved by the Voivodeship Sejmiks [Klepka 2005].

Until taking work on the Regional Innovation Strategies, the issue of innovativeness in the regions remained on the margin of analyses carried out for the purposes of various strategy papers, including the voivodeship development strategy. What should be emphasized, thanks to a need to create the RIS in Poland, innovativeness-related processes have become the subject of a broad discussion of the stakeholders. In the majority of the voivodeships, research teams have been set up to determine the state of innovativeness in the sphere of science, entrepreneurship and business environment, analyses and empirical research were made to support the formulation of objectives at the level of the regions and the rules for the implementation of the strategy and its monitoring were defined [Gorzelak et al. 2006]. Therefore, the RIS have become a basis for building the modern knowledge-based economy in Poland.

The defects of the then RIS include mainly the absence of coordination of creating these strategies at the central level. The scope of research implemented in the process of creating the strategies, research methods and the selection of samples have been determined individually by the research teams carrying out this research in each region. This is a significant difficulty in terms of assessments and comparisons of the efficiency of implementing the strategies and objectives defined therein [Grzybowska 2012]. Therefore, an opportunity to create a coherent image of innovativeness of the Polish regions has not been used [Gorzelak et al. 2006].

In addition, the first RIS were based mainly on the internal potential, while ignoring the external links and interactions among various entities and processes. The region was treated as a socio-economic structure confined within the administrative borders and self-sufficient. They could not identify regional development mechanisms, specific processes and interactions in a given region. Another drawback was the selection of too many priorities, losing the uniform and consistent direction for the development of innovativeness in the region [Nowakowska 2007].

According to the OECD [2010], the RIS may be efficient when they identify region-specific comparative advantages as well as barriers hampering the functioning of innovation systems in the region. They should be sufficiently specific and formulated in such a way so as to provide opportunities of solving issues. Excessively general strategies, similar priorities in many regions, an unclear relationship with the implementation policy result in the inefficiency of the RIS. 
After 2005, the activity of regional authorities in the sphere of the innovation policy increased. This change was driven by the possibilities of obtaining significant EU funds in the financial perspective 2007-2013. Therefore, local government authorities started updating the RIS in all voivodeships (in the Mazowieckie Voivodeship, work on the RIS was completed in 2008). This process gained importance again in the context of obtaining funds from another financial perspective 2014-2020.

\subsection{Smart specializations as a leading element of the third generation RIS}

Smart specializations have become a new generation of the EU innovative activities, going beyond the traditional understanding of support for innovativeness. Their essence is a need for the regions to become specialised due to their distinctness, which determines their strength and ability to stand out among the others and also stresses the importance of identifying the strengths increasing regional innovativeness. Thus, efforts to establish priorities for the RIS is a process of discovering niches in which the region may have an advantage in terms of research and innovation ${ }^{30}$.

The basic assumption of the smart specialization concept is to improve innovativeness and competitiveness of the regions by means of their endogenous potential and branches already operating in them. This may include specializations within one sector or cross-sectoral projects, allowing to achieve a competitive advantage. The European Commission guidelines with regard to the so-called third generation innovation strategies (RIS3) postulate a need to enhance smart specializations through the application of the following four principles, known as $4 \mathrm{C}$ : choices, competitive advantage, critical mass and collaborative leadership [Guide... 2012].

In accordance with the assumptions of the Innovation Union, one of 7 flagship projects of the Europe 2020 strategy, the Member States have been obliged to reconstruct the national and regional systems of research, development and innovation, as well as to correct the previously implemented regional innovation strategies (RIS), just towards so-called smart specialization. In practice, a recommendation for the regions to prepare smart specialization has become mandatory for them, because in the planning and financial perspective 2020-2014 they are a basis for the allocation of funds within the Operational Programmes of the EU Cohesion Policy [Wyznaczanie... 2014].

${ }^{30} \mathrm{http}: / /$ ec.europa.eu/research/regions/index.cfm?pg=smart_specialisation (accessed: 10.11. 2015). 
The designation of smart specializations and the RIS update is not a simple extension of the current planning, but is to constitute an important change. A strategic approach to building innovativeness of the economy differs from the existing strategy papers for the period 2007-2013 mainly due to [Słodowa-Hełpa 2013]:

- departure from the sectoral approach to innovativeness for the benefit of integrated and cross-sectoral measures in building the innovation capacity and from the innovation policy orientation around the development of enterprises for the benefit of creating complementary systems and innovation environment;

- shifting the emphasis in the implementation of the strategy from the level of defining measures to the greater concentration on the policy effectiveness.

The Polish regions are at different stages of designating smart specializations. Table 4.1. shows the previously proposed smart specializations in 16 Polish voivodeships, related to the agri-food sector and rural areas.

The analysis shows that with the exception of the Małopolskie, Pomorskie and Śląskie Voivodeships, almost all voivodeships point out among smart specializations of the region, the areas directly or indirectly related to the agri-food sector. The most extensive concept of the "bioeconomy/green economy" is present in three voivodeships: Lubelskie, Lubuskie and Zachodniopomorskie. However, it should be pointed out that the European Commission's definition of the bioeconomy is very extensive, therefore, at this stage it is difficult to predict whether the rules of this economy will be really carried out.

The remaining voivodeships (apart from those three mentioned above) refer, to a varying degree, to the agricultural production and processing of agricultural products. The lack of specific guidelines on how to define smart specializations was a reason for which the voivodeships designated them at various levels of generality. In addition to very general ones, such as the quality of life, the much narrower ones, for example, food production, were selected. Many of them are repeated in various regions, therefore, there was no attempt to look for specializations, which would correspond to the specific conditions of the region and reflect its actual endogenous potential. Often, many specializations were provided, even with regard to the agri-food sector, which in the end could result in the dispersion of activities and measures. Moreover, striking is the fact that the majority of the voivodeships selected more traditional specializations, such as the agri-foof sector. Should it be associated with a low level of development of innovation systems in these regions? Usually, it is assumed that the higher is the level of innovativeness, the higher is the use of specializations based on knowledge-intensive techniques services. 
Table 4.1. Selected smart specializations in the Polish regions, related to the agri-food sector and rural areas

\begin{tabular}{|c|c|}
\hline Voivodeship & Specialization \\
\hline Dolnośląskie & $\begin{array}{l}\text { Among the emerging industries: production of healthy food; } \\
\text { Among scientific and technological specializations: biotechnology and } \\
\text { genetics, biochemistry, environmental engineering. }\end{array}$ \\
\hline $\begin{array}{l}\text { Kujawsko- } \\
\text { pomorskie }\end{array}$ & $\begin{array}{l}\text { Best safe food processing, fertilizers and packaging; } \\
\text { Health-related tourism; Biosmart specialization - natural potential, } \\
\text { environment, energy industry. }\end{array}$ \\
\hline Lubelskie & $\begin{array}{l}\text { Key specialization: bioeconomy (primary production, processing of } \\
\text { bioresources, production of food - agri-food sector, chemical, } \\
\text { papermaking, pharmaceutical, energy sectors); } \\
\text { Complementary specialization: medical and health-related services - } \\
\text { nutrition and dietetics, functional food, food production chain, } \\
\text { production of pharmaceuticals and probiotics. } \\
\text { Emerging specialization: low-carbon energy industry - RES energy. }\end{array}$ \\
\hline Lubuskie & $\begin{array}{l}\text { Specializations based on the industry approach: technologies and } \\
\text { environmental services; Technologies and services for human health; } \\
\text { Specializations based on the cross-sectoral approach: green economy, } \\
\text { health and quality of life. }\end{array}$ \\
\hline Łódzkie & $\begin{array}{l}\text { Key specializations: innovative agriculture and agri-food } \\
\text { processing, energy industry, including RES; } \\
\text { Key areas of technology: biotechnology, nanotechnology and } \\
\text { functional materials. }\end{array}$ \\
\hline Małopolskie & Sustainable energy. \\
\hline Mazowieckie & Safe food; High quality of life. \\
\hline Opolskie & $\begin{array}{l}\text { Specializations: agri-food technologies; } \\
\text { Potential specializations: processes and products of health and } \\
\text { environment protection. }\end{array}$ \\
\hline Podkarpackie & $\begin{array}{l}\text { Sustainable tourism; } \\
\text { Health, food, nutrition. }\end{array}$ \\
\hline Podlaskie & $\begin{array}{l}\text { Green technologies - agri-food processing, life science, renewable } \\
\text { energy industry, eco-innovations. }\end{array}$ \\
\hline Pomorskie & $\begin{array}{l}\text { RES; Civilisation and aging-associated diseases (technologies, } \\
\text { therapies, quality of life). }\end{array}$ \\
\hline Śląskie & Environmental technologies; Energy industry. \\
\hline Świętokrzyskie & $\begin{array}{l}\text { Modern agriculture and food processing; Health-related and health- } \\
\text { oriented tourism. }\end{array}$ \\
\hline $\begin{array}{l}\text { Warmińsko- } \\
\text { mazurskie }\end{array}$ & $\begin{array}{l}\text { High quality food; } \\
\text { Water economy. }\end{array}$ \\
\hline Wielkopolskie & $\begin{array}{l}\text { Initial specializations: food production - agricultural production, } \\
\text { food processing, biotechnology, agricultural sciences; } \\
\text { Specializations to be consulted: quality of life - modern medical and } \\
\text { environmental technologies. }\end{array}$ \\
\hline Zachodniopomorskie & Bioeconomy; Tourism and health. \\
\hline
\end{tabular}

Source: Own elaboration based on Wyznaczanie... 2014. 
The report drawn up in 2014 by the World Bank and regarding the review of the national and regional research and innovation strategies for smart specialization (RIS3) in Poland ${ }^{31}$ indicates the following areas which need to be improved:

- systems of research and innovation strategies for smart specialization at the national and regional level should form a coherent whole;

- the proposed new strategic framework does not go sufficiently beyond the current approach known from the financial perspective of the European union in the years 2007-2013 which put an emphasis mainly on the absorption of inputs and not on the outputs;

- the scope of the activities assigned to the national, macro-regional and regional level, including the scope of responsibility, is not clearly defined and differentiated;

- more attention should be paid to building confidence and improving communication between the central government and local government authorities and to strengthening the potential of institutions operating at all three levels of authority.

A key question regarding the RIS and related smart specializations is how they contribute to innovativeness of the regions. Unfortunately, so far, the existing efforts for the development of innovativeness in Poland have brought little results. Poland comes off averagely when compared to other EU countries. Alarming is the fact that innovativeness in our country, according to the European Commission estimates, is even decreasing, from 58\% in 2007 to $56 \%$ in 2014 [European Commission 2015]. Paradoxically, an analysis carried out by the Deloitte company [W czym... 2013] showed that the theoretical and formal preparation of the innovativeness strategy in Poland turns out to be the most developed among the five analyzed areas and does not deviate in terms of its level from the best innovators in Europe. The average for all 16 voivodeship was almost six points in the ten point scale and the best region scored 8.3 points. Assuming the relationship between the RIS and the state of development of the innovation system, such a good rating of the RIS would point to the fairly high development of the latter. In the Deloitte analysis, the average for all regions was, however, quite low and amounted to 4.1 and the leader was given 5.7 points. So, it should be concluded that the regions have just started building an effective system to support innovation.

\footnotetext{
${ }^{31} \mathrm{http} / /$ www.worldbank.org/pl/news/press-release/2014/04/04/world-bank-advises-on-howto-improve-innovation-strategies-for-smart-specialization-in-poland (Accessed: 15.11.2015).
} 
Based on the results of this analysis the assessment of progress in the development of innovativeness systems in the regions by 2013 could be summarized as presented in Table 4.2.

Table 4.2. Level of progress in the development of regional innovation systems in Poland

\begin{tabular}{|l|l|}
\hline \multicolumn{1}{|c|}{ Evaluated area } & \multicolumn{1}{c|}{ Description of the progress } \\
\hline $\begin{array}{l}\text { System and involved } \\
\text { institutions }\end{array}$ & $\begin{array}{l}\text { Selected regions have defined a system to support key clusters in the } \\
\text { region, built a technology transfer system, collected the information } \\
\text { about available sources of financing and created a network of } \\
\text { coordinated business environment institutions }\end{array}$ \\
\hline $\begin{array}{l}\text { Division of tasks and } \\
\text { responsibilities }\end{array}$ & $\begin{array}{l}\text { Most of the regions are at the stage of identifying the institutions and } \\
\text { determining the scope of responsibilities of these institutions } \\
\text { resulting from the operational and strategic objectives of the RIS. } \\
\text { Monitoring and measurement of the effects of the institutions' } \\
\text { activities is carried out in few regions }\end{array}$ \\
\hline $\begin{array}{l}\text { Internal processes in } \\
\text { the system }\end{array}$ & $\begin{array}{l}\text { The regions have defined internal processes in the system to } \\
\text { a negligible extent }\end{array}$ \\
\hline $\begin{array}{l}\text { Projects/initiatives } \\
\text { taken jointly } \\
\text { within the system }\end{array}$ & $\begin{array}{l}\text { Most of the regions have just started system cooperation at the } \\
\text { regional level (between institutions) and cooperation as part of } \\
\text { national and international projects }\end{array}$ \\
\hline
\end{tabular}

Source: Own elaboration based on W czym... 2013.

In turn, the studies carried out by the PARP [Regionalne... 2013] show that in general the low level of innovativeness in Poland is accompanied by a strong differentiation among various regions. Table 4.3. contains the rankings of the individual voivodeships based on four selected indicators of innovativeness such as: share of net revenues from sale of innovative products in total net revenues from sale in percent (1), percentage of enterprises which have introduced new or significantly improved products (2), number of reported inventions per one million inhabitants (3), and number of patents granted per one million inhabitants (4).

The first place (ordered from the highest value of the general synthetic indicator of innovativeness - an aggregate of the four indicators described above), is occupied by the Mazowieckie Voivodeship. The second cluster is formed by the Śląskie and Dolnośląskie Voivodeships. The slightly lower places are occupied by the Małopolskie, Pomorskie and Podkarpackie Voivodeships. The next class is formed by the Wielkopolskie and Łódzkie Voivodeships. The largest group is the fifth group, made of five voivodeships: Opolskie, Kujawsko-Pomorskie, Lubelskie, Świętokrzyskie and Podlaskie. The lowest potential for innovativeness is characteristic of the last two groups. The first one consists of 
the Lubuskie and Warmińsko-Mazurskie Voivodeships. On the other hand, the greatest distance from the leader of the innovativeness ranking is characteristic of the Zachodniopomorskie Voivodeship. The size of the innovative potential of the individual voivodeships is significantly associated with their general level of the economic development as measured by the GDP value.

Table 4.3. Ranking of innovativeness of the voivodeships

\begin{tabular}{|l|r|r|r|r|r|r|r|r|}
\hline \multirow{2}{*}{ Voivodeship } & \multicolumn{2}{|c|}{ Indicator 1 } & \multicolumn{2}{c|}{ Indicator 2 } & \multicolumn{2}{c|}{ Indicator 3 } & \multicolumn{2}{c|}{ Indicator 4 } \\
\cline { 2 - 10 } & \multicolumn{1}{|c}{ V } & \multicolumn{1}{c|}{ R } & \multicolumn{1}{c|}{ V } & \multicolumn{1}{c|}{ R } & \multicolumn{1}{c|}{ V } & \multicolumn{1}{c|}{ R } & \multicolumn{1}{c|}{ R } \\
\hline Dolnośląskie & 6.0 & 13 & 14.9 & 2 & 99.8 & 2 & 59 & 2 \\
\hline Kujawsko-pomorskie & 13.5 & 3 & 12.9 & 8 & 55.6 & 11 & 26 & 11 \\
\hline Lubelskie & 6.1 & 9 & 12.8 & 9 & 22.8 & 16 & 28 & 10 \\
\hline Lubuskie & 7.4 & 12 & 13.6 & 5 & 63.5 & 10 & 18 & 14 \\
\hline Łódzkie & 6.7 & 11 & 9.8 & 15 & 69.6 & 8 & 45 & 4 \\
\hline Małopolskie & 10.4 & 6 & 12.3 & 11 & 78.2 & 6 & 43 & 5 \\
\hline Mazowieckie & 14.8 & 2 & 11.3 & 14 & 123.3 & 1 & 65 & 1 \\
\hline Opolskie & 5.9 & 15 & 14.2 & 4 & 72.7 & 7 & 33 & 7 \\
\hline Podkarpackie & 11.0 & 5 & 17.9 & 1 & 33.3 & 14 & 21 & 13 \\
\hline Podlaskie & 9.8 & 7 & 13.3 & 6 & 42.0 & 12 & 13 & 15 \\
\hline Pomorskie & 23.4 & 1 & 13.1 & 7 & 96.9 & 3 & 35 & 6 \\
\hline Śląskie & 7.1 & 10 & 14.5 & 3 & 80.6 & 5 & 59 & 2 \\
\hline Śiętokrzyskie & 6.0 & 114 & 12.0 & 12 & 37.0 & 13 & 29 & 9 \\
\hline Warmińsko-mazurskie & 11.4 & 4 & 12.7 & 10 & 24.5 & 15 & 6 & 16 \\
\hline Wielkopolskie & 8.0 & 8 & 11.4 & 13 & 82.7 & 4 & 31 & 8 \\
\hline Zachodniopomorskie & 5.4 & 16 & 8.9 & 16 & 64.4 & 9 & 25 & 12 \\
\hline
\end{tabular}

$\mathrm{V}$ - value of indicator; $\mathrm{R}$ - rank.

Source: Regionalne... 2013.

The analysis carried out indicates the lack of relationships between the quality of strategy papers and activities related to preparing and implementing the RIS and innovativeness of the regions in Poland. The Regional Innovation Strategies regarded as the most consistent with the regional development strategy were those of the following voivodeships: Kujawsko-Pomorskie, Warmińsko-Mazurskie, Świętokrzyskie and Zachodniopomorskie, i.e. the voivodeships characterised by low or just average innovativeness ${ }^{32}$. So it is clear that the level of innovativeness and the effective use of the existing potential do not depend on the RIS, but on many other factors. Their importance can be highlighted using results of a survey conducted among 1280 enterprises $^{33}$. Based on that surveys the following ranking of factors determining innovativeness of the region was elaborated:

\footnotetext{
${ }^{32}$ Regional innovation systems in Poland - study report, PAED, Warsaw, January 2013.

${ }^{33}$ Regional innovation systems in Poland - study report, PAED, Warsaw, January 2013.
} 
- entrepreneurs' awareness of a need to introduce innovations in companies $63 \%$;

- transfer of knowledge from science to technology - $44 \%$;

- potential of the research and development sector in the region $-36 \%$;

- activities of local self-government removing barriers to cooperation between enterprises and scientific institutions $-27 \%$;

- potential of the science sector in the region $-23 \%$;

- providing sources of financing for the objectives of the Regional Innovation Strategy $-22 \%$;

- effective operations of institutions of the innovative business environment such as technology transfer centers, technology parks, business incubators, etc. $-17 \%$;

- development of innovative sectors in the regions such as: ICT sector, biotechnology, electronics, automation, nanotechnology, etc. $-14 \%$;

- access to high risk capital e.g. venture capital in the region $-11 \%$;

- effective management of implementing the Regional Innovation Strategy $8 \%$;

- developed document in a form of the Regional Innovation Strategy - 6\%;

- functioning of the system of cooperation among entities forming the regional innovation system in the region $-5 \%$;

- including into the regional activities of the guidelines of new European strategies $-2 \%$;

- effective monitoring and assessment of the results of the innovation-oriented policy $-2 \%$.

\subsection{Potential increase in innovativeness of the agri-food sector and rural areas based on the existing RIS}

In case of innovativeness of a sector or industry, account shall be taken of the structure and rate of their development in relation to developing new products, and from the point of view of a relationship between enterprises operating in the industry, and other organizations cooperating with them. The industry system of innovation and production is based on various organizations and their (market and non-market) interactions participating in the development, adoption and use of technologies for the design, manufacture and use of innovative products included in the given industry [Weresa 2014].

The agri-food sector belongs to the sectors characterized by a low level of innovativeness. This results from the specific nature of manufacturing processes, 
type of used materials or technologies. At the same time, this sector is one of the more important areas of the economy, due to the volume of production and export and the number of employees. According to Evenson and Pingali [2007], only about $1 \%$ of innovations comes from the agricultural sector, while more than $80 \%$ of agricultural patents are delivered by other sectors, such as chemical, pharmaceutical or machinery. The studies by Józwiak et al. [2012] showed that farmers in Polish holdings in the years 1995-2009 allocated their funds for the purchase of machinery, tractors and equipment. A similar situation occurred in case of the Polish food industry. According to Szczepaniak [2014], the share of expenses for the R\&D activity and the purchase of ready knowledge in a form of patents, licences or technical services in the total innovation inputs was from 1 to $5 \%$ in the years 2003 and 2011. The dominant expenses were those for technical machinery and equipment, tools and means of transport.

Taking into account the individual voivodeships, a strong leader are food industry enterprises located in the Mazowieckie Voivodeship, which in the years 2005-2011 allocated about $40 \%$ of the nationwide pool of resources spent on the innovation activity in this sector. The lowest position was occupied by enterprises in the Świętokrzyskie Voivodeship (0.8\%) [Grzybowska 2013]. The ranking of voivodeships changes when we take into account the share of expenses for the investment activity in the food industry in relation to industrial processing. The leading role is played by the Podlaskie Voivodeship, but also by the Lubelskie, Opolskie and Mazowieckie Voivodeships, which incur significant inputs on the food industry in relation to their industrial processing. In these voivodeships, the production of food products has a significant impact on the economy of the region.

It is worth stressing that the voivodeships allocating higher inputs for the investment activity of the food industry in relation to industrial processing (Podlaskie, Lubelskie, Opolskie), are located in the middle of the ranking of the voivodeships with regard to the synthetic indicator of innovativeness of the regions. The exception is the Mazowieckie Voivodeship, occupying top positions in both lists of the Polish voivodeships. This would confirm a hypothesis that the regions with the lower innovation capacity are based mainly on traditional sectors.

In the existing studies carried out on the RIS, the sectoral/branch issues were rarely analyzed as separate research problems. This results mainly from the difficulties associated with the measurement of innovativeness in sectors and industries. Particularly, in assessing the first RIS the relationships with the agrifood sector were not raised, the focus was primarily on an analysis of the process of creating and implementing the strategy. More relationships with the agrifood sector may be found in the RIS3 based on smart specializations. Although 
the assumption of this concept is to depart from sectoral activities in favor of creating integrated, cross-sectoral innovation systems, many Polish regions indicated the bioeconomy or food sector as a leading specialization.

A good example might be the Lubelskie Voivodeship, which admittedly did not indicate any specific industries, but placed them within the manufacturing chain of value added. The key specialization has been the bioeconomy, based on the production of high-quality food (from the primary production through processing, distribution and consumption). As the complementary specialization, medicine and health, covering, inter alia, functional food, has been selected. In turn, the low-carbon energy industry was regarded as the emerging specialization with such value chain elements as acquisition of energy raw materials, production and storage of energy, and distribution and sale of energy. Finally, IT and automation were identified as a supporting specialization. Clearly some of these areas overlap and are complementary to each other covering those activity which are justified in traditional types of the economic and scientific-technological specialization of the voivodeship. In addition, these areas of economic activities have already gained or may gain, in the future, a competitive advantage on a national and/or international scale. They are characterized by the existence of well-developed cluster initiatives and have a potential to form the critical mass necessary to launch a new path of development for the voivodeship.

It should be stressed that almost $77 \%$ of the production sold of the voivodeship's industry comes from the sectors belonging to the low and medium-low technology sectors. Among the low-technology sectors, the leading role is played by: agri-food processing; production of tobacco products; production of textile and clothing products; production of wood (including furniture) and paper products. Among the medium-low technology sectors, the leading role is played by: reproduction of recorded media; manufacture and processing of coke and refined petroleum products; production of rubber and plastic products; production of ready-to-use metal products; repair, maintenance and installation of machinery and equipment. The high-technology sectors (mainly the production of pharmaceuticals and medicines, production of computers, electronic and optical products and production of helicopters) generate only about $2 \%$ of the production sold. Also, the export structure of the Lubelskie Voivodeship points to the advantage of products from the low (39\%) and medium-high $(60 \%)$ technology sectors. Noteworthy is the small (about 1\%) share of goods from the high-technology group with a high degree of processing in the export. The consequence of this is the very low innovation position of the voivodeship on an international scale. 
It is also worth mentioning that in the Lubelskie Voivodeship all key branches of the agri-food industry are developing, including processing of vegetables and fruits, sugar factories (e.g. in Krasnystaw and Strzyżów), dairy industry (inter alia in Radzyń Chełmiński, Chełm, Krasnystaw, Piaski, Ryki), meat processing (e.g. in Łuków, Wierzejki, Lublin, Rossosz), brewing industry (e.g. Browary Lubelskie Perła in Lublin), grain/milling companies (e.g. Zamojskie Zakłady Zbożowe), production of pasta (e.g. Lubella S.A., As Babuni), herbal industry (e.g. Herbapol Lublin S.A.), tobacco industry (e.g. Lubelskie Zakłady Tytoniowe) and production of beverages (e.g. Nałęczów Zdrój) and spirits (e.g. Stock Polska). The development of agri-food processing is characterised by the high growth rate and high, i.e. $25 \%$ (4.4\%, higher than the national average and the greatest among the Eastern Polish voivodeships) share of the export in the total sales volume. In the food industry, also four, out of eighteen, cluster initiatives are functioning (Dolina Ekologicznej Żywności, Stowarzyszenie Lubelski Klaster Branży Spożywczej, Lubelski Cebularz) [Regionalna... 2014]. So we may assume that the selection of the bioeconomy as smart specialization is correct and corresponds to the needs of the Lubelskie Voivodeship.

The RIS of the voivodeship is based on an optimistic development scenario, assuming the absence of adverse external and internal factors, such as a new wave of financial and economic crisis, growing political tensions in the European Union and the reduction in the amount of funds allocated for the Cohesion Policy, depletion of the existing simple development reserves. In order to prevent this risk, the RIS provides for a range of development-oriented activities, which are to promote the acceleration of the economic development, i.e. [Regionalna... 2014]:

- more balanced use of the supply and demand support innovation instruments and greater involvement of private funds;

- introduction of a new instrument (pilot programs), which is to serve the systematic search for new solutions (directions and types of activities and specific projects), better and better adapting to the directions and forms of intervention to the changing needs associated with the development of regional areas of smart specializations.

Interesting initiatives going beyond the RIS are supraregional strategies, as, for example, "Socio-economic development strategy for Eastern Poland by 2020" covering five voivodeships: Lubelskie, Podkarpackie, Podlaskie, Świętokrzyskie and Warmińsko-Mazurskie. A common denominator for the Eastern Poland voivodeships is their socio-economic situation. This is indicated 
by the convergent development indicators. In accordance with the strategy, by 2020, the development of the macro-region should consist mainly in ${ }^{34}$ :

- enhancing innovativeness of the economy;

- development of skills of the employed, so that they corresponded to the needs of the modern economy and prevention of social exclusion;

- building modern transport and power infrastructure.

Undoubtedly, a similar economic specialization of the entire region, based on the agri-food sector and other economic specializations deeply rooted in the macro-region, may bring significant benefits in the long term. It is advisable to focus support on the branches in which we observe the development based on the endogenous factors, especially where there is already a sufficient critical mass in terms of the concentration of companies, staff with appropriate competences and skills and associated institutions. The supraregional development support towards the regular improvement in innovativeness will bring better effects than building advantages based on new specializations which are not rooted yet. In addition, it is important to permanently seek the possibilities of developing and commercializing innovations at the meeting point of traditional and advanced industries such as, e.g. agri-food sector and biotechnology [Słodowa-Hełpa 2013].

Speaking of the implementation of the bioeconomy as a smart specialization, in case of Poland it is worth taking into account such factors as human capital, which is of crucial importance for the conditions and the quality of research and activities in the area of bioeconomy. Important factors are also finance and the fiscal system applied, which largely determines the availability of solutions resulting from science and research. The current financing system, at least in Poland, does not meet the standards satisfactory not only to the academic environment, but also to business. It should be predicted that the legal status and the rules for financing research and implementing its results in the area of the bioeconomy will require changes. This concerns mainly access to technical infrastructure and tools of modern communication. The efficiency of the development of the bioeconomy is also specified by the rules of the pursued policies, including, in particular, the consistency of the scientific policy with the economic policies. Therefore, what is important is the integration of the pursued policies, including the policies affecting the functioning of financing for science, knowledge transfer and innovations.

It is interesting to what extent the necessity to identify smart specializations will actually contribute to the growth in innovativeness of the agri-food

34 https://www.mir.gov.pl/strony/zadania/polityka-rozwoju-kraju/zarzadzanie-rozwojem$\mathrm{kraju} /$ strategie-ponadregionalne/ (Accessed: 01.12.2015). 
sector and rural areas. The benefits may include the identification of the current strengths and weaknesses of the given area, a need to create a long-term vision of the regional development, commitment and cooperation of many partners in the public sector, the world of science and business environment. However, the implementation of the concept of smart specializations also entails difficulties and potential threats. Smart specializations in the highly developed regions are usually based on innovation branches, from the so-called high-technology group, in turn, less wealthy regions are based on traditional branches, from the so-called low technology group. Thus, the differences among the regions may become even deeper. The regions may imitate the development profile of other regions, while not seeking their own comparative advantages, or vice versa, concentrate on supporting traditional industries and fixed interest groups, without thinking of the long-term development. According to Kukliński [Transformacja... 2012], the regions must avoid "strategic blindness". Smart specializations are to help the regions achieve the leadership position in certain fields, but it is particularly difficult for the regions with the low level of innovativeness.

The concentration of measures on a small number of key research and development and innovation priorities, which are regional smart specializations, entails the risk of failure to achieve the objectives assumed in the RIS because of the too general or too narrow or too short-sighted definition of regional areas of smart specialization and/or stopping state aid for the relevant endogenous development potentials, currently lying outside the areas of smart specialization. In connection with that, the previously mentioned "Regional Innovation Strategy for the Lubelskie Voivodeship by 2020 " provides for the following activities [Regionalna... 2014]:

- stimulating effective networks of business environment institutions, market services and financial markets, which are essential to the growth in the demand for innovations on the part of all companies, both those located within and outside the regional and supraregional areas of smart specialization;

- support for the endogenous development potentials lying outside the regional areas of smart specialization, by including the voivodeship into the global chain of innovation and the development of intraregional, interregional (also as part of Eastern Poland) and international cooperation;

- possibility of redefining, in the subsequent years, the regional areas of smart specialization (extending or narrowing and adding new) without a need to revise the strategy itself. 


\subsection{Impact of the RIS on the agri-food sector and rural areas in the future}

At the present stage, the assessment of the impact of the RIS on the agrifood sector and rural areas is rather difficult. The first innovation strategies contained too many priorities, and if the above-mentioned sector was mentioned, this took place among others. An additional problem is the absence of monitoring and evaluation of the then RIS. We may assume that an obligation to introduce and assess smart specializations should significantly facilitate analyzing the impact of the RIS on the agri-food sector. However, the concept of smart specializations is new and it takes time to obtain the appropriate information for research.

Taking into account the results of the previous analyses, we may try to assess the impact of the RIS on innovativeness in the region, and in this indirect manner, also on the agri-food sector. As we have previously mentioned, the RIS should strengthen the innovation systems, by helping the regional authorities and other regional development organizations in defining and implementing these systems. Paradoxically, the results of the previous analyses indicate the absence of relationships between the quality of strategy papers and activities related to preparing and implementing the RIS and innovativeness of the regions in Poland.

In turn, the assessment based on smart specializations may also prove to be ineffective, because they already assume the departure from the sectoral approach to innovativeness for the benefit of integrated and cross-sectoral activities. Therefore, the regions offer such specializations, as e.g. bio-economy, whose range covers many sectors and industries. A lot depends on the adopted rules for monitoring and evaluation of the RIS, and on their consistent application. So far, as part of the work the RIS3, the regions adopted various concepts, depending on the degree of progress in the work on updating the strategy, awareness of competitive advantages or applied methods and techniques to identify the innovation potential. As a consequence, each region has a different vision as for the course of the monitoring and evaluation processes. Some of the regions see only a need to monitor the RIS, its objectives and activities. Other, in turn, see a need to monitor also implementation plans relating to smart specializations. And others intend to monitor the disbursement of funds from the Regional Operational Programmes that support smart specializations at the level of the region and the effects of their measures [Wyznaczanie... 2014]. Therefore, we need one model of coherent monitoring and evaluation of the RIS in the future in Poland, which would take into account not only indicators of assessing 
the effectiveness of implementing the RIS, but also innovativeness of the sectors/industries.

Moreover, a major problem in the future may be the fact that some voivodeships selected traditional, less innovative specializations, including the agrifood sector. Then, there is then a risk of a slowdown in their economic development in the future. Therefore, a good initiative is to create supraregional innovation strategies, forming a common innovation development system based on the endogenous potentials of the individual regions.

The existing results of the studies on the RIS in Poland show what areas of innovativeness in the regions are the weakest and should be improved in the future (Table 4.4).

Table 4.4. Benchmarking assessment of major areas of innovativeness in the regions

\begin{tabular}{|l|c|c|}
\hline \multirow{2}{*}{\multicolumn{1}{|c|}{ Innovativeness area }} & \multicolumn{2}{c|}{ Results (scale 0-10 points) } \\
\cline { 2 - 3 } & $\begin{array}{c}\text { Average for all } \\
\text { voivodeships }\end{array}$ & The top voivodeship \\
\hline Innovativeness policy/RIS & 5.9 & 8.29 \\
\hline Regional innovation system & 4.1 & 5.71 \\
\hline $\begin{array}{l}\text { Results of pursuing the innovation policy within } \\
\text { the framework the RIS }\end{array}$ & 2.7 & 5.03 \\
\hline RIS management at the Marshal's Office & 5.4 & 6.94 \\
\hline Resources in the region & 3.8 & 5.81 \\
\hline
\end{tabular}

Source: Own elaboration based on W czym... 2013.

According to the previously mentioned analysis by the Delloitte company, a weakness of Polish innovativeness is the quality of the research system, particularly the transfer of scientific achievements to enterprises. A barrier to the creation of innovations is also low social capital, and this, in turn, gives rise to the consequences in a form of excessive bureaucratisation. It is also necessary to increase the operationability of the RIS by linking them with regional development strategies, which will increase the actual impact of the RIS on the growth in innovativeness of the regions. What is also recommended is the better functioning of the mechanisms for the exchange of ideas, cooperation and knowledge transfer among the partners, in line with the rules of partnership and participation of key RIS stakeholders [ $W$ czym... 2013].

Unfortunately, both the past and present RIS lack the references to rural areas. We may only presume that if they apply to agricultural regions, they also refer to rural areas. But it should be stressed that Polish countryside is less and less dependent on agriculture. Nowadays, the rural economy is a mix of local economic entities representing all three economic sectors: agriculture, industry, 
including processing and market and public services. The number of people for whom agriculture is the only or main source of subsistence is only 1.1 million ( $7 \%$ of the rural population). According to the estimates, about $25 \%$ of enterprises registered with the REGON system operate in rural areas (of 1.7 million of active companies registered in Poland in 2011). Non-agricultural rural enterprises are rarely large entities which saw their chance of development in the location in rural areas. Dominant are, first of all, micro-enterprises which do not employ workers [Nurzyńska and Poczta 2014].

The studies on innovativeness of the aforementioned Lubelskie Voivodeship show that the innovative activity is a realm of medium-sized enterprises. But they are supported by large companies characterized by good relationships with suppliers and customers, provided that they are located outside the region. The search for partners at home or abroad results mainly from the deficit of knowledge in the region, while providing a channel for the transfer of knowledge from outside the region. Innovative enterprises produce a multiplier effect by launching the regional development processes. A significant role is also played by the fact that the local authorities and institutions build business climate for the economic activity and production and service innovativeness in the region [Brzeziński and Mietlicka 2013]. As previously mentioned, even the best RIS is not enough. It is necessary to use the positive synergistic effects, derived from the exchange of knowledge and experience and the interaction of networks of various enterprises. 


\section{Summary}

Innovations constitute a complex and multidimensional phenomenon bringing about numerous economic implications. Multidimensionality of innovations results mainly from diversity of their character (product, process, organizational, marketing, and communication innovations) and relatively assessed degree of novelty (company level, market level, or world level). These basic dimensions of innovations overlap with the time dimension related to their development, implementation, and pace of dissemination, what additionally complicates the measurement, and consequently evaluation of innovativeness of the companies, branches, sectors, and whole economies. There are plenty of methodological and analytical solutions in this area, among which the approach used by the European Commission called Innovation Union Scoreboard, allowing to systematically compare innovativeness of the EU countries and regions, deserves a special attention.

According to the recent Innovation Union Scoreboard Reports Poland is a moderate innovator. All considered indicators were lower than the EU averages, what resulted in the rank below the 20 among the EU countries. What is additionally worrying, is the observed in the last few years decline in the relative level of innovativeness, and in the number of marketing and organizational innovations. This state of affairs translates into assessment of innovativeness of the Polish agri-food sector, however, situation in this sector should not be treated as identical with the situation in the whole economy. In the last few decades Polish agri-food has undergone a tremendous transformation and adjustment to be able to compete within the enlarged EU. At present, Polish food industry is perceived as one of the most modern among the EU member states, it continues to rapidly develop showing a high resilience to crisis events, and its economic and financial standings are considered as good ones. Also, international competitiveness of the Polish food producers is regarded as high. They compete successfully in the international markets with attractive prices and high quality of the offered products, and so far, they focus mostly just on these factors to increase their competitiveness. Much more rarely they look for improving their competitive positions through introduction of new technologies and/or products, organizational and marketing innovations.

Paradoxically, in the context of innovations as a driver of monopolistic competition, Polish agri-food sector seems to be almost perfectly predestined to introduce product and marketing innovations due to its existing market structures. Relatively low level of market concentration and heterogeneous consumer expectations are in favor of product differentiation and creation of strong brands, 
which are foundations of the monopolistic competition. However, one needs to be aware that development and introduction of innovations in a given sector of the economy is determined firstly by exogenous factors independent of the sector itself, such as patenting and public R\&D financing systems, and then endogenous factors as, for example, market structure and ability to adopt innovations.

Market incentives are of key importance, but in the current Polish conditions are not yet sufficiently strong. The sector follows the world food markets patterns as an effect of globalization of the producer innovative trends. A careful attention to the changing occurrence of these trends has to be paid because, as it was found out, its importance is related to country income levels. It means that the nature of food product innovations may evolve together with the income path of a country.

Innovativeness of enterprises including those operating in the food sector is determined by a set of factors. Market incentives to develop and implement innovations are of key importance, however in Polish conditions they seem to be not strong enough. Simply, as long as market success can be achieved in a conventional way (good quality and affordable price) developing innovations is not a priority. Weak linkages between parts of the food marketing chain, insufficient cooperation between business and academia, and shortage of public financing to support innovative activities are problems as well. A low level of innovation performance of the Polish agri-food sector is also caused by internal factors, such as: low awareness of innovation needs among many entrepreneurs (especially in small and medium enterprises), little creativity of the personnel, lack of willingness to take risk and cooperate in the area of innovation activities (e.g. within food clusters), or insufficient financial resources at the enterprise level.

Increase in innovativeness is on the top of the EU policy agenda in 20142020. During this period Poland is supposed to receive 82.5 billion euros of the EU funding, of which considerable part can be spent on development of innovativeness including strengthening the institutional system of innovation transfer. The challenge is to design appropriate policy tools helping correct market failures resulting from non-competitive company behaviors and information asymmetry. Supporting entrepreneurship through subsidizing transfer of knowledge without a strong enough competition may bring limited effects, if any, because enterprises will not have adequate incentives to use it.

When designing institutional support for innovation transfer system it is important to take into account interactions between existing forms of backing economic activities and their new forms such as public spending on specific innovative activities. Such policies should be complementary, especially under hardly existing competition, where financial transfers can lead to establishing 
new entities motivating existing ones to improve efficiency through, for instance, implementation of innovative solutions. A positive role in this regard can be played by well formulated and effectively executed Regional Innovation Strategies (RIS), especially those based on the properly understood concept of smart specializations. In the regions with favorable conditions for competitive development of the food sector this policy solution should be used in order to enhance innovativeness of enterprises operating in this sector. Unfortunately, analysis of the RIS documents does not lead to optimistic observations regarding their potential impact on innovation performance of the Polish food sector. Also, an assessment of the RIS at this stage is difficult because of lack of monitoring and evaluation. Smart specializations identified in the regions are rather generally and superficially understood with little focus on the agri-food sector activities. In most cases the declared smart specializations are not specific enough to see clear opportunities for improvement of innovation performance of that sector. 


\section{Bibliography}

1. Agénor P., Canuto O., 2012: Middle-income growth traps. Policy Research Working Paper 6210, World Bank.

2. Aghion P., Jaravel X., 2015: Knowledge spillovers, innovation and growth. The Economic Journal, 125 (March), pp. 533-573.

3. Ajefu J.B., Barde F., 2015: Market efficiency and government intervention revisited: what do recent evidence tell us? Journal of International Business and Economics, Vol. 3, No. 1, pp. 20-23.

4. Albury D., 2005: Fostering innovation in public services. Public Money \& Management, Vol. 25, Issue 1, pp. 51-56.

5. Alińska A., Gajewski M., Górecki M., Kopytek M., Mika M., Rogowiecki P., Sabarańska K., Szczucki J., 2015: Rynek funduszy pożyczkowych w Polsce. Raport 2014. Polski Związek Funduszy Pożyczkowych, Warsaw.

6. Antle J.M., 1999: The new economics of agriculture. American Journal of Agricultural Economics, Vol. 81, No. 5, pp. 993-1010.

7. Arrow K., 1962: Economic welfare and the allocation of resources for invention. In: Nelson R., (ed.), The rate and direction of inventive activity: economic and social factors. Princeton University Press, Princeton.

8. Arundel A., Es-Sadki N., Barjak F., Perrett P., Samuel O., Lilischkis S., 2013: Knowledge Transfer Study 2010-2012. https://ec.europa.eu/research /innovation-union/pdf/knowledge_transfer_2010-2012_report.pdf (accessed: 30.10.2015).

9. Barczak B., Białkiewicz J., 2012: Źródła efektów synergicznych w sieciach organizacyjnych. In: Borowiecki R., Rojek T., (eds.), Wspótpraca międzyorganizacyjna $w$ działalności przedsiębiorstw: klastry, allianse, sieci. Cracow University of Economics, Cracow.

10. Baruk J., 2002: Innowacje, kultura innowacyjna i poziom innowacyjności przedsiębiorstw przemysłowych. Gospodarka Narodowa, 11-12, pp. 78-94.

11. Bąkowski A., 2015: Preinkubatory i akademickie incubatory przedsiębiorczości. In: Bąkowski A., Mażewska M., (eds.), Ośrodki innowacji i przedsiębiorczości w Polsce. Raport 2014. Business and Innovation Centers Association in Poland, Poznan-Warsaw, pp. 55-69.

12. Bąkowski A., Mażewska M., (eds.), Ośrodki innowacji i przedsiębiorczości $w$ Polsce. Raport 2014. Business and Innovation Centers Association in Poland, Poznan-Warsaw.

13. Bąkowski A., Mażewska M., Hołub-Iwan J., Tomaszewski M., Tórz A., Stawiarz R., 2014. Ośrodki innowacji w Polsce ( $z$ uwzględnieniem inkubatorów przedsiębiorczości). Raport z badania 2014. Polish Agency for Enterprise Development, Warsaw. 
14. Bednarz J., 2011: Klasyczne a nowe teorie przewagi konkurencyjnej przedsiębiorstw. Prace i Materiały Instytutu Handlu Zagranicznego Uniwersytetu Gdańskiego, No. 30, Wydawnictwo Uniwersytetu Gdańskiego, Gdańsk, pp. 112-122.

15. Bengtsson M., Kock S., 2000: Coopetition in business networks - to cooperate and compete simultaneously. Industrial Marketing Management, No. 29(1), pp. 411-426.

16. Boguski J., 2010: Regionalne Systemy Innowacji. In: Białoń L., (ed.), Zarządzanie działalnościa innowacyjną. Placet, Warsaw.

17. Bojewska B., 2011: Tworzenie nowych wartości w przedsiębiorstwie z nastawieniem na wzrost i rozwój. In: Strużycki M., (ed.), Przedsiębiorstwo, region, rozwój. Difin, Warsaw.

18. Book of Lists 2015. Valkea Media, Warsaw.

19. Boschma R., 2005: Proximity and innovation: a critical assessment. Regional Studies, Vol. 39, Issue 1, pp. 61-74.

20. Brzeziński M., Mietlicka D., 2013: Innowacyjność regionów Polski Wschodniej. Wyższa Szkoła Ekonomii i Innowacji w Lublinie, Lublin.

21. Brzozowska K., 2008: Fundusze zalażkowe w rozwoju przedsiębiorczości $w$ Polsce. Ekonomika i Organizacja Gospodarki Żywnościowej, No. 65, pp. 85-94.

22. Calvert R., 1964: The encyclopedia of patent practice and invention management. Reinhold, New York.

23. Carlton D., Perloff J., 2005: Modern industrial organization. Pearson, New York.

24. Chodyński A., 2012: Sieciowość w koncepcjach biznesu - aspekty społeczne i ekologiczne. In: Chodyński A., (ed.), Zarzadzanie odpowiedzialnym rozwojem przedsiębiorstwa. Oficyna Wydawnicza AFM, Cracow.

25. Christensen C., 1997: The innovator's dilemma: when new technologies cause great firms to fail. Harvard Business Review Press, Boston.

26. Ciesielska D.A., Radło M.J., 2014: Determinanty wejścia w pułapkę średniego dochodu: perspektywa Polski. Kwartalnik Nauk o Przedsiębiorstwie, Vol. 31, No. 2, pp. 5-13.

27. Cordato R.E., 1980: The Austrian theory of efficiency and the role of government. The Journal of Libertarian Studies, Vol. IV. No. 4, 99. 393-403.

28. Czakon W., 2015: Sieci międzyorganizacyjne w naukach o zarządzaniu w kierunku sieciowych modeli biznesu. Studia Ekonomiczne. Zeszyty Naukowe Uniwersytetu Ekonomicznego w Katowicach, No. 217, pp. 9-18.

29. Dembinski P.H., 2009: Very large enterprises, focal firms and global value chains. Revista de Economía Mundial, Issue 23, pp. 107-130. 
30. Dhanaraj C., Parkhe A., 2006: Orchestrating innovation networks. Academy of Management Review, Vol. 31, Issue 3, pp. 659-669.

31. Dobski P., 2005: Rola partnerstwa rynkowego w budowaniu przewagi konkurencyjnej. In: Marketing ustug profesjonalnych. Wspótpraca na konkurencyjnym rynku ustug profesjonalnych. Wydawnictwo Akademii Ekonomicznej w Poznaniu, Poznań.

32. Downes L., Nunes P., 2014: Bing bang disruption. strategy in the age of devastating innovations. Portfolio Penguin, New York.

33. Doz Y., Santos J., Williamson P., 2001: From global to metanational. Harvard Business School Press, Boston.

34. Drucker P.F., 1985: Innovation and entrepreneurship. Harper, New York.

35. Drucker P.F., 1992: Innowacja i przedsiębiorczość. Praktyka i zasady. PWE, Warsaw.

36. Dutta S., Lanvin B., Wunsch-Vincent S., 2015: The Global Innovation Index. Effective Innovation Policies for Development. https://www.globalinnovationindex.org/content/page/GII-Home (Accessed: 30.11.2015).

37. Eichengreen B., Park D., Shin K., 2013: Growth slowdowns redux: new evidence on the middle-income trap. NBER Working Paper No. 18673, National Bureau of Economic Research, Cambridge.

38. Engel J., del-Palacio I., 2009: Global networks of clusters of innovation: accelerating the innovation process. Indiana University, Bloomington.

39. Eriksson A., (ed.), 2011: Postklastrowa polityka innowacji. PARP, Warsaw.

40. European Commission, 2014a: Innovation Union Scoreboard http://ec.europa.eu/growth/industry/innovation/facts-figures/scoreboards_pl (Accessed: 11.11.2015).

41. European Commission, 2014b: Polityka regionalna. Zrozumieć polityke Unii Europejskiej. http://europa.eu/pol/pdf/flipbook/pl/regional_policy_pl. pdf (Accessed: 02.11.2015).

42. European Commission, 2015: Innovation Union Scoreboard http://ec.europa.eu/growth/industry/innovation/facts-figures/scoreboards_pl (Accessed: 11.11.2015).

43. European Commission, 2017: European Innovation Scoreboard http://ec.europa.eu/growth/industry/innovation/facts-figures/scoreboards_pl (Accessed: 11.11.2017).

44. Evenson R.E., Pingali P., 2007: Handbook of Agricultural Economics. Agricultural Development: Farmers, Farm Production and Farm Markets. Vol. 3, North-Holland. 
45. Farrell J., Gallini N., 1986: Second-sourcing as a commitment: monopoly incentives to attract competition. Working Paper, 8618, University of California, Berkeley.

46. Farrell J., Saloner G., 1985: Standardization, compatibility, and innovation. Rand Journal of Economics, No. 64, pp. 70/83.

47. Feldman A.M., Serrano R., 2006: Welfare economics and social choice theory. Springer.

48. Fiedor B., 1979: Teoria innowacji. PWN, Warsaw.

49. Figiel S., 2016: Recent product innovation trends in global food markets. Competitiveness of Agro-Food and Environmental Economy, Conference Proceedings CAFEE 2016, pp. 303-311.

50. Figiel S., Kuberska D., Kufel J., 2011: Analiza uwarunkowań i stanu rozwoju klastrów rolno-żywnościowych w Polsce. IERiGŻ-PIB, Warsaw.

51. Figiel S., Kuberska D., Kufel J., 2013: Rola klastrów w konkurencyjnym rozwoju sektora rolno-żywnościowego w Polsce. IERiGŻ-PIB, Warsaw.

52. Figiel S., Kufel J., 2016: Food product innovations and the main consumer trends. Acta Scientiarum Polonorum, Oeconomica, Vol. 15, No. 3, pp. 5-14.

53. Figiel S., Kufel-Gajda J., 2017: Trends in food product innovations and the level of economic development. Economic and Environmental Studies, Vol. 17, No. 2 (42/2017), pp. 429-446.

54. Firestone O.J., 1971: Economic implications of patents. University of Ottawa Press.

55. Fisher M., 2001: Innovation, knowledge creation and systems of innovation. The Annals of Regional Science, No. 35(2).

56. Freeman Ch., 1987: Technology, policy, and economic performance: lessons from Japan. Pinter Publishers, London.

57. Freeman Ch., 1991: Networks of innovators: a synthesis of research issues. Research Policy, Vol. 20, Issue 5, pp. 499-514.

58. Gaczek W.M., 2005: Innowacyjność jako czynnik podnoszenia konkurencyjności gospodarki regionu. In: Gaczek W.M., (ed.), Innowacje w rozwoju regionu. Zeszyty Naukowe Akademii Ekonomicznej w Poznaniu, 57.

59. Gajewski M., Kubajek R., Szczucki J., 2015: Raport o stanie funduszy poręczeniowych $w$ Polsce - stan na dzień 21.12.2014 r. Krajowe Stowarzyszenie Funduszy Poręczeniowych, Warsaw.

60. Gallini N., 1984: Deterrence through market sharing: a strategic incentive for licensing. American Economic Review, No. 74, pp. 931-941.

61. Gallini N., Winter R., 1985: Licensing in the theory of innovation. Rand Journal of Economics, No. 16, pp. 237-252. 
62. Gilbert R., 2002: Antitrust for patent pools: a century of policy evolution. University of California, Berkeley, Working Paper.

63. Gilbert R., Shapiro C., 1990: Optimal patent length and breadth. Rand Journal of Economics, No. 21, pp. 106-112.

64. Gołębiowska-Tataj D., 2013: Nowe modele wspótpracy między nauka, edukacja a biznesem. Rola przedsiębiorczości w integracji Trójkąta wiedzy. IX Kongres Ekonomistów Polskich, Warszawa.

65. Gorzelak G., Bąkowski A., Kozak M., Olechnicka A., 2006: Polskie regionalne strategie innowacji: ocena i wnioski dla dalszych działań. Ministerstwo Rozwoju Regionalnego, Warsaw.

66. Gotsch M., Hipp C., Gallego J., Rubelcaba L., 2011: Sectoral innovation watch. Knowledge intensive services sector. http://www.praxis.ee/wpcontent/uploads/2014/03/sector-report-knowledge_en.pdf (Accessed on 03.11.2015)

67. Grand J., 1991: The theory of government failure. British Journal of Political Science, Vol. 21, No. 4, pp. 423-442.

68. Grossman G., Shapiro C., 1986: Research joint ventures: an antitrust analysis. Journal of Law, Economics, and Organization, No. 2, pp. 315-337.

69. Grzybowska B., 2012: Innowacyjność przemystu spożywczego w Polsce ujęcie regionalne. Wydawnictwo UWM w Olsztynie, Olsztyn.

70. Grzybowska B., 2013: Regionalna konwergencja innowacyjności przemystu spożywczego. Zagadnienia Ekonomiki Rolnej, No. 3, pp. 124-137.

71. Guide to Research and Innovation Strategies for Smart Specializations (RIS 3), 2012. http://ec.europa.eu/regional_policy/sources/docgener /presenta/smart_specialisation/smart_ris3_2012.pdf (Accessed on 14.11. 2015).

72. GUS, Bank danych lokalnych. http://stat.gov.pl/bdl/app/dane podgrup.display?p_id=660306\&p_token=0.008077228209003806 (Accessed: 15.11.2015).

73. GUS, 2014: Działalność innowacyjna przedsiębiorstw w latach 2011-2013. http://stat.gov.pl/obszary-tematyczne/nauka-i-technika-spoleczenstwoinformacyjne/nauka-i-technika/dzialalnosc-innowacyjna-przedsiebiorstww-latach-2011-2013,2,8.html (Accessed: 30.11.2015).

74. GUS, 2015: Działalność innowacyjna przedsiębiorstw w latach 2012-2014. http://stat.gov.pl/obszary-tematyczne/nauka-i-technika-spoleczenstwoinformacyjne/nauka-i-technika/dzialalnosc-innowacyjna-przedsiebiorstww-latach-2012-2014,2,13.html (Accessed: 30.11.2015).

75. GUS, 2017: Działalność innowacyjna przedsiębiorstw w latach 2014-2016. Warszawa, Szczecin. 
76. Herbener J.M., 1997: The Pareto rule and welfare economics. Review of Austrian Economics, Vo. 10, No. 1, pp. 79-106.

77. Hollanders H., van Cruysen A., 2008: Rethinking the European Innovation Scoreboard: A New Methodology for 2008-2010. http://www.eustat.eus/ elementos/ele0006100/ti_Methodology_Report_EIS_20082010/inf0006199_c.pdf (Accessed: 15.11.2015).

78. http://ec.europa.eu/research/regions/index.cfm?pg=smart_specialisation (Accessed: 10.11.2015).

79. http://innowacyjnypomysl.eu/źródł-finansowania-etapy-rozwojuprzedsiębiorstwa (Accessed: 15.11.2015).

80. http://www.worldbank.org/pl/news/press-release/2014/04/04/world-bankadvises-on-how-to-improve-innovation-strategies-for-smart-specializationin-poland (Accessed: 15.11.2015).

81. https://ec.europa.eu/programmes/horizon2020/what-horizon-2020 (Accessed: 01.12.2017).

82. https://www.mir.gov.pl/strony/zadania/polityka-rozwoju-kraju/zarzadzanierozwojem-kraju/strategie-ponadregionalne/ (Accessed: 01.12.2015).

83. Huggins R., 2000: The success and failure of policy-implanted inter-firm network initiatives: motivations, processes and structure. Entrepreneurship and Regional Development, Vol. 12, Issue 2, pp. 111-135.

84. Hughes J., Moore M., Snyder E., 2002: Napsterizing' pharmaceuticals: access, innovation, and consumer welfare. National Bureau of Economic Research Working Paper, 9229.

85. Janasz W., 1997: Podstawy ekonomiki przemystu. PWN, Warsaw.

86. Jankowska B., 2009: Konkurencja czy kooperacja? Ekonomista, No. 1, pp. 67-89.

87. Jasiński A.H., 1992: Przedsiębiorstwo innowacyjne na rynku. Wydawnictwo Książka i Wiedza, Warsaw.

88. Jewtuchowicz A., 2001: Strategie przedsiębiorstw innowacyjnych: wspótpraca czy konkurencja? In: Skawińska E., (ed.), Konkurencyjność podmiotów gospodarczych $w$ procesie integracji $i$ globalizacji. Zeszyty Naukowe Politechniki Poznańskiej, No. 32, pp. 196-203.

89. Jewtuchowicz A., 2005: Terytorium i wspótczesne dylematy jego rozwoju. Wydawnictwo Uniwersytetu Łódzkiego, Łódź.

90. Jewtuchowicz A., 2009: Terytorium jako podstawa procesu tworzenia innowacyjnych środowisk przedsiębiorczości. In: Nowakowska A., (ed.), Budowanie zdolności innowacyjnych regionów. Wydawnictwo Uniwersytetu Łódzkiego, Łódź. 
91. Jones C., Williams J., 1998: Measuring the social return to R\&D. Quarterly Journal of Economics, No. 113, pp. 1119-1135.

92. Journal of Laws 1991, No. 80, item 350, as amended.

93. Journal of Laws 1992, No. 21, item 86, as amended.

94. Journal of Laws 2005, No. 57, item 491, as amended.

95. Journal of Laws 2015, item 1767.

96. Józwiak W., Kagan A., Mirkowska Z., 2012: Innowacje w polskich gospodarstwach rolnych, zakres ich wdrażania $i$ znaczenie. Zagadnienia Ekonomiki Rolnej, No. 3, pp. 3-27.

97. Kamien M., Schwartz N., 1982: Market structure and innovation. Cambridge University Press, Cambridge.

98. Kamien M., Tauman Y., 1983: The private value of a patent: a game theoretic analysis. Discussion Paper, 576, Northwestern University.

99. Kasperkiewicz W., 2008: W poszukiwaniu strategii innowacyjnej polskiej gospodarki. In: Bednarczyk J., Bukowski S., Przybylska-Kapuscińska W., (eds.), Mechanizmy i źródła wzrostu gospodarczego. Polityka ekonomiczna a wzrost gospodarczy. CeDeWu, Warsaw.

100. Katz M., Shapiro C., 1985a: On the licensing of innovations. Rand Journal of Economics, No. 16, pp. 504-520.

101. Katz M., Shapiro C., 1985b: Network externalities, competition and compatibility. The American Economic Review, No. 75, pp. 424-440.

102. Katz M., Shapiro C., 1986a: How to license intangible property. Quarterly Journal of Economic, No. 101, pp. 567-590.

103. Katz M., Shapiro C., 1986b: Product compatibility choice in a market with technological progress. Oxford Economic Papers, No. 38, pp. 146-165.

104. Katz M., Shapiro C., 1986c: Technology adoption in the presence of network externalities. Journal of Political Economy, No. 94, pp. 822-841.

105. Ketels Ch., 2003: The development of the cluster concept: present experiences and further developments. NRW Conference on Clusters, Duisburg, Germany, www.isc.hbs.edu (Accessed: 31.10.2011).

106. Klepka M., 2005: Raport z inwentaryzacji Regionalnych Strategii Innowacji (RIS) w Polsce. PARP, Krajowy Punkt Kontaktowy Programów Badawczych UE.

107. Korenik S., Szostak E., 2006: Polityka naukowa i innowacyjna. In: Winiarski B., (ed.), Polityka gospodarcza. PWN, Warsaw.

108. Kowalski A.M., 2013: Znaczenie klastrów dla innowacyjności gospodarki w Polsce. Oficyna Wydawnicza, Szkoła Główna Handlowa w Warszawie, Warsaw. 
109. Kozłowski J., 2009: Statystyka nauki, techniki i innowacji w krajach UE i OECD. Stan i problemy rozwoju. http://www.nauka.gov.pl/g2/oryginal/ 2013_05/79ec9321e2fae75053fa584f1402fafa.pdf (Accessed: 20.11.2015).

110. Krzak J., 2011: Parki i inkubatory technologiczne w Polsce. Studia BAS, Vol. 25, Issue 1, pp. 97-116.

111. Landes W., Posner R., 1987: Should indirect purchasers have standing to sue under the antitrust laws? An economic analysis of the rule of Illinois Brick. University of Chicago Law Review, No. 46, pp. 602-635.

112. Landsperger J., Spieth P., 2011: Managing innovation networks in the industrial goods sector. International Journal of Innovation Management, Vol. 15, Issue 6, pp. 1209-1241.

113. Lerner J., Tirole J., 2002: Efficient patent pools. National Bureau of Economic research Working Paper, No. 9175.

114. Levin R., Klevorick A., Nelson R., Winter S., 1987: Appropriating the returns from industrial research and development. Brookings Papers on Economic Activity, No. 3, pp. 783-820.

115. Lichtenberg F., 1987: The effect of government funding on prvate industrial research and development: a re-assessment. The Journal of Industrial Economics, No. 36, pp. 97-104.

116. Lindelöf P., Löfsten H., 2004: Proximity as a resource base for competitive advantage: university-industry links for technology transfer. Journal of Technology Transfer, Vol. 29, Issue 3-4, pp. 311-326.

117. Lindqvist G., 2009: Disentangling clusters. Agglomeration and proximity effects. EFI, Stockholm.

118. Lityński K., 2015: Fundusze kapitału zalążkowego. In: Bąkowski A., Mażewska M., (eds.), Ośrodki innowacji i przedsiębiorczości w Polsce. Raport 2014. Business and Innovation Centers Association in Poland, PoznanWarsaw, pp. 149-168.

119. Lundvall B.Å. (ed.), 1992: National innovation systems: towards a theory of innovation and interactive learning. Pinter, London.

120. Lundvall B.A., 2007: National systems of innovation - analytical concept and development tool. Industry and Innovation, Vol. 14, Issue 1, pp. 95119.

121. Łobejko S., 2013: Mierzenie efektów polityki innowacyjnej. Wybrane rankingi $i$ wskaźniki innowacyjności oraz trendy na przyszłość. In: ZaduraLichota P., (ed.), Świt innowacyjnego społeczeństwa. Trendy na najbliższe lata. Polish Agency for Enterprise Development, Warsaw.

122. Malerba F., Orsenlgo L., Peretto P., 1997: Persistence of innovative activities, sectoral patterns of innovation and international technological spe- 
cialization. International Journal of Industrial Organization, Vol. 15, Issue 6, pp. 801-826.

123. Manley K., 2003: Frameworks for understanding interactive innovation process. International Journal of Entrepreneurship and Innovation, No. 4(1), pp. 25-36.

124. Mansfield E., 1984: $R \& D$ and innovation: some empirical findings. In: Griliches Z., (ed.), R\&D, patents and productivity. University of Chicago Press, Chicago.

125. Mansfield E., 1985: How rapidly does new industrial technology leak out? Journals of Industrial Economics, No. 34, pp. 217-223.

126. Mansfield E., 1998: Academic research and industrial innovation" an update of empirical findings. Research Policy, No. 26, pp. 773-776.

127. Martin R., Sunley P., 2003: Deconstructing clusters: chaotic concept or policy panacea? Journal of Economic Geography, No. 3(1), pp. 5-35.

128. Mas-Colell A., Whinston M.D., Green J.R., 1995: Microeconomic Theory. Oxford University Press.

129. Matusiak K.B., 2006: Rozwój systemów wsparcia przedsiębiorczości: przesłanki, polityka, instytucje. IE, Radom-Łódź.

130. Matusiak K.B., (ed.), 2008: Innowacje i transfer technologii. Stownik pojęć. Polish Agency for Enterprise Development, Warsaw.

131. Matusiak K.B., 2011: Wyzwania strategiczne rozwoju parków technologicznych. In: Matusiak K.B., (ed.), Strategiczne obszary rozwoju parków technologicznych. Polish Agency for Enterprise Development, GdańskCracow-Opole-Poznan-Warsaw.

132. Mażewska M., Tórz A., 2015: Parki technologiczne. In: Bąkowski A., Mażewska M., (eds.), Ośrodki innowacji i przedsiębiorczości w Polsce. Raport 2014. Business and Innovation Centers Association in Poland, PoznanWarsaw, pp. 26-41.

133. Mroczek R., (ed.), Drożdż J., Tereszczuk M., Urban R., 2014: Polish food industry in 2008-2013. Institute of Agricultural and Food Economics - National Research Institute, Warsaw.

134. Mync A., 1998: Instytucjonalne aspekty innowacyjności regionalnej. Zarys problemu. In: Kukliński A., Pawłowska K., (eds.), Innowacja - Edukacja Rozwój regionalny. WSB, Nowy Sącz.

135. Nelson R.R., (ed.), 1993: National Innovation Systems. A comparative analysis. Oxford University Press, New York/Oxford.

136. Niemczyk J., 2013: Strategia. Od planu do sieci. Wydawnictwo Uniwersytetu Ekonomicznego we Wrocławiu, Wroclaw.

137. Noga A., 2009: Teorie przedsiębiorstw. PWE, Warsaw. 
138. Nordhaus W., 1969: Inventions, growth, and welfare: a theoretical treatment of technological chance. The MIT Press, Cambridge.

139. North D.C., 2005: Understanding the process of economic change. Princeton University Press, Princeton-Oxford.

140. Nowakowska A., 2007: Regionalne strategie innowacji w Polsce - pierwsze doświadczenia $i$ oceny. Zeszyty Naukowe Uniwersytetu Szczecińskiego. Eknomiczne Problemu Usług, 453, No. 8, pp. 203-210.

141. Nowakowska A., 2011: Regionalny wymiar procesów innowacji. Wydawnictwo Uniwersytetu Łódzkiego, Łódź.

142. Nurzyńska I., Poczta W., (eds.), 2014: Polska wieś 2014. Raport o stanie wsi. Wydawnictwo Naukowe Scholar, Warsaw.

143. OECD, 2001: Cities and regions in new learning economy. OECD Publishing, Paris.

144. OECD, 2010: Regional innovation strategies. http://www.oecd.org/ innovation/policyplatform/48137737.pdf (Accessed: 15.11.2015).

145. OECD, 2012: OECD Science, Technology and Industry Outlook 2012. OECD Publishing, Paris.

146. Okoń-Horodyńska E., 1999: Potrzeba narodowego systemu innowacji w gospodarce polskiej. Ekonomista, 3, pp. 347-364.

147. Oliński M., 2009: Przedsiębiorczość akademicka wśród studentów. Ekonomika i Organizacja Przedsiębiorstwa, Issue 3 (710), pp. 40-48.

148. Ordover J., Willig R., 1985: Antitrust for high-technology industries: assessing research joint ventures and mergers. Journal of Law and Economics, No. 8, pp. 311-333.

149. Pangsy-Kania S., 2007: Polityka innowacyjna państwa a narodowa strategia konkurencyjnego rozwoju. Wydawnictwo Uniwersytetu Gdańskiego, Gdańsk.

150. Pavitt K., 1984: Sectoral patterns of technical change: Towards a taxonomy and a theory. Research Policy, Vol. 13, Issue 6, pp. 343-373.

151. Penc J., 1999: Innowacje i zmiany $w$ firmie. Placet, Warsaw.

152. Pierański B., 2013: Orkiestracja innowacyjnych sieci przedsiębiorstw. In: Ciechomski W., Romanowski R., (eds.), Marketing terytorialny oparty na wiedzy. Wydawnictwo Uniwersytetu Ekonomicznego w Poznaniu, Poznań.

153. Pierścionek Z., 2007: Strategie konkurencji i rozwoju przedsiębiorstwa. PWN, Warsaw.

154. Pomykalski A., 2001: Zarzadzanie innowacjami. PWN, Warsaw.

155. Porter M.E., 1998: Competitive Advantage. Creating and Sustaining Superior Performance. The Free Press, New York.

156. Porter M.E., 2001: Porter o konkurencji. PWE, Warsaw. 
157. Przybyciński T., 2005: Konkurencja i ład rynkowy - przyczynek do teorii i polityki konkurencji. Oficyna Wydawnicza SGH, Warsaw.

158. Przychodzeń J., 2015: Ekoinnowacje w przedsiębiorstwie. Zarzadzanie, pomiar $i$ wptyw na wyniki finansowe. CeDeWu, Warsaw.

159. Ratković T., 2015: HRM in foreign-owned agricultural and food processing companies in Serbia. Economics of Agriculture, Vol. 62, Issue 2, pp. 353-367.

160. Regionalna Strategia Innowacji Województwa Lubelskiego do 2020 roku. 2014. Lublin.

161. Regionalne Systemy Innowacji w Polsce. Raport z badań. 2013. PARP, Warsaw.

162. Romer P.M., 1986: Increasing returns and long-run growth. Journal of Political Economy, Vol. 94, No. 5, pp. 1002-1037.

163. Rudzka M., Góralski M., 2012: Klastry. In: Niemczyk J., Stańczyk-Hugiet E., Jasiński B., (eds.), Sieci międzyorganizacyjne. Wspólczesne wyzwanie dla teorii i praktyki zarzadzania. CH Beck, Warsaw.

164. Saxenian A., 2006: The new argonauts: regional advantage in a global economy. Harvard University Press, Cambridge.

165. Schumpeter J.A., 1939: Business cycles: a theoretical, historical and statistical analysis of capitalist process. McGraw-Hill, New York.

166. Schumpeter J.A., 1942: Capitalism, socialism and democracy. Routledge, London and New York.

167. Schumpeter J.A., 1960: Teoria rozwoju gospodarczego. PWN, Warsaw.

168. Shaw F., 2002: Uncertainty and the new consumer. Foresight, Vol. 4, Issue 6, pp. 4-13.

169. Shepard A., 1986: Licensing to enhance demand for new technologies. Mimeo, Yale University.

170. Skawińska E., Zalewski R.I., (eds.), 2009: Klastry biznesowe w rozwoju konkurencyjności i innowacyjności regionów. Świat - Europa - Polska. PWE, Warszawa.

171. Słodowa-Hełpa M., 2013: Inteligentne specjalizacje regionów - wyzwania, możliwości i dylematy. Roczniki Nauk Społecznych, Vol. 5(41), No. 1, pp. 87-120.

172. Smith K., 2006: Measuring innovation. In: Fagerberg J., Mowery D.C., Nelson R.R., (eds.), The Oxford handbook of innovation. Oxford University Press, Oxford.

173. Sosnowska A., Łobejko S., Kłopotek A., 2001: Zarzadzanie firma innowacyjna. Difin, Warsaw. 
174. Sölvell Ö., 2009: Clusters - balancing evolutionary and constructive forces. Ivory Tower, Stockholm.

175. Stankiewicz M.J., 2005: Konkurencyjność przedsiębiorstwa. Budowanie konkurencyjności przedsiębiorstwa w warunkach globalizacji. TNOiK, Stowarzyszenie Wyższej Użyteczności „Dom Organizatora”, Toruń.

176. Stańczyk-Hugiet E., 2012: Renta ekonomiczna dźwignia sieci międzyorganizacyjnych. In: Niemczyk J., Stańczyk-Hugiet E., Jasiński B., (eds.), Sieci międzyorganizacyjne. Wspótczesne wyzwanie dla teorii i praktyki zarzqdzania. CH Beck, Warsaw.

177. Stiglitz J., 2004: Ekonomia sektora publicznego. PWN, Warsaw.

178. Stuart T., 2000: Interorganizational alliances and the performance of the firms: a study of growth and innovation rates in a high-technology industry. Strategic Management Journal, Vol. 21, Issue 8, pp. 791-811.

179. Szczepaniak I., 2014: Innovative activity in the process of competition on the food market. In: Kaczmarek J., Kolegowicz K., (eds.), Developmental challenges of the economy and enterprises after crisis. Cracow University of Economics, Cracow, pp. 379-394.

180. Szewczuk A., 2011: Rozwój lokalny i regionalny - główne determinanty. In: Szewczuk A., Kogut-Jaworska M., Zioło M., Rozwój lokalny i regionalny. Teoria i praktyka. Wydawnictwo C.H. Beck, Warsaw.

181. Świtalski W., 2005: Innowacje i konkurencyjność. Wydawnictwo Uniwersytetu Warszawskiego, Warsaw.

182. Taylor C., Silberston Z., 1973: The economic impact of the patent system. Cambridge University Press, Cambridge.

183. The Act of 20 March 2002 on financial support for investments, (Journal of Laws 2002, No. 41, item 363).

184. The Act of 27 July 2005 law on higher education, (Journal of Laws 2005, No. 164, item 1365).

185. The Act of 6 December 2006 on the principles of development policy, (Journal of Laws 2006, No. 227, item 1658).

186. The Oslo Manual, 2008. The Ministry of Science and Higher Education, Warsaw.

187. Thirtle C.G., Ruttan V.W., 1987: The role of demand and supply in the generation and diffusion of technical change. Chur, Harwood Academic Publishers.

188. Tirole J., 1988: The theory of industrial organization. The MIT Press, Cambridge.

189. Tobin J., 1997: An overview of the general theory. In: Harcourt G.C., Riach P.A., (eds.), A second edition of the general theory. Vol. 2, Routledge, pp. 2-19. 
190. Tórz A., 2015: Inkubatory technologiczne. In: Bąkowski A., Mażewska M., (eds.), Ośrodki innowacji i przedsiębiorczości w Polsce. Raport 2014. Business and Innovation Centers Association in Poland, Poznan-Warsaw, pp. 42-54.

191. Transformacja sceny europejskiej i globalnej XXI wieku. Strategie dla Polski. Kukliński A., Woźniak J., (eds.), 2012. Biblioteka Małopolskiego Obserwatorium Polityki Rozwoju, Vol. V, Cracow.

192. Vejlgaard H., 2008: Anatomy of a trend. McGraw-Hill, New York.

193. W czym tkwi sekret liderów innowacji. Analiza benchmarkingowa innowacyjności polskich regionów - raport z badania. 2013. Deloitte, Warsaw.

194. Weresa M.A., 2014: Polityka innowacyjna. PWN, Warsaw.

195. Wissema J.G., 2005: Technostarterzy: dlaczego i jak? Polish Agency for Enterprise Development, Warsaw.

196. Wojnicka E., 2004: System innowacyjny Polski z perspektywy przedsiębiorstw. IBnGR, Gdańsk.

197. World Bank, 2010. Escaping the middle-income trap. http://siteresources.worldbank.org/INTEAPHALFYEARLYUPDATE/Res ources/550192-1287417391641/EAP_Update_Oct2010_chapter3.pdf (Accessed: 01.12.2015).

198. World Economic Forum, 2015: Global Competitiveness Report. http://reports.weforum.org/global-competitiveness-report-20152016/downloads/ (Accessed: 30.11.2015).

199. Wyznaczanie, monitoring i ewaluacja inteligentnych specjalizacji. 2014. Stawicki M., Wojnicka-Sycz E., (eds.). Ministerstwo Infrastruktury i Rozwoju, Warsaw.

200. XTC World Innovation, 2015: World Innovation Panorama. Key facts, new trends, outstanding concepts in food innovation. XTC World Innovation, Paris.

201. Zaheer A., Bell G., 2005: Benefiting from network position: firm capabilities, structural holes and performance. Strategic Management Journal, Vol. 26, Issue 9, pp. 809-825.

202. Zalega T., 2013: Nowe trendy i makrotrendy $w$ zachowaniach konsumenckich gospodarstw domowych w XXI wieku. Konsumpcja i Rozwój, Vol. 2(5), pp. 3-21.

203. Zastempowski M., 2010: Uwarunkowania budowy potencjału innowacyjnego polskich matych i średnich przedsiębiostwa. Publishing House of Nicolaus Copernicus University, Toruń. 



\section{COPY FREE}

Print run: 250 copies, 8,95 publisher 's sheets

Printing and binding: ZAPOL Sobczyk Spółka Jawna 